Andrews University

Digital Commons @ Andrews University

\title{
The Coping Strategies of Nontraditional Female Students in Southwest Michigan and Northern Indiana
}

Desiree Davis

Andrews University, desireed@andrews.edu

Follow this and additional works at: https://digitalcommons.andrews.edu/dissertations

Part of the Educational Psychology Commons, and the Higher Education Commons

\section{Recommended Citation}

Davis, Desiree, "The Coping Strategies of Nontraditional Female Students in Southwest Michigan and Northern Indiana" (2017). Dissertations. 1623.

https://digitalcommons.andrews.edu/dissertations/1623

https://dx.doi.org/10.32597/dissertations/1623

This Dissertation is brought to you for free and open access by the Graduate Research at Digital Commons @ Andrews University. It has been accepted for inclusion in Dissertations by an authorized administrator of Digital Commons@ Andrews University. For more information, please contact repository@andrews.edu. 


\begin{abstract}
THE COPING STRATEGIES OF NONTRADITIONAL FEMALE STUDENTS IN SOUTHWEST MICHIGAN AND NORTHERN INDIANA
\end{abstract}

by

Desiree Davis

Chair: Elvin Gabriel 


\title{
ABSTRACT OF GRADUATE STUDENT RESEARCH
}

Dissertation

\author{
Andrews University \\ School of Education
}

\section{Title: THE COPING STRATEGIES OF NONTRADITIONAL FEMALE STUDENTS IN SOUTHWEST MICHIGAN AND NORTHERN INDIANA}

Name of researcher: Desiree Davis

Name and degree of faculty chair: Elvin Gabriel, Ed.D.

Date completed: April 2017

\section{Problem}

The purpose of this research study was to examine the coping strategies of nontraditional female students in a private university in Southwest Michigan, and a public university in Northern Indiana. According to Carney-Compton \& Tan (2002), nontraditional female students characterize the leading emergent set of students beginning college. This study examined the reasons why they are in college, the problems they face while there, and the coping strategies they used to make the adjustment to school life. 


\section{Method}

The Coping Scale for Adults survey was used to determine what coping strategies are utilized by nontraditional female students. The factor analysis produced seven factor scales (work at succeeding, positive ways to cope, healthy coping strategies, selfdefeating behaviors, proactive self-care, negative coping skills, and means of getting help) that adequately depicted coping strategies employed by this population. Descriptive statistics, multivariate analysis of variance were used to analyze the data.

\section{Results}

The result of the Coping Scale for Adults survey indicated the following:

1. Work at succeeding is used often as a coping strategy.

2. Positive ways to cope, healthy coping strategies, self-defeating behaviors, proactive self-care, and negative coping skills are sometimes used.

3. Means of getting help is the least used coping strategy.

4. Non traditional female students used proactive self-care only sometimes with Caucasian using it significantly less than African-American or students from other ethnic background.

5. Non traditional female students use work at succeeding frequently with students with one child using it more frequently than those with no children, or students with two or more children.

6. Self-defeating behaviors, positive ways to cope and proactive self-care as coping strategies are related to income levels. Generally, higher income non traditional students use these coping strategies less frequently than lower income students. 
7. Self-defeating behaviors, positive ways to cope and proactive self-care were related to age groups. Younger students tend to use self-defeating behaviors and positive ways to cope slightly more than older students. Older students tend to use proactive selfcare slightly more than younger students.

8. Coping strategies are not related to marital status.

\section{Conclusions}

Based on the analysis, the following conclusions were deduced.

1. Nontraditonal female students work hard to succeed. However, they utilize the other coping strategies only sometimes to cope with their problems. Means of getting help is the least used coping strategy but possibly one of the most needed.

2. It is easier for nontraditional female students with one child to work at succeeding than parent with none, two, or three or more children.

3. Minority nontraditional female students' utilization of proactive self-care may derive from a need to take care of oneself in a hostile environment.

4. Nontraditional female students with higher incomes tend to use different coping strategies from nontraditional female students from lower socio economic levels.

5. Age does make a difference in which coping strategies are used by nontraditional female students.

6. Coping strategies are not related to marital status. 
Andrews University

School of Education

THE COPING STRATEGIES OF NONTRADITIONAL FEMALE STUDENTS IN SOUTHWEST MICHIGAN AND NORTHERN INDIANA

\author{
A Dissertation \\ Presented in Partial Fulfillment \\ of the Requirements for the Degree \\ Doctor of Philosophy
}

by

Desiree Davis

April 2017 
(C) Copyright by Desiree Davis 2017

All Rights Reserved 


\title{
THE COPING STRATEGIES OF NONTRADITIONAL FEMALE STUDENTS IN SOUTHWEST MICHIGAN AND NORTHERN INDIANA
}

\author{
A dissertation \\ presented in partial fulfillment \\ of the requirements for the degree \\ Doctor of Philosophy
}

\section{by}

Desiree Davis

APPROVAL BY THE COMMITTEE:

Chair: Elvin Gabriel

Member: Jimmy Kijai

Member: Lena Caesar

External: Lionel Matthews
Dean, School of Education

Robson Marinho
Date approved 


\section{TABLE OF CONTENTS}

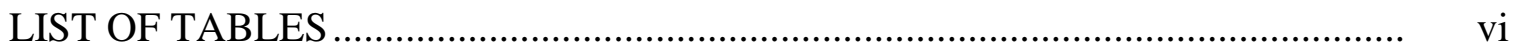

LIST OF ABBREVIATIONS ................................................................... viii

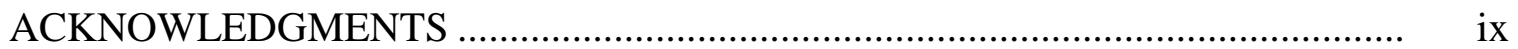

\section{Chapter}

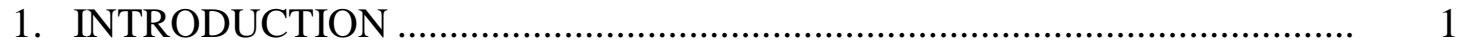

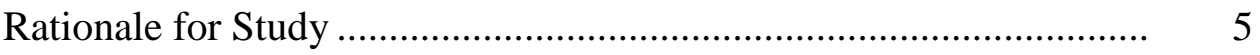

Statement of the Problem.................................................................... 7

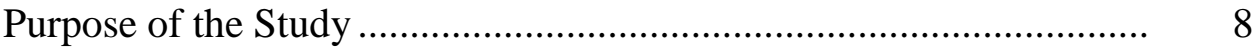

Conceptual Framework ................................................................... 8

Transactional Analysis ................................................................... 8

Vigilant Anticipatory Coping ………………………………......... 10

Research Questions ........................................................................ 12

Significance of the Study ................................................................ 13

Definition of Terms.................................................................... 14

Limitations of Study ………………………………………....... 15

Delimitation of the Study .................................................................. 16

Overview of Research Methodology …………………….................. 16

Organization of the Study ……………………………………........ 17

2. REVIEW OF THE LITERATURE ......................................................... 18

Introduction ............................................................................ 18

History of Nontraditional Women in Higher Education..................... 18

The Move to the Four Year College ................................................... 21

Reasons Why Nontraditional Female Students are Going to

College ....

Problems Nontraditional Female Students Face While

Pursuing a Collection Education.................................................. 26

Role Conflicts for Nontraditional Female Students............................ 33

Theoretical Perspectives on Nontraditional Female Students ............. 35

Coping Strategies Used by Nontraditional Female Students ............... $\quad 40$

Conclusion ……........................................................................... 42 
Research Questions ...................................................................... 45

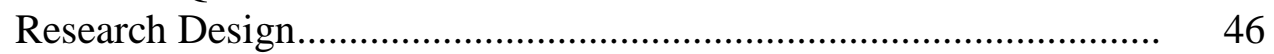

Population and Sample ............................................................. 46

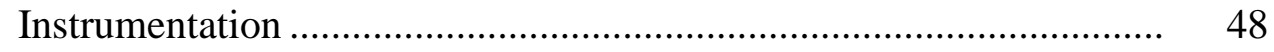

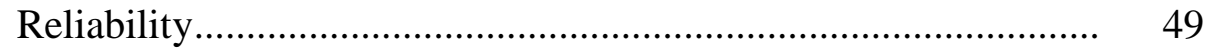

Validity .................................................................... 49

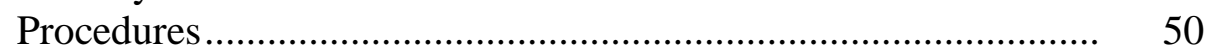

Treatment of the Data ................................................................. 51

Analysis Strategies ................................................................... 52

Summary …….................................................................. 53

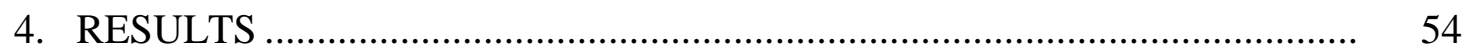

Participant Demographic Characteristics............................................. 54

Preliminary Analysis of the Coping Scales for Adults ....................... 57

Data Screening/Testing Assumptions ................................................ 58

Factor Extraction........................................................................ 59

Number of Factors Retained ....................................................... 59

Rotation of Factors.................................................................. 59

Identification of Items of Each Factor ......................................... 60

Results of the Factor Analysis .................................................... 60

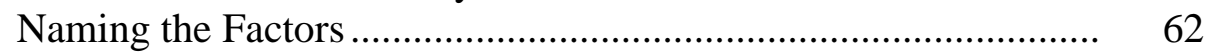

Research Questions .................................................................... 69

Research Question 1 ............................................................ $\quad 70$

Research Question 2 ............................................................ 79

Research Question 3 ........................................................ 81

Research Question 4 ............................................................... 83

Research Question 5 ……………………………............... 85

Research Question 6 ............................................................. 87

Summary of Major Findings ............................................................ 88

5. SUMMARY, DISCUSSION, IMPLICATIONS AND

RECOMMENDATIONS ............................................................... 90

Purpose of the Study ………………….......................................... 90

Overview of the Literature Review................................................... 90

Reasons Why Nontraditional Female Students are Going to

College

Problems Nontraditional Female Students Face While

Pursuing a College Education ........................................................ 91

Role Conflicts for Nontraditional Female Students............................. 92

Theoretical Perspectives on Nontraditional Female Students ............. $\quad 93$

Coping Strategies Used by Nontraditional Female Students ............... 94

Summary of the Methodology .......................................................... 95 
Summary of Major Findings .......................................................... 95

Discussion of Major Findings ............................................................ 96

Research Question 1 and Discussion/Implications ........................ 97

Research Question 2 and Discussion/Implications ....................... 106

Research Question 3 and Discussion/Implications ...................... 108

Research Question 4 and Discussion/Implications ...................... 109

Research Question 5 and Discussion/Implications ....................... 111

Research Question 6 and Discussion/Implications ........................ 113

Conclusion ....................................................................... 114

Limitations of Study ……………………………………....... 119

Recommendations for Practice ...................................................... 119

Recommendations for Future Research ............................................ 120

Appendix

A. INFORMED CONSENT AGREEMENT AND SURVEY ....................... 122

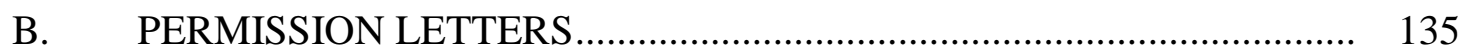

C. PARTICIPANT LETTERS .............................................................. 139

D. FOLLOW-UP LETTER ……………………............................ 142

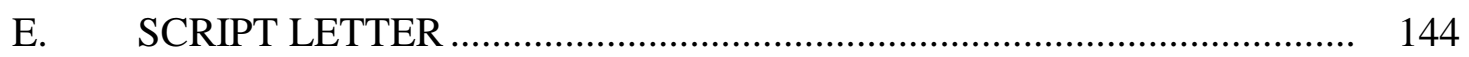

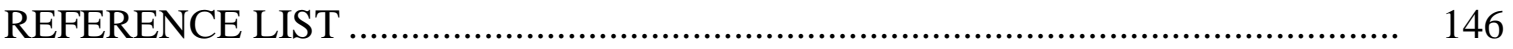

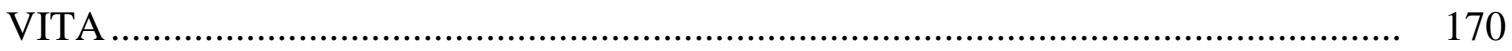




\section{LIST OF TABLES}

1. Research Question Type and Testing ............................................................ 52

2. Demographic Information................................................................... 55

3. Items Comprising the 19 Scales of the Coping Scale for Adults.......................... 56

4. Eighteen Scales of the Coping Scales for Adults................................................ 57

5. Commonalities and Percentage of Explained Variance, CSA .............................. 62

6. Factor Loading, Commonalities $\left(\mathrm{h}^{2}\right)$, and Percentage of Variance ..................... 63

7. Scale Statistics, Reliability and Inter-correlation................................................ 69

8. Coping Strategies Used by Nontraditional Female Students ............................... 69

9. Scale and Item Mean and Standard Deviation: Work at Succeeding ................... 71

10. Scale and Item Mean and Standard Deviation: Positive Ways to Cope ............... 72

11. Scale and Item Mean and Standard Deviation: Healthy Coping Strategies.......... 73

12. Scale and Item Mean and Standard Deviation: Self-Defeating Behavior............. 74

13. Scale and Item Mean and Standard Deviation: Proactive Self-Care .................... 75

14. Scale and Item Mean and Standard Deviation: Negative Coping Skills .............. 76

15. Scale and Item Mean and Standard Deviation: Means of Getting Help .............. 77

16. Univariate Table for the Two Universities ...................................................... 78

17. Means and Standard Deviations by Race Group ……........................................ 80

18. Univariate Analysis Table for Race Group.................................................... 80

19. Means and Standard Deviation by Number of Children....................................... 82 
20. Univariate Analysis Table for Number of Children

21. Means and Standard Deviations by Age Range ........................................... 84

22. Univariate Analysis Table for Age Range ................................................... 84

23. Means and Standard Deviation by Income Range ....................................... 86

24. Univariate Analysis Table for Income Range ............................................ 87 


\section{LIST OF ABBREVIATIONS}

$\begin{array}{ll}\text { ANOVA } & \text { Analysis of Variance } \\ \text { CSA } & \text { Andrews University } \\ \text { GED } & \text { Geping Scale for Adults } \\ \text { IRB } & \text { Institutional Review Board } \\ \text { IUSB } & \text { Indiana University South Bend } \\ \text { KMO } & \text { Kaiser-Meyer-Oklin Measure of Sampling Adequacy } \\ \text { MANOVA } & \text { Multivariate Analysis of Variance } \\ \text { NCES } & \text { National Center for Education Statistics } \\ \text { OCED } & \text { Organization for Economic Cooperation and Development } \\ \text { PAF } & \text { Principle Axis Factor } \\ \text { PCA } & \text { Principle Component Analysis } \\ \text { SPSS } & \text { Statistical Package for the Social Sciences }\end{array}$




\section{ACKNOWLEDGEMENTS}

To my heavenly Father who has been with me all the way, thank you for keeping me in your care.

Thank you to my mother and father who introduced me to my best friend Jesus and who modeled for me how to face challenges but still continue on the journey. A special thank you to my daughter- Starr, who remained strong throughout our many obstacles and has supported me with her prayers and love. To my siblings, Valerie, James, Priscilla, Anthony, Jackie, Jennifer, Philip, LaTonya, Chameka, and Pamela, thank you for your amazing support, love, and encouragement.

To my niece, Carissa and nephew, Gilford thank you for your prayers and support. To my brother in law, Linwood Stone thank you for always being willing to help me in time of need. A special thank you to all my relatives, friends and church family who have prayed and encouraged me during this journey.

I am indebted to the dedicated members of the dissertation committee for their untiring support, and guidance throughout the dissertation process. A special thank you to Dr. Jimmy Kijai for his assistance and guidance with the research design, theoretical framework, and the statistical analyses. Thank you for helping me see my dissertation through the eyes of others. A special thank you to Dr. Lena Caesar for having faith in me and for encouraging me to persevere. 
A special "thank you" for my dissertation chair, Dr. Elvin Gabriel, for his tender guidance, caring manner, and his untiring support of me throughout this journey. I am grateful to him for going the extra mile to support and encourage me throughout this experience.

To Dr. Curt Vanderwaal who gave me whatever I needed to complete this journey. I am grateful for all the ways you helped me. To my co-workers, Dr. Krista Cooper, Twyla Smith, Ingrid Slickers, Dr. Alina Baltazar, Jan Wrenn and Susie Oliver thank you for your prayers, words of encouragement, and support. To my co-worker, Margaret Howell who prayed with me, cooked for me, and encouraged me, I express my sincere gratitude. To my co-worker, Dr. Shannon Trecartin who encouraged me and gave me feedback, I say simply “thank you”. A warm thank you to Dr. Wendy Thompson whose faith in me never wavered. To Rhoena Bearce and Cindy Swanson-their encouragement and prayers were a blessing and inspiration to me. To Dr. Edith Fraser my professor, mentor and friend, thank you for being you and believing in me. A special thank you to T. Marshall Kelly, my uncle who gave unconditionally his prayers, advice, and encouragement. To Rose Philips, my sister-in-law whose prayers and encouragement kept me going. Thank you to Carmen George who checked in with me, prayed for me, and encouraged me along the journey. To Dr. Duane McBride who allowed me to use his space at IPA for writing when I needed peace and quiet, thank you.

Finally, I want to say thank you to all the nontraditional female students who participated in the study by offering their candid responses and knowledgeable feedback. 


\section{CHAPTER 1}

\section{INTRODUCTION}

Nontraditional female student enrollment is increasing in higher education. From 2000 to 2012, there has been a 35 percent increase in the admission of college students who are younger than 25 years of age and a rise in admission of those who are 25 years of age and older by 35 percent (US Department of Education, National Center for Education Statistics, NCES, 2015). However, the NCES (2015) anticipates a 12 percent growth rate for traditional age students, in contrast to a 20 percent growth rate for nontraditional students over the age 25 . Nontraditional students bring with them a distinctive set of wants and requirements that is unlike that of the traditional student (Newbold, Mehta, \& Forbus, 2009). This makes nontraditional female students an exceptional group of students that require special care and attention in order to retain them in school and provide them with a comprehensive education that reflects the world in which they live and function.

In accordance with terminology used in the literature, nontraditional is defined as those students who are 25 and older. The literature on this population describes them as students who have not adhered to an uninterrupted learning course into the university (Newbold, Mehta \& Forbus, 2010). Therefore, adult students tend to be more experienced than younger students (Evelyn, 2002). Nontraditional students are usually those who are older than 24 years of age and who are employed full-time and generally have children in 
their care (Forbus, Newbold, \& Mehta, 2011). Another definition of nontraditional students has labeled them as those who are full-time or part-time students and who are 25 and older (Ely, 1997; Jinkins, 2009; O’Keefe, 1993).

Nontraditional female students have most often seasoned years of wisdom which they have learned through other areas in their world and, finally, these adult students may have finished another academic program in previous years and are now returning for specialized training to go into another educational proficiency (Davies, 1995; Kasworm, 1993; OECD, 1996).

These changes have come full-circle since the days of the state normal schools. State normal schools were instituted in the mid-nineteenth century to provide a venue where teachers could be educated for developing custom of education in the United States (Ogren, 2003). Nontraditional female students were a part of the educational scene from the mid-nineteenth century through the mid-twentieth century. Women of color came on the scene in the late nineteenth century with the emergence of schools for colored people. The first school for colored females was Spelman in 1881 (Giddings, 1984).

There are many challenges that institutions of higher learning are facing at this time. The Council on Adult and Experiential Learning (2000) stated there is a real battle for colleges and universities to accommodate the changing demographic population at their institutions. In order for nontraditional female students to be successful, institutions of higher learning must attempt to eliminate the obstacles that nontraditional female students encounter. This shift during the past half century in the United States' employment arena from industrial labor jobs to professional jobs has brought more 
nontraditional female students to university campuses to prepare them for career adjustments. This shift has caused a reappearance of nontraditional female students to postsecondary education. The overall education of the masses of the nineteenth and twentieth centuries called for a specialized educational system for this group of students. Nontraditional female students have identified a number of different reasons for returning to school. It is often with trepidation that women make this decision, but with resilience and support their dreams can become a reality.

The demand for more education has led to the admittance of an increasing number of older female students who are seeking more education to improve their job skills or promotion opportunities. In addition to this, there has emerged a subpopulation of single mothers who are going to school in record numbers. Wilsey (2013) found that " $34 \%$ of younger mothers stated that they entered to provide a better life for their families, compared with $13 \%$ of adult student mothers" (p. 211). These were traditional age female students who were also single mothers. The younger mothers stressed that education was their way to a more autonomous life, giving them the income to create an individual home and support their children. Nontraditional female students expressed comparable motives for going to college, however, such as finishing a college degree program, while traditional-aged mothers were more concerned about what their improved earning capability represented for their loved ones in the years to come (Wilsey, 2013).

The overwhelming increase of nontraditional female students in higher education has amazed the educational system with its' multi-faceted needs and demands. There has been a $256 \%$ growth over the past forty years of women who are finishing their college education, in contrast to men who generated a $110 \%$ increase during the same time period 
(U.S. Department of Commerce, 2011). Most likely not since the days of the state normal schools has such a resurgence of versatility of individuals with similar aspirations but different situational and ethnic makeup caused a shakeup in the educational world as we know it.

Nontraditional female students are often presented with multiple challenges which they must face as they go to college either for the first time or as reentry students. These students are often faced with increases in roles, demands, and time as re-entry students. Such challenges produce complex levels of tension, fear, and despair for adult students (Backels \& Meashely, 1997; Leavitt, 1989; Mallinckrodt \& Leong, 1992; Puryear, 1988; Roehl \& Okun, 1984).

Another aspect of changing faces is the demographics of reentry college women.

In 1965, the typical profile of the reentry woman was a White, middle-class housewife in her mid to late 30s with some level of college education. The face of the reentry female population today is racially diverse, particularly with growing number[s] of African-American women. Many of these female students are also firstgeneration college students which brings additional challenges related to departure from the pattern established by family and friends. (Thomas, 2001, p. 140)

Kerta (1989) described current conditions where nontraditional female students are juggling the additional challenges of multiple roles and financial concerns when they enter school. The institution has no control over these particulars hurdles because they are distinct to the student. Nevertheless, nontraditional students need services in place at the institution that will allow them to focus on their role as students. It is important to be mindful of the needs of this particular population. Financial want may block a nontraditional female student from enrolling or continuing her education (Hardin, 2008). Eifler and Pottoff (1998) support this premise that economics are a critical matter for adult students. 


\section{Rationale for Study}

This study was done to examine coping strategies utilized by nontraditional female students in higher education. There is a need for current research on specific coping strategies for this population. Customarily, the literature focuses on two aspects of handling one's problems: problem-focused and emotion-oriented strategies (Boekaerts, 1993).

There have been some studies which addressed coping strategies such as adaptive coping strategies proposed by Johnson and Nussbaum (2012), and Giancola, Grawitch, and Borchert (2009) who also discuss maladaptive coping. Morris, Brooks, \& May (2003) discussed the importance of task-oriented coping which connect with study objectives and higher grades; whereas, Howell (2004) discussed the significance of resilience which helps to overcome obstacles.

There have been few studies which address specific strategies which are geared for nontraditional female students to help them in the day-to-day process of occupying more than one role. Although Home $(1995,1998)$ discussed various role-overlap factors such as parent, student, wife that occurs in the lives of nontraditional female students, students often utilized supports such as from their academic institution, place of employment, and even loved ones who provided sources of assistance.

More recently, Folkman (2010) proposed the concept of meaning-focused coping which focuses on intensely kept standards and ideas that manifest themselves in the shape of having a set plan of action. Nontraditional female students come from different backgrounds regarding their obligations at home, on the job, and at the university. Some nontraditional female students need particular assistance in order for them to accomplish 
their goals despite such circumstances as having financial need, belonging to an ethnic persuasion, or being the only adult responsible for the children in the home (Rice \& Meyer, 1989).

Nontraditional female students pursue education for different reasons which should indicate to educational institutions the importance of being flexible in class scheduling, support, and assistance provided for this population of students. It is the responsibility of the institution to provide the necessary services needed by the student body. Seminars geared to assisting nontraditional female students organize their schedules along with seminars that focus on how to manage the pressure of school, work, and family can be beneficial in helping nontraditional female students handle the added strain and the multiple-responsibility tension that often occurs (Kohler \& Munz, 2006; McClary, 1990).

There are nontraditional female students who are seeking to improve their lives, and higher education provides for them a means by which to increase their financial resources as well as provide them with a sense of accomplishment. However, there may be barriers to achieve this goal which impact on how they deal with the demands of college.

Colleges and universities are providing education to nontraditional female students from America and from abroad which calls for a specialized education system that is able to provide services in addition to curricula that match this population of students. There are a number of challenges that international students face while studying in the United States. Numerous students reported prejudice and bigotry (Lee \& Rice, 2007; Poyrazli \& Lopez, 2007), communication difficulties (Perrucci \& Hu, 1995), 
absence of emotional comfort (Hechanova-Alampay, Beehr, Christiansen, \& Van Horn, 2002), and racial distress (Chapdelaine \& Alexitch, 2004; Winkelman, 1994).

\section{Statement of the Problem}

Nontraditional female students characterize the leading emergent set of students beginning college (Carney-Compton \& Tan, 2002). These students need to learn coping strategies that will help them cope in higher education. The demanding lifestyle of juggling family, work, and school has produced many challenges for women who are already overworked and stressed due to the multiple demands made upon them. These stressors present themselves in a number of ways such as outside pressures from home, economic worries, limited numbers of mature students in classes, and little support for their brave decision to attend college (Benshoff, 1991; Richter-Antion, 1986; Terrell, 1990; Thomas, 2001). Furthermore, studies have indicated that minority students have additional stressors such as education challenges, difficulty to adjusting to the educational system, and feeling left out (Ferguson, 1992; Tinto, 1993) that they have to deal with as they pursue higher education. Numerous nontraditional students have delayed their education until they have married and had children (Leonard, 2002; Newbold et al., 2010). Nontraditional students are not only present in the classroom, but may also need counseling as they struggle to balance their life challenges. Nontraditional female students cope in a variety of ways to manage their complicated lives, and educational institutions need to recognize that this population of students presents with a unique set of challenges that may hinder their success, progress, and future retention in higher education. 


\section{Purpose of the Study}

The purpose of this study was to examine the coping strategies used by undergraduate, nontraditional female students in higher education. These students were selected from a private and a public university.

\section{Conceptual Framework}

The conceptual framework focused on two dominant theories of coping that may provide some explanations for the way women cope. The first theory is transactional analysis which was developed by Richard Lazarus and Susan Folkman who started their joint endeavors at the end of the 1970s when they initiated the first of their crosssectional investigations on stress and coping in adults of different ages. Lazarus and Folkmon sought to further their knowledge on two structural concepts of the approach: appraisal and coping (Lazarus \& Folkman, 1987). Thereafter, they discussed multiple functions of coping. Several forms of coping discussed include emotion-focused coping, problem-focused coping, and appraisal (primary and secondary), reappraisal, meaningfocused coping. The second theory covered is vigilant anticipatory coping which has been researched by several theorists, but this research has focused on Laveist, Thorpe, Pierre, Mance, and Williams (2014).

\section{Transactional Analysis}

Lazarus \& Folkman (1984) define coping as "constantly changing cognitive and behavioral efforts to manage specific external and/or internal demands that [are] appraised as taxing or exceeding the resources of the person" (p. 141). Earlier studies by Folkman and Lazarus (1980) sought to differentiate between two key purposes: the first 
dealing with difficulties that people experience in their surroundings which "they called problem-focused and the second directed at managing emotional distress, which they called emotion-focused" (p. 219). Problem-focused coping results when an individual seeks to change the problem by finding a realistic solution whereas emotion-focused coping seeks to respond to the problem by utilizing a variety of coping mechanisms which often result in the problem being avoided or reinterpreted to fit the person's concept of what a solution could be, but in essence not really solving the problem (Lazarus \& DeLongis, 1983). Furthermore, one of the most significant discoveries of their initial research was that individuals utilized problem-focused and emotion-focused coping in all demanding situations.

According to Lazarus and Folkman (1987), primary appraisal presents itself in three forms: harm that is felt, threat that functions as harm that is expected, and challenge where the individual must rally to manage difficulties in an effort to create a result of optimistic worth. This last-mentioned appraisal may come with certain risks or harm in order for a challenge to occur; thus, challenge and threat, at a certain level, usually mix. The concept of benefit is included to develop the classification of emotion. Secondary appraisal derives from the belief that we are in charge of our thinking as it relates to our changing the results (Lazarus \& Folkman, 1987). Reappraisal is constantly being done by thinking and reassessing situations as a means of coping. (Lazarus \& Folkman, 1984).

When a situation is not resolved favorably, a circular effect would probably take place with emotion-coping reappraisal duplicating the problem, therefore creating prolonged tension. A modified replica formed a different type of managing meaningfocused coping and positive emotions (Folkman, 2008). 
Park and Folkman (1997) postulated that meaning-focused coping is reviewcentered managing whereby individuals draws from their faith, morals, and reason for living to inspire and endure surviving and promote welfare throughout trying periods.

Meaning-focused coping is usually not related to any particular circumstance which could be the case with emotion-focused or problem-focused coping (Folkman, 2008). However, four types of meaning were developed: "positive reappraisal, revision of goals, spiritual beliefs, and the infusion of ordinary events with positive meaning" (Folkman, 1997, p. 1212; Folkman, Moskowitz, Ozer, \& Park, 1997). Positive reappraisal is the capacity to present a negative situation in a reassuring way. This type of approach can be utilized from start to finish in a tense situation. Goal revision is the capacity to examine goals and state which ones were successful or unsuccessful and revise them as needed. Richards and Folkman (in press) found in their study of bereavement participants that when a person had spiritual beliefs they assisted them in challenging situations by assessing their circumstances in a more optimistic manner than those who did not express religious experiences. Their studies also indicated the importance of permeating everyday life with cheerful moments.

Hope is another means of coping that is useful in this theory. Hope is the desire for improvement of a feared result (Lazarus, 1991). Hope is putting faith into action.

\section{Vigilant Anticipatory Coping}

This second coping theory, vigilant anticipatory coping, suggests that a person is on guard to deal with greater readiness and anticipation that something negative may happen (LaVeist, Thrope, Pierre, Mance, \& Williams, 2014). Previous studies indicate

that while this phenomenon has been studied here in the United States, it is quite probable 
that in other parts of the world where there are marginalized groups they would experience similar results (Averill, 1972; Schneiderman \& McCabe, 1989; Williams, 1986). Studies show that prejudice is prevalent everywhere in American culture (Cose, 1993; Feagin, 1991; Gardiner, 1995).

Prevalent in American society is the opinion that there are several groups of people who are subordinate. Prominent leaders who were researchers of the 18th and 19th centuries and some of our greatest national and government champions condoned ethnic order with Native Americans under Caucasians and African-Americans at the bottom (Gould, 1981). Bigotry has continued and flourished because it is supported by all facets of our society (Goldberg, 1993). Bigotry is hard to recognize but universal, difficult to discern at times with little done about it because it is just part of everyday life and what is acceptable to society (Essed, 1991).

"Several studies indicate that experiences of discrimination based on race or ethnicity can adversely affect physical and mental health" (Amaro, Russo, \& Johnson, 1987; Jackson et al., 1996; James, La Croix, Kleinbaum, \& Strogatz, 1984; Krieger, 1990; Salgado de Snyder, 1987; Williams, Yu, Jackson, \& Anderson, 1997, p. 338). Krieger (1990) studied the relationship among ethnic and gender bias and high blood pressure in a study of African-American and Caucasian females. African-American females who reacted submissively to the encounter of ethnic bias were four times more likely to have hypertension compared to females who shared incidents with others or handled the situation in a proactive manner to the mistreatment. Hicken, Lee, Morenoff, House, and Williams (2014) found "that Blacks reported higher levels of vigilance than both Whites and Hispanics. Not only did they have the highest mean vigilant score, but 
they were also more likely to report weekly vigilance than were the other racial/ethnic groups" (p. 121). According to Kim and Lewis (1994), Asians are also as familiar with discrimination as are Hispanics (Telles \& Murgia, 1990). Williams (1994) postulated that African-Americans have the capacity to deal with racism with stronger fortitude which enables them to be resilient due to prior experiences. Furthermore, Blacks might have at their disposal other strategies such as the Black church which enables them to survive and deal with adverse situations. The birth of the Black church occurred during slavery, and it is one of numerous expressions of spirituality for Black people. It serves as a social establishment and creates for Black people a sense of confidence, a sense of group cohesiveness, and provides tools for shaping fairness in society (Frame, Williams, \& Green, 1999).

\section{Research Questions}

1. What are the coping strategies used by nontraditional female students in higher education?

2. Are coping strategies related to the ethnicity of nontraditional female students?

3. Are coping strategies related to the number of children of nontraditional female students?

4. Are coping strategies related to age groups of nontraditional female students?

5. Are coping strategies related to income levels of nontraditional female students?

6. Are coping strategies related to marital status of nontraditional female students? 


\section{Significance of the Study}

This study proposed to examine coping strategies used by undergraduate nontraditional female students from a public university and from a private university in order to determine what they have utilized to help them cope in their current academic environment. This study investigated whether race, marital status, income status, age, and children make a difference.

The audience for the study are nontraditional female students in higher education, educators who teach them, and administrators who are in charge of developing curricula, programs, and activities for this student population. Also, included are the counselors who provide the counseling services that may enable nontraditional female students to stay in school and complete their degrees. It is the academic institution's responsibility "to help them become full members of the college community and to get involved in institutional life" (Rendon, 1996, p. 17).

It is hoped that the results from this study would add additional information to the body of knowledge regarding how nontraditional females cope in higher education. I anticipate that this information will be beneficial to administrators who establish programs and seminars at their institutions for nontraditional female students that will support retention as they address strategies to assist nontraditional female students cope as they matriculate in higher education.

Thus, this research will provide a source of data regarding coping strategies of undergraduate nontraditional female students in Southwest Michigan and Northern Indiana identifying coping strategies related to specific demographic factors of (a) marital status, (b) socio-economic status, (c) race/ethnicity, (d) age, and (e) number of children. 
This information will add to the existing body of knowledge some interesting information regarding minority nontraditional female students and younger nontraditional female students in higher education.

Data from this study may potentially provide a significant source of information for nontraditional female students who are considering going into higher education. Furthermore, this study will provide inferential data regarding the coping strategies that undergraduate nontraditional females are currently using as they attend universities in Southwest Michigan and Northern Indiana thus providing for information that can be beneficial to other undergraduate nontraditional female students in higher education. This information will not only be of interest to nontraditional female students, but will also be informative for university administrators, faculty, and counselors in higher education.

\section{Definition of Terms}

The following section defines terminology as it is used in this study.

Nontraditional Students - Students who are 25 years old or older, attend colleges on a part-time basis, and/or commute to school (Allen, 1993).

Traditional Students - Students who are right out of high school and are dependent on their parents for financial support (Corrigan, 2003).

Coping - The process whereby an individual attempt to manage, through cognitive and behavioral efforts, external and internal demands that are assessed as exceeding one's resources (Utsey, Ponterollo, Reynolds, \& Cancelli, 2000).

Vigilant Anticipatory Coping - A response of hyper-awareness in case something happens (LaVeist et al., 2014). 
Problem-Solving Coping - This type of coping results by finding solutions to the problem (Lazarus \& DeLongis, 1983).

Emotion Coping - This type of coping results when a person avoids the problem and involves others but does not solve the problem (Folkman \& Lazarus, 1980).

Meaning-Focused Coping - This type of coping results when an individual uses inner faith, morals, and reason for living to inspire and endure during trying periods (Park \& Folkman, 1997).

Primary Appraisal - Presents in three forms: harm, threat of harm, and challenge (Lazarus \& Folkman, 1987).

Secondary Appraisal - Belief that people are in charge of their thinking as it relates to our changing the results (Lazarus \& Folkman, 1987).

Reappraisal - Reappraisal is constantly being done by thinking and reassessing situations as a means of coping (Lazarus \& Folkman, 1984).

\section{Limitations of Study}

This study would be more generalizable if the sample of nontraditional female students had been drawn from a greater cross-section of the country. Due to the small number of undergraduate nontraditional females at the private university, subjects were not randomly selected for this study. The undergraduate nontraditional female students from public university were selected by using the total number of nontraditional female student population who were interested in participating in the study.

Second, the Coping Scale for adults (CSA) that was used in the study was a selfreport coping instrument; it had all the limitations of such self-reports, including the tendency for the respondents to choose socially desirable responses. The CSA does not 
address the effectiveness o fthe strategies of that respondents say they used to cope.

Third, this study focused on coping strategies used by nontraditional female students. The study does not examinein any great detail how nontraditional males cope in higher education or in other challenges they encounter.

\section{Delimitation of the Study}

The sample utilized in this study comprised only nontraditional female students aged 25 and older who were currently enrolled students at a private, parochial university, and public university, during the academic year 2012-2013. The subjects from the private university were chosen from a list provided by the Office of Student Life, and the Office of Enrollment provided the list for the respondents at the public university. The subjects from the private university come from around the world whereas the subjects from public university are typically Indiana residents or out of state residents.

\section{Overview of Research Methodology}

The study utilized the survey research method in collecting data. Survey research was used in this study because of its flexibility to explore a variety of problems or questions.

The selection procedure for the two universities were nontraditional female students, 25 and older who agreed to participate in the study. The study examined what coping strategies nontraditional female students have utilized to help them cope in their current academic environment.

The CSA was developed by Erica Frydenberg and Ramon Lewis as a selfreporting questionnaire consisting of 73 items. 


\section{Organization of the Study}

The study will provide an introduction that looks at the current reality of nontraditional female students in United States and the rapidly changing society in which we live. It will also provide a conceptual framework that reviews two dominant coping theories that lay the foundation of coping and the mechanisms to explain how coping is utilized and formulated in order to deal with stressful situations.

In Chapter two the literature review will highlight a historical account of the role of nontraditional female students in higher education. It will also address reasons why nontraditional female students are going to college as well as explore problems nontraditional female students face while pursuing their degree. Role conflicts for nontraditional female students will also be examined as well as the impact of spiritual support.

Chapter three will highlight the methodology of the study, describing the procedures utilized to carry out the study. Chapter four addresses the results of the study and the major findings from the two universities. Chapter five presents the summaries, conclusions, and recommendations for practice and future research. 


\section{CHAPTER 2}

\section{REVIEW OF THE LITERATURE}

\section{Introduction}

This study examined the coping strategies used by undergraduate nontraditional female students at a private university and a public university to determine the specific coping strategies these students have utilized to help them deal with the demands of their current academic world, their personal lives, and their work environment.

The purpose of the literature review is to provide the readers with a comprehensive picture of what the literature says about nontraditional female students in higher education. The criterion used to analyze and compare information in the literature will highlight past, present, and future information on such nontraditional female students as it pertains to the history of these students, along with reasons why nontraditional female students are going to college in the first place. It will also include information that focuses on special challenges faced by nontraditional female students in higher education, and, finally, the literature review will provide some overview to quantitative and qualitative studies on these students and how this population of students utilizes various coping strategies to combat their stressors.

\section{History of Nontraditional Women in Higher Education}

Women attended state normal schools in the nineteenth and twentieth centuries to 
be educated as teachers for the expanding educational system that would ultimately provide for the educating of American children. There are records that go back as far as 1839 showing Massachusetts as the first state to found a normal school; that state's example was followed by Connecticut and New York (Ogren, 2003).

The purpose of these schools was [sic] to prepare teachers to teach on high school faculties which allowed these schools to further their range of education by offering four year bachelor degrees. The majority of state normal schools became teachers' colleges in the 1920s and 1930s. (Ogren, 2003, p. 642)

These students were often older students, women, and representative of different minority groups. Unlike nontraditional female students today, these students were fulltime and lived in the vicinity of the school due to lack of transportation (Ogren, 2003). “At West Virginia's normal in West Liberty, some students commuted to campus in an effort to save money. Similarly, many normalites at the Territorial Normal School in Tempe, Arizona, during the decade or so after it opened in 1886, commuted" (Ogren, 2003, p. 646).

A common characteristic of these students was that they had had work experience and many of them had taught school before returning to further their own education.

As early as the 1840 s and early 1850 s at Bridgewater, "nearly all" of the students had themselves taught school. Of the 2,500 students who enrolled at Oswego between its opening in the mid-1860s and 1880, more than 1,000 had teaching experience, with an average of three years in the classroom. Furthermore, like today's nontraditional students, found it financially necessary to continue working while attending normal school. (Ogren, 2003, p. 646)

Many of these normalites hailed from country towns or remote areas around the country. What was paramount in this process was the institutions' ability to make the education they provided affordable and accessible to students who had an interest in attaining an education. There were instances where students were unable to pay for their 
education but were allowed to attend school. E. E. Smith of Fayetteville, North Carolina and Pine Bluff's Joseph Corbin, administrators at all-Black normal schools allowed their students to come to school even though they could not pay for school fees. Smith had a reputation for allowing students to pay for school fees with farm equipment. Other state normal schools provided scholarships, tuition waivers, and loan funds to make the education more available to students in need (Ogren, 2003).

The entrance expectations for the state normal schools were free from any set protocols. This allowed administrators to be accommodating to students as needed. "They did not require matriculants to be high school graduates until education at that level was attainable by most residents of their states, which generally was not until the early twentieth century" (Ogren, 2003, p. 649). State normal schools did require entrance exams; however, potential students could show documentation of their teaching credentials or diplomas in lieu of taking exams.

History shows that nontraditional students have been a fixture on the educational scene for well over a hundred and seventy-six years. Ogren (2003) observes that:

At a time when women were an unwelcome minority on many coeducational campuses, they were a visible majority at state normal schools. A small number of normal, mainly in the South, restricted their enrollments to women only. But, most normal schools were coeducational, with enrollment made up increasingly of women with each passing decade. Before the turn of the century, the enrollments at coeducational normals nationwide were between 25 and $90 \%$ female. At coeducational southern normal, only one-quarter to one-half of the students were women. Typical of normals outside the South, the institutions in Cedar Falls, Iowa, and Greeley, Colorado enrolled $70 \%$ women. After the turn of the century, throughout the country the percentage of students who were women was consistently well over 50, and occasionally higher than $90 \%$. The large numbers of female normalites are consistent with the schools' official mission of preparing students the female-dominated profession. (p. 643)

There were segregated normal schools for African-American students in the South as 
well as for Native American students in Oklahoma and North Carolina (Ogren, 2003).

State normal had a reputation for involving students in the life of the school by providing them an atmosphere where they felt comfortable. These students had many wants that required state normal to address in providing this population with a wellrounded education. Due to this impetus, state normal were able to provide normalites a service that was uniquely designed to meet their needs and as well expose them to other experiences that would not otherwise have been available to them. State normal schools did not set out to provide this type of education to nontraditional students but inevitably added to history the importance of providing what is lacking. There were common characteristics that provided a bond for many of these normalites. They were poor, from rural areas, and minority. Many of these normalites came from families who were farmers. These educators would provide a venue that would lay the foundation for many institutions' becoming four year colleges.

\section{The Move to the Four Year College}

The arrival of World War II veterans into higher education prompted the normals' desire for a new mission, therefore normal began to reformulate their original goal of teacher education. This event brought about changes in name for many normals during the 1940s, 1950s, and 1960s (Ogren, 2003). However, this change in mission prompted many normals to merge into state universities (Selingo, 2000). "In their quest for higher status, formal normals have tended to bury their history as 'an impoverished past thankfully left behind"' (Goodlad, 1990, p. 73). Unfortunately, only the top educational institutions are often written about by historians. Historians of teacher education have more often than not concentrated on the normal school administrators and formal 
strategies used by these institutions (Ogren, 2003). In her quest to amend this inaccuracy Ogren (2003) offered a thorough account of the normalites that were so much a part of this historic narrative.

The present scene of nontraditional female students in the academic arena shows a similar picture of the state normal schools but with a different backdrop of adult women not only being older but with numerous responsibilities that often demand their attention. The following section gives some reasons why nontraditional female students are going to college.

\section{Reasons why Nontraditional Female Students are Going to College}

The literature points to several reasons why nontraditional female students are coming to college in record numbers to get an education. One of the motivating factors that prompt nontraditional female students to return to school is a change in life situation. Johnson, Schwartz, and Bower (2000) found that adult women students are often forced to return to school after loss of employment, the ending of a marriage, the passing of a spouse, and/or the inability to advance in a vocation because of inadequate training.

The trend of nontraditional female students in higher education is something that institutions are accepting as a subpopulation that present with their own set of needs and challenges. This trend has been portrayed by older students who are returning to college or coming for the first time (Bauman et al., 2004; Johnson \& Nussbaum, 2012).Like the state normal schools of previous generations, institutions of higher learning today are searching for new ways to provide adequately for the needs of this population. The unique circumstances of the nontraditional student may pose a problem for the fast pace 
life of a college/university setting as it often coincides with the daily struggles nontraditional students have in working or raising a family.

The literature has cited nontraditional students "over the age of 25 as the fastest growing group of undergraduates and the majority of this group are [sic] female” (Carney-Compton \& Tan, 2002, p.140; Graham \& Donaldson, 1999; Kasworm, 2003; Sales, Drolet, \& Bronneau, 2001). Additional studies done by Choy (2002) and Kohler, Munz, and Trares (2007) have depicted them as first-time college students, women, parttime students attending community colleges, and parents. In quantitative studies done by Shank, Winchell, and Myers (2001), Haggan (2000), and Quimby and O’Brien (2006), these factors are based on what has been seen in colleges and universities across the United States.

So why are nontraditional female students entering or returning to school? Changes in one's life circumstances have led to the rapid increase of female students in higher education (Carney-Crompton \& Tan, 2002; Graham \& Donaldson, 1999; Kaswarm, 2003; Sales et al., 2001). Studies have indicated that nontraditional female students go back to school under trying situations (Benshoff \& Lewis, 1992; Brandenburg, 1974; Evanoski, 1988; Moore, 1990). The explanations seem to be summed up in two main areas: (a) changes in the current world we live in, including economics, and (b) individual problems (Miller, 2000). Johnson et al. (2000) "found that adult women students are often motivated to return to school after the loss of a job, divorce, death of a spouse, and career limitations due to lack of education" (p. 291). Mohney and Anderson (1988) had similar findings that nontraditional female students often re-entered academia because of some transforming occurrence in their lives. 
Hardin (2008) introduced the concept of transitions which can be regarded as positive or negative for this population of students. These transitions can be categorized into a number of different areas, such as alteration in one's work situation, individual change in circumstances, or simply their time in life when they can pursue their own goals. So, often nontraditional female students enter institutions of higher learning as a means to care their families (Allen, 1993). Nontraditional female students are often pursuing their education on a part-time basis due to work and family responsibilities. Griffith and Connor (1994) noted that for community college students, their attendance behaviors depend on their personal lives, job, and the outside world, more than on anything going on within the college. The increase in divorce rates in recent years, as well as the high number of single-parent households headed by women, has led many adult women to view the community college as a good way to further their education and achieve greater economic security and a better standard of living for themselves and their children (Allen, 1993; Hardin, 2008; Herideen, 1998).

Qualitative studies by Johnson-Bailey (1998) and Thomas (2001) indicated that African-American women were trying to improve their life situations from the previous generation and seeking to increase their earning potential. Minority women were returning to school to have a better life. Information on how these nontraditional women have coped despite their many obstacles might be helpful to other women who are coming behind them.

Merdinger (1991) found that nontraditional female students are leaving school more than men for reasons other than their studies. Nontraditional female students, in their position as an undergraduate, frequently feel separated because of personal and job 
obligations, they have limited occasions where they can intermingle with their peers either informally or formally outside of the classroom. Furthermore, they may feel uncomfortable around their traditional-aged peers. Nontraditional female students regularly face dispositional obstacles such as dread of alteration, insufficient level of obligation and assurance, and even remorse about accomplishing a goal for them alone and not for someone else (Bean \& Metzner, 1985; Harris \& Brooks, 1998; MacKinnonSlaney, 1994).

Donaldson and Graham (1999) postulated that although adult students do not participate much in school activities, may not have current educational capabilities, and have multiple contradictory responsibilities; they have a goal in mind, and value their interaction with their teachers genuinely. They associate more closely the current information they are learning with events that have occurred in their lives and exhibit determination to acquire knowledge. Shields' (1993) study found that the nontraditional students were more apt to identify the more likely they were to give personal and circumstantial reasons for going to school. Therefore, nontraditional students tend to be more intrinsically motivated, while traditional students tend to be more extrinsically motivated with regard to their college experiences. These differences suggest that nontraditional students may be more likely to endorse a learning orientation, while traditional students may be more likely to endorse a performance orientation. Jinkins (2009) supported this premise that traditional students are not as engaged in the learning process or as committed to their educational success but stated that traditional students do want to be acknowledged for performing well in their classes. Although nontraditional students placed higher importance on learning new information; earning good grades is 
also important for nontraditional female students.

\section{Problems Nontraditional Female Students Face While Pursuing a College Education}

There are a number of areas that pose a threat to nontraditional female students on their academic journey. These stressors may be present in the work environment, in the school environment or in the home. While women often are accustomed to juggling multiple roles the intense demands of school add's another layer of expectations by an outside source that may at times feel totally overwhelming to first-time college students or reentry students. The support received from family and friends may help, or the lack thereof may hinder, a student's perception of his/her ability to succeed in the face of many challenges and obstacles.

The literature points to several barriers that nontraditional female students frequently face as they matriculate in higher education. These barriers include organizational barriers, their present condition, mental state, and learning capacity (Council on Adult and Experiential Learning, 2000; Compton, Cox, \& Laanan, 2006; Donohue \& Wong, 1997; Hammer, Grisby, \& Woods, 1998; Hardin, 1997; Nordstrom, 1997). These obstacles have the potential to avert the achievement of nontraditional female students and block them from the completion of their ambitions.

Organizational barriers are those that impede progress due to bureaucratic regulations. Nontraditional female students are often not as accepting as traditional students when faced with this type of an obstacle and frequently end their academic career instead of then bringing more pressure into their world (Madfes, 1989). Nontraditional female students often do not anticipate the many stressors that go along 
with going to college, especially if they are working and have families.

Gilligan (1982) and Belenky, Clinchy, Goldberger, and Tarule (1986) discussed challenges encountered by nontraditional females as they matriculate in academia: (a) failing in academic pursuits and (b) failing in personal relationships. Often this fear spills over into the classroom setting and prevents a student from completing an assignment, a class, or their degree. Nontraditional female students may feel afraid to speak in class (Miller, 2000). Gilligan (1977) discussed the importance of voice for women and the direct responsibility women have for making their own choices for their lives. She further asserted "the essence of the moral decision is the exercise of choice and the willingness to accept responsibility for that choice" (p. 487). Furthermore "women are silencing themselves in order to be with other people; women are giving up relationship for the sake of having relationships, and then missing themselves and missing relationship or feeling stranded in a confusing isolation which is often filled with self-condemnation" (Gilligan, 1995, p. 125; Gilligan, 1982; Gilligan, 1990; Jack, 1991; Miller, 1988; Miller, 1991; Stern, 1991).

Older female students often doubt their own abilities to navigate the educational system. It is with great boldness that they take on the task of stepping out to accomplish something totally out of the realm of their prior experience. Women give considerable amount of credence to their relationships with others often to their own detriment. Success in relationships depends not only on a woman's ability to maintain relationship successfully with others but her ability to define adequately the relationship from her own worldview. She must continually provide her own definitions of success for herself while staying connected to those she loves and cares about in her life. 
There are additional problems older female students encounter by not having taken challenging high school courses, earning a General Education Diploma (GED), delayed enrollment, or if their parents did not attend college, they are less likely to persist in obtaining their degrees (Adelman, 1999). "Many adult students, particularly from families in which neither parent has earned a college degree may lack what Bourdieu (1977) termed cultural capital, the accumulation of knowledge of higher education that facilitates academic decision-making and adjustment to college" (Howell, 2004, p. 35). Corrigan (2003) found that "two-thirds of low-income dependent students come from families in which neither parent attended college, compared with less than one-third of middle- and upper-income students (p. 27). Corrigan (2003) further noted that because of their situation, first-generation students do not have the knowledge or the where withal to navigate their way through the collective and educational pressures of the university. This lack of experience leaves a gap for first-generation students that they often do not know what they are missing until they feel overwhelmed by their own inadequacies about this new world in which they now find themselves. Johnson-Bailey (1998) cited that the majority of respondents in her qualitative study were first generation college students. Many ethnic minority college freshmen who may be characterized as being the first generation of anyone from their family who is attending college and these students encounter a number of different stressors that the ordinary college student does not face (Ross, Niebling, \& Heckert, 1999; Towbes \& Cohen, 1996). First time college students may experience limited support from family who are unaware of the stress the student is going through. 
Thomas (2001) found that

(89.4\%) of respondents in her study identified a particular person someone who encouraged them to further their education. The person named by most was another African American (e.g. relative, friend, and co-worker). A few of the respondents cited their boyfriend or husband. Reportedly, these individuals offered varied kinds of assistance that helped the women during college reentry. For example, some respondents reported that the individual offered emotional support, while others indicated that he or she provided instrumental support (i.e., assistance in paying the tuition and other fees. Seven women indicated that they were discouraged from returning to college by their husband/partner, supervisor, or friend. (p. 150)

A family's income influences a woman's choice of college, attendance and financial choices in ways that can negatively influence her persistence. Home (1997) found that female students with lower incomes had more stress, while those females with a stronger support system with family and friends had less stress. Corrigan (2003) found that older, low-income students come to college with a different set of variables such as responsibilities to their families and financial reasons that may differ from traditional age students. Corrigan (2003) also found that after "three years after entering postsecondary education, 47 percent of low-income independent students with children had dropped out, compared to 31 percent of low-income dependents" (p. 29). Launier (1997) found students who had anxieties about money seemed worried about their financial responsibilities to the point that it inhibited their success in their studies.

Many are trying to pay for college at the same time they are dealing with a reduction of income. For many women, the motivation to attend college happens with their changing role in the family. Some are forced to enter college as they face financial difficulties as a result of divorce or the death of a spouse. (Hardin, 2008, p. 50)

Eifler and Potthoff (1998) found similar results indicating that many nontraditional students were worried about money. Often these students are self-sufficient and have others whom they are supporting as well. Furthermore, nontraditional students have the extra expenses of lodging and daycare. 
Nontraditional students face obstacles that have been identified by (Cross, 1980; Pitts, 1992) as belonging in one of three classes: institutional, situation, and dispositional. Institutional barriers signify issues related to the educational institution, for instance issues with finances, advisors, or professors. Additional barriers for nontraditional students may be poor scheduling for classes or location, limited childcare for those students who are parents, inadequate scholarships or monies for nontraditional students because of their half-time status in school, classes that are not applicable and uninteresting, transportation problems, entrance barriers, unsuitable guidance, lack of services for this population, and teachers who do not respect the wisdom of nontraditional students and treat them like teenagers (Breese \& O'Toole, 1994).

Situational barriers also exist that are related to what is going on in a person's life such as challenges with day-care, employment issues, and little or no assistance from a partner. The most cited obstacles stem from scheduling and economics. It is often the case that nontraditional students encounter considerable scheduling constraints, responsibility tension and financial pressure due to other obligations that are related to their children and spouse, residence, and employment (Bianchi, 1991; Gerson, 1985; Hybertson, Hulme, Smith, \& Holton, 1992; Mercer, 1993; Pits, 1992; Richter \& Witten, 1984; Sands \& Richardson, 1984; Smallwood, 1980; Spanard, 1990).

Dispositional obstacles are related to a person's belief about him/her, this includes, but is not limited to, having negative thoughts regarding one's abilities, worries about one's ability to be a successful student and how this will affect his/her life, and experiencing self-reproach for attending college (Bean \& Metzner, 1985). Howell (2004) found similar results in her mixed methods study that nontraditional female students often 
have inadequate views regarding their abilities and the way they feel about themselves. Older students often feel as if they do not belong in the environment that is strongly geared to traditional-aged students, so they often withdraw and refuse to solicit help in the adjustment to college life. Dispositional barriers may prevent a student from remaining in college and succeeding in their academic programs. Chartrand (1990) supported this premise that adult female students more than any other student view themselves as incapable of being successful. Another barrier which presents itself for nontraditional female students who do not speak English is that they may have a difficult time with their coursework and keeping up with the class (Hardin, 2008). Other studies such as Calaguas (2011) revealed that male students often have more problems in their overall experience while Cantwell, Archer, and Bourke (2001) cite that older female students adapt more easily and do better academically.

The literature indicates that

the new undergraduate students (women, minorities, first-generation students) often experience dispositional and situation challenges that can hinder their academic progress. Barriers faced by older students include multiple, non-school-related commitments and responsibilities, financial and family concerns, lack of an age cohort in the classroom, insufficient support from family and friends, and limited social acceptability and support for their student status. (Benshoff, 1991; RichterAntion, 1986; Terrall, 1990; Thomas, 2001, p. 140)

Nontraditional female students with families have many additional obligations that most male students do not have to worry about, such as raising children, taking care of sick children, and household tasks. Men tend to experience more anxiety due to insecurity while women encounter blame regarding the challenging pressures of child-care obligations (Benshoff \& Lewis, 1992). Furthermore, Tinto (1993) found that women who 
were married were less likely to have completed their education when they had family responsibilities.

Johnson-Bailey (1999) discovered that African American female reentry students faced not only the usual obstacles of child-care problems, class scheduling, limited family support, financial challenges, and a history of school failure, these women also shared problems relating to the Black experience, such as the lack of mentoring Black faculty and staff, and the lack of Black peers. These students had to learn despite the barriers, and cope with the problems they faced regardless of their race, gender, and class. Collins (1991) argued against the ideal perception of Eurocentric motherhood which is being a homemaker and rearing her children while the husband is the breadwinner for the family, stating that this is not the same standard for Black motherhood. The Black mother has always had to work outside of the home while raising her children and maintaining her home (Carothers, 1990). Minority students have to adjust to societal and ethnic issues on campus. This can be a challenge for adult female students and for students who are the first in their family to attend college who tend to experience the campus atmosphere as unfriendly and threatening (Terenzini et al., 1996).

Nontraditional female students face additional stressors not faced by younger traditional-aged students such concerns as obligations related to their employment and private lives that necessitate overwork and task struggles when merged with attending college. These extra challenges and obligations can produce time restrictions that traditional students are most likely not to encounter. Often older students have multiple outside obligations that deter them on their academic journey (Graham \& Donaldson, 1999; Keith, 2007). Studies also found that women who were students and single mothers 
were at higher risk for job-family strain (Burden, 1986; Kelly \& Voyadnoff, 1985). There are numerous nontraditional students who have delayed their education for degree attainment until they have married and had children (Leonard, 2002; Newbold et al., 2010). However, when nontraditional students go back to school it is an additional commitment that does affect the family dynamics. Various partners have divided domestic responsibilities and care of their offspring to adapt to adjustments in calendars and jobs (Sweet \& Moen, 2007). Canales-Gonzales and Kranz (2008) asserted that, as regards handling the tension brought on by additional duties, nontraditional students related devoting periods where they interact with their loved ones is great way for them to decrease anxiety. Kearns and Gardiner (2007) found that nontraditional students who have organized schedules have better performance and mitigation of emotions and worry. The literature indicates that nontraditional students related that most of their pressures are derived from two entities: their job and college. Furthermore, these job tensions were a clear indicator of overall welfare (Giancola et al., 2009). Students who attempted to earn a degree were in danger of experiencing adverse effects such as being absent from lectures, preparing less for class, and feeling greater amounts of anxiety (Robotham, 2009).

Women often have to wear many hats and for those who are in school with families this is their story.

\section{Role Conflicts for Nontraditional Female Students}

Coverman (1989) and Hirsch and Rapkin (1986) identity three separate categories of responsibility-stress experienced by women: (a) personal discord due to ongoing opposing pressures (b) feeling overwhelmed with multiple responsibilities, and (c) 
fixation with various responsibilities. Kelly and Voydanoff (1985), Mikolaj and Boggs (1991), and Voydanoff (1993) found women who were not married and had young families had more incidences of strain with their job and family disputers. Nontraditional female students with limited finances describe greater pressure and more trouble fulfilling obligations (Patchner, 1982; Sands \& Richardson, 1984). In addition, considerations for nontraditional female students may include the number of children in the home (Schmidt \& Scott, 1986), what they are studying, and what their attendance is with school and work (Koeske \& Koeske, 1989).

Home (1998) found nontraditional female students who had young children who were not autonomous stated feeling burdened and described greater tension. This is because, no matter what role a woman occupies, as a mother she is expected to care for the children (Baines, Evans, \& Neysmith, 1992), it is no wonder women feel conflicted when their child becomes ill and they have exams to take at school. It becomes problematic when nontraditional female students are required to address multiple pressing issues. Home's (1998) study indicated that

distance education and higher income decrease conflict by enabling women either to postpone one demand or to replace themselves temporarily in one role. Mothers of school-aged children have difficulty attending late afternoon or evening classes designed for students with full time jobs. (p. 95)

Thomas's (2001) study of Black reentry women found that " $63.1 \%$ cited balancing multiple roles and time pressures as their biggest challenge while trying to interface their various life roles. Furthermore, seventy-four percent of the respondents reported a conflict between raising children and continuing their education" (p. 144). Johnson-Bailey (1998) found Black reentry women's home and life responsibilities remained the same even though they were in school. If nontraditional female students do 
not have support, they will not succeed and inevitably will not continue their education (Lewis, 1988).

Mohoney and Anderson (1988) found that nontraditional female students often

face multiple obligations with family, job, and now school which often makes this added responsibility as student hard for them to adjust to. Read, Elliot, Escobar, and Slaney (1988) found another interesting concept in their study of reentry women 25 years of age and older: that the various responsibilities of nontraditional female students have caused them anxiety or cause them to blame themselves for coming to school. Furthermore, Johnson et al. (2000) found that "in a survey of 350 adult female students, that $84 \%$ of the women were responsible for children in the home and suggested that one of the most pressing concerns among students who are parents is child care" (p. 292).

\section{Theoretical Perspectives on Nontraditional Female Students}

Richard Lazarus and Susan Folkman started their joint endeavors at the end of the 1970s when they started the first of three elaborate, cross-sectional investigations of anxiety and survival in mature people in different stages of life (Lazarus \& Folkman, 1987). Their research on transactional analysis informs the variables in this study by providing a foundation for understanding how human beings respond to stress and methods they utilize to cope with their problems. Nontraditional female students cope in a variety of ways in reaction to multiple stressors in their lives. Problem-focused, emotion-focused, and meaning-focused coping provide a framework in which to categorize the phenomena of coping.

The coping strategies that were the lowest for nontraditional female students in this study were a "means of getting help" and "negative coping skills." Problem-focused 
coping can provide solutions for nontraditional female students as they seek help either from a professional or from supportive family and friends. Meaning-focused coping can be very instrumental for nontraditional female students as they seek to dismiss their negative thinking by remembering why they sought to go back to school in the first place. This is where hope and positive thinking can be beneficial to them in difficult times.

Minority nontraditional female students deal with racism and discrimination on a regular basis that white female students may not encounter. Utilizing problem-focused coping is helpful to minorities to learn how to handle their problems as it relates to doing something constructive in handling acts of discrimination. Some minority nontraditional female students may utilize emotion-focused coping as a means to vent their frustrations to people in their support system. However, meaning-focused coping can be helpful in assisting nontraditional female students find peace as they examine their reasons for going back to school and for maintaining hopefulness in the presence of disappointments.

This theoretical model provides a framework for addressing how nontraditional female students with children handle the difficult responsibilities of being a parent and going to school simultaneously. There are additional challenges for those nontraditional female students who are single mothers and who have to concern themselves with finances, childcare, and possibly a limited support system. Those nontraditional female students who are married may or may not have support from their spouse. Some nontraditional female students reported receiving emotional and tangible support from their spouse. Problem-focused coping may be utilized in order to solve everyday problems.

Completing a degree can, in the long run, help nontraditional female students 
make more money which can provide them with a more stable future. There are multiple obstacles that nontraditional female students face along the way. It takes fortitude to complete one's education. Sometimes nontraditional female students do not recognize the real cost of a college education which is both financial and emotional. Problem-focused coping can assist in this area as nontraditional female students endeavor to make realistic plans for how to pay not only for their education, but for all the expenses that they will incur. Meaning-focused coping can also help as nontraditional female examine the reasons why they are attending school in the first place. It is beneficial for nontraditional female students to find meaning in pursing an education. At the onset, the challenges may appear to outweigh the benefits, so finding a way to attach some meaning, even from the beginning, is important and valuable. Thomas (2001) found that Black, returning nontraditional female students in her study did not hesitate to counsel other adult, Black female students to go back to school without postponement. The majority sincerely felt that the repayment for returning to school greatly surpassed the actual and urgent schedule limitations and contending stressors.

Older adult female nontraditional students tend to exhibit better coping strategies than younger nontraditional female students. Teaching nontraditional female students how to use problem-focused coping early in the educational process can be of benefit to them on their journey. It is with this theoretical framework that meaning-focused coping can assist those nontraditional female students with finding meaning for what they are attempting to accomplish while providing them with practical tools to use such as hope and positive thinking.

Vigilant anticipatory coping informs the variables in this study by providing a 
framework which is helpful in viewing how different ethnic groups cope with stressors they face not only in higher education, but in life in general. Numerous researchers have hypothesized that prolonged pressure is a significant factor of cultural/racial differences in physical condition, including high blood pressure (Geronimus, Bound, Keene, \& Hicken, 2007; Sternthal, Slopen, \& Williams, 2011). Their research depicts the physiological as well as the emotional reactions produced by these occurrences of hypervigilance and the relevant information that this provides, not for nontraditional female students, but to the institutions that educate them. Vigilant anticipatory coping can assist nontraditional female students to react in a nonthreatening manner. However, the downside is that vigilant anticipatory coping often leads people to internalize their frustrations which can lead to unhealthy biological responses which then trigger health issues such as hypertension.

Some nontraditional female students may be coming to academia to improve their lives or to become financially stable and this transition may be for them a time that tests their ability to manage stress. Nontraditional female students may not anticipate the numerous financial expenses that go along with attending college. It will be even more taxing for those nontraditional female students who are single mothers. There will be multiple costs for them to consider depending upon the age of the child or children. Younger minority nontraditional female students may be ill-prepared for the college life and, depending upon how well they performed in high school, it could prove a challenge for them as they seek to navigate the educational system. Minorities may have high rates of hypertension and other health problems due to internalizing their stress instead of finding other means by which to vent their frustrations. 
There have been studies which have stated that adult students are more apt to be conscientious regarding learning for learning's sake in contrast to younger learners (Eppler, Carsen-Plentl, \& Harju, 2000; Morris et al., 2003). These contrasts have been noted in the experience of those faced with considerable obstacles, like managing numerous obligations and perhaps not having their relatives' loving encouragement regarding academic goals (Carney-Crompton \& Tan, 2002; Chartrand, 1990; HustonHoburg \& Strange, 1986). Younger nontraditional female students may find it difficult to utilize problem-solving coping as they seek to maintain balance in their lives. The literature cites emotion-focused coping as the strategy utilized the most by younger nontraditional female students. Emotion-focused coping may be utilized more by this group of nontraditional female students due to where they are in their maturation process. Erik Erikson described young adulthood as the stage of identity versus identity confusion. Regarding this process, Ashford and LeCroy (2013) have stated that the "two most critical development tasks during the age of young adulthood are economic independence and independent decision making. Adulthood is seen as reaching maturity, leaving home, and taking on new responsibilities” (p. 492).

Minorities often experience discrimination and racism as they matriculate in academia. However, for minority nontraditional female students there seems to be another layer of consideration that must be given when looking at the connection between coping and dealing with racism and discrimination. Some African-American female students in college have abandoned the traditional concept that academic success, seeing it as existing just for Caucasians (Ogbu, 1992). 
The following section outlines some coping strategies used by nontraditional female students that the literature highlights.

\section{Coping Strategies Used by Nontraditional Female Students}

Studies have indicated that nontraditional female students utilize emotion-focused and problem-solving coping to handle challenges (Dweck \& Leggett, 1988). Another coping strategy used by nontraditional female students is avoidance-oriented coping, where a person endeavors to evade a demanding circumstance by substituting that tense circumstance with another circumstance (diversion) or by looking for people (Parker \& Endler, 1992). Utsey et al. (2000) found that African-American women utilized the coping behaviors of seeking social support considerably more than African-American men. This study further indicated that when African American women were in situations of racial discrimination, they often used avoidance coping strategies, more than problemsolving coping techniques, or in seeking social support strategies.

A qualitative study done by Johnson-Bailey (1998) found that Black women utilized several different coping mechanisms that they identified as "silence, negotiation, and resistance. These were not new strategies; over the course of living the women had used them to survive or to succeed" (p. 43). In interviews with respondents they expressed their experience of being Black in America. This view is what DuBois (1903/1953) termed "double consciousness" (p. 3).

Nontraditional female students have numerous responsibilities which often leads them to be more goal-directed regarding the many tasks they must accomplish. In addition to this, their level of experience enhances the probability of their being more flexible in their situation and being interested in their studies because of the importance 
of that goal (Morris et al., 2003). Support for nontraditional female students is very important to their academic success. Studies have shown the importance of increased support (Home, 1993, 1997; Kaswarm, 1990; Rice, 1982), enhanced educational achievement, and belief in one's ability to be successful (Home, 1997; 1998; Kell \& VanDeursen, 2000; Kevern, Ricketts, \& Webb, 1999; Leavitt, 1989; McCue-Herliby, 1997; Novak \& Thacker, 1991; Ofori, 2000) are sometimes the individual and educational compensation for adult female students who attend delay their education.

Brazier (1998) was instrumental in revealing that time organization, working as a team and the use of a support group produced healthier survival skills when there were struggles with relatives and class assignments. Furthermore, additional research by Giancola et al. (2009) found that occupation strain might account for a larger part of family or school strain for adult students. It is because of these issues that nontraditional female students utilize more duty directed managing which concentrates on the issue. Some examples of handling stressors comprised hiring someone to assist them with the subject matter, having additional review periods, or finding additional means to resolve the issue. The literature indicated that adult students state they use more productive survival approaches, such as organizing, and fewer nonproductive tactics, such as avoidance and drug or alcohol misuse (Giancola et al., 2009).

Resilience is another coping strategy that can be useful to nontraditional female students. Resilience could be the interceding influence amid the difficulties of college experience and educational accomplishment (Munro \& Pooley, 2009). Furthermore, it is important for nontraditional female students to know to whom they can talk about problems and how to contact those individuals when they need encouragement (Bewick, 
Koustsopoulou, Miles, Slaa, \& Barkham, 2010).

Giancola et al. (2009) outlined that

two categories of coping behaviors are included: maladaptive and adaptive coping. Adaptive coping behaviors are those that lead to constructive, healthy psychosocial and physical outcomes for the individual. Conversely, maladaptive coping have a negative impact. Four types each of positive and negative coping strategies: adaptive (viz., positive reinterpretation, instrumental social support, active coping, and planning) and maladaptive (viz., venting, denial, behavioral disengagement, and substance use. (p. 249)

The following section portrays the conclusion derived from the literature review on coping strategies of nontraditional female students in higher education.

\section{Conclusion}

It appears that this trend of nontraditional female students in higher education will continue for a while. These nontraditional female students are 25 years and older and many of them are attending for the first time. Some of these students are reentry students and may present with challenges. Johnson-Bailey (1998) found in her study of Black reentry students that these students expressed that their journey was totally different from that of their Caucasian counterparts. They returned to academia to improve their situation and that of their family. Furthermore, they hoped that furthering their education would benefit them in their jobs, but this outcome was doubtful. Nontraditional female students may be returning to college for a variety of reasons such as switching vocations or improving their employment abilities. Adults who are leaving their jobs may have entered college to achieve a lifetime goal in completing an initial or terminal degree. Still some nontraditional females want to acquire additional proficiencies or information (Hardin, 2008).

There are many challenges that nontraditional female students may face once they 
decide to enter higher education. Resistance may first be felt in their own mind regarding their own ability to be successful in academia. Miller (2000) supported this premise that many nontraditional female students enter college fearing they will not succeed. Women often sabotage their own success by feelings of inadequacy and insecurity. It is these barriers they must first overcome before tackling a myriad of others. Astin and Kent (1983) found that, in addition to feelings of inadequacy and insecurity, nontraditional female students also felt remorseful for putting school ahead of all the other needs of their loved ones. Some nontraditional female students may be concerned about their family and work responsibilities and how they will handle all the things they are responsible for in their lives. Home $(1993,1998)$ reinforced this point by stating that for nontraditional female students juggling responsibilities may provide them a source of pride however, it really does causes stress as a consequence of limited time and energy. Giancola et al. (2009) discussed similar concerns regarding the overlap of responsibilities for nontraditional female students. For some adult female students there may be some sort of change in their lives such as ending a marriage or becoming a widow. Others attend because their kids are now in school or have left the household. However, in many circumstances, nontraditional females are arriving in higher education in order to offer financial assistance for their households (Allen, 1993). For those single nontraditional female students, there may be a long list of obstacles to tackle before they enter college, such as finances and childcare. Furthermore, for some nontraditional female students it may be the only option for them to go to college as they face a major life transition and for still others, it may be the achievement of a long awaited goal.

Glass and Rose (1994) state one of the common rationales given by nontraditional 
female students for resuming their education is dissolution of marriage. Minority nontraditional female students may experience fears of how they will be treated by classmates and professors because of their race. This is added to the experience of being older and without comrades who are their age in classes. Hardin (2008) stated that older students sometimes feel lonely once they come to academia, however, Eifler and Potthoff (1998) reinforce the importance of these students establishing a support system that will combat those views that goes along with a job move. It is with these decisions that nontraditional female students enter the uncertain world of academia.

The consideration of how one is to pay for tuition, books, and other necessities may seem impossible as they consider how to share their decision with love ones and friends who may or may not be supportive. Corrigan (2003) found this to be the case for nontraditional female students in making financial decisions regarding their education. Graham and Donaldson (1999) and Keith (2007) postulate that there are various situations that can impede nontraditional female students' educational advancement such as absence of assistance from her family, along with overlapping obligations, and home/work duties. Some nontraditional female students feel they are too old to embark upon such a journey; for others, it provides them with a sense of excitement to know they are attempting something they thought impossible. However, whatever the circumstance of the woman, she will face trials that can strengthen her on this unpredictable journey or test her and cause her to feel she incapable of achieving her dreams. 


\section{CHAPTER 3}

\section{METHODOLOGY}

The coping strategies used by undergraduate nontraditional females from a private university and public university were examined in this study. The study also investigated coping strategies of those of different ethnic groups, from different socioeconomic groups, age levels, marital status, and having different numbers of children to determine if there are any differences among the groups who are currently enrolled in the private and public unversity.

This chapter will focus on the research design used in this study and the methods and procedure used to collect the data, the population and sample, and the instrument chosen for this project.

\section{Research Questions}

1. What are the coping strategies used by nontraditional female students in higher education?

2. Are coping strategies related to the ethnicity of nontraditional female students?

3. Are coping strategies related to the number of children of nontraditional female students?

4. Are coping strategies related to age groups of nontraditional female students? 
5. Are coping strategies related to income levels of nontraditional female students?

6. Are coping strategies related to marital status of nontraditional female students?

\section{Research Design}

The study utilized the survey research method in collecting data. Survey research was used in this study because of its flexibility to explore a variety of problems or questions. McMillan and Schumacher (2001) stated that survey research is the preferred research method when the investigator is examining "the incidence, frequency, and distribution of the characteristics of an identified population. In addition to being descriptive, surveys can also be used to explore relationships between variables" (p. 304). This study explores and describes the various coping strategies used by nontraditional female students in reference to their ethnicity, number of children, age, and marital status.

\section{Population and Sample}

The population for this study was undergraduate nontraditional female students who were 25 years and older who attended the public university, and those who attended the private university. These institutions were selected based on the proximity to the researcher and because they represented a public school and a private institution. The procedure utilized to select subjects was to use the total population of nontraditional female students at both the private and public university. The data was collected between November 2012 to April 2013. A letter requesting respondents' participation in the study was sent to the eligible sample via email. Respondents who were eligible for participation 
were female and met the age requirement of 25 or older.

This project utilized email as a means to communicate with students about the possibility of participating in the study. At the private university, the Office of Student Life sent a letter from the researcher via email requesting respondents to participate by completing the survey. At the public university the email was sent out by the researchers' faculty sponsor, Dr. Carolyn Schult, requesting all nontraditional female students age 25 and older to go the URL if they were interested in completing the survey. The survey was completed on Survey Monkey.

Respondents were eligible for inclusion in the study if they were female and 25 years old and older. Both universities selected respondents based on this criteria and respondents were requested to participate in the study.

The public university was chosen because of its high percentage of nontraditional students and because the researcher sought to look at a population of nontraditional female students who attend a public university. The public university, which is the third largest institution in the state and had a student population of 8,490 in the Fall 2012, is in close proximity to where the researcher is attending school, so their inclusion was ideal. The public university is part of an eight- university system of institutions of higher learning in the state.

The private university does not have a high nontraditional undergraduate female student population; however, the university does have a high international student population. Ethnicity was a factor in this study and this university is considered to be one of the most diverse universities in the United States.

The total population of undergraduate nontraditional female students of 131 
constitutes .5 percent of the total student population at the private institution. The total population of undergraduate nontraditional female students of 1,678 constitutes about 20 percent of the total student population at the public institution.

\section{Instrumentation}

The CSA was designed to measure coping strategies used by adults. Erica Frydenberg and Ramon Lewis developed this self-reporting questionnaire consisting of 74 items.

In this study, the "Specific Long Form" of the CSA was used for asking respondents to identify the coping strategies as it relates to being an undergraduate nontraditional female student in higher education. The CSA was reviewed by the Institutional Review Board (IRB) of Andrews University (AU) and Indiana University South Bend (IUSB) and revisions were made to the instrument. Of these items, 73 structure items reliably assess 18 conceptually and empirically distinct coping strategies. The five-point Likert scale was revised to (1- don't do it; 2-used very little; 3-used sometimes; 4-used often; 5-used a great deal), for this study to address the specific responses made by respondents. (Frydenberg \& Lewis, 1993). There were items that were revised to meet IRB approval. Item 46 was revised from: Find a way to let off steam: for example, cry, scream, drink, and take drugs, to find a way to let off steam. The public university was not comfortable with this item because it involves privacy. Another item that was not included on the survey was the qualitative question -item \#74 which ask respondents to list any other things they do to cope with their concern/s. Also, not listed on the survey was the information stating that within this scale are three items, which were devised primarily for clinical purposes that indicated problems with coping (the Not 
Cope scale). The IRB stated that the information could not be listed as clinical information on the survey for respondents so it was excluded from the questionnaire.

Permission to use the CSA was obtained through the publisher from the author. The survey can be found in Appendix A.

\section{Reliability}

Test-retest reliability was reported for 25 participants who took a second testing of the CSA 10 to 14 days after the first administration of the questionnaire. Test-retest correlations were computed and the items considered were those reaching at least .58 or higher. Those items with less than adequate test-retest correlations were considered reliable if at least $80 \%$ of the subjects gave responses that were within one point of the first test response on the second testing (Frydenberg \& Lewis, 1997). "Coefficient alpha reliabilities for the 18 subscales averaged .80 . Sound test development has resulted in excellent overall reliability for the CSA" (Plake, Impara, \& Spies, 2003, p .264). Reliability analyses of the 73 items encompassing the CSA were run and 13 of the 18 subscales had reliabilities of less than .700 and this suggested that some of these subscales did not hold together and that, perhaps, the dimensionality of the CSA may not be supported by the data from this particular sample; thus, an exploratory factor analysis was done.

\section{Validity}

The authors did an exploratory factor analysis of the CSA to determine validity of the instrument. Seventy-three items were subjected to factor analysis. (Frydenberg \& Lewis, 1997). The authors do not provide any concurrent or comparative studies from 
which to reference their results. However, Plake et al. (2003) state that the "CSA does offer commonsense validity" (p.265). They say, further, that it appears on the surface that the various scales seem to measure what they are intended to measure in uniquely separate ways of reacting to demanding situations.

\section{Procedures}

The IRB staff was contacted by phone for both universities. A letter outlining the purpose and nature of the study, and the manner in which the researcher wished to facilitate the process was submitted to the IRB for both universities.

Written permission to have students complete the questionnaire via Survey Monkey for public and private university students was obtained from the Student Enrollment Department at the public university and Student Life Office at the private university and submitted to the private university IRB for its approval. The public university required that this researcher have a faculty sponsor from their university. Dr. Carolyn Schult was the faculty sponsor from the public university. The public university also required that an application be completed outlining the research project online along with consent for respondents to agree to participate in the research study. The public university also required that the certification be completed which was done online.

The private university respondents were sent an email by the Office of Student Life requesting their participation in the study. Participants received an email outlining the purpose of the research and requesting their participation in the study. Students were requested to complete the CSA questionnaire on Survey Monkey. The public university respondents were emailed the same letter by the faculty sponsor, Carolyn Schult, who 
requested their participation in the study. The study was opened in November for respondents to take the survey.

The study was initially exempt for both the public and the private university but became expedited in February to get more participation from the private university respondents due to the low enrollment of participants. This researcher called the private university participants via phone requesting their participation in the study.

Specific measures were taken to maintain the confidentiality of data and respondents' identity. Respondents were given the option of participating in a random gift drawing at the end of the survey. Respondents were given the option of submitting a partially completed or completely blank questionnaire and still be eligible for the $\$ 25$ gifft card drawing. They were asked to supply their email address in order to have their names entered into a random drawing for a gift card. Six respondents were selected to receive a $\$ 25$ gift card. There was no further attempt to identify individual surveys. The data was not identifiable in any other manner. And data from individual surveys will not be reported. Surveys will be part of a database which will be totally anonymous.

\section{Treatment of the Data}

There were 541 respondents who completed the survey; however, when the initial analysis was reviewed there were numerous missing values. These respondents were excluded from the study due to unanswered questions. The criteria for eliminating respondents was five percent missing values. The final number of respondents who participated in the study was 444 . 


\section{Analysis Strategies}

The following research questions were analyzed using the following statistical procedures (see Table 1).

Table 1

Research Question Type and Testing

\begin{tabular}{|c|c|c|c|}
\hline $\begin{array}{l}\text { Research } \\
\text { Questions }\end{array}$ & Dependent & Independent & Statistical Test \\
\hline Q1 & $\begin{array}{l}\text { What are the coping strategies } \\
\text { used by nontraditional } \\
\text { females in higher education? }\end{array}$ & & Descriptive Statistics \\
\hline Q2 & $\begin{array}{l}\text { Are coping strategies related } \\
\text { to the ethnicity of } \\
\text { nontraditional female } \\
\text { students? }\end{array}$ & Race & $\begin{array}{c}\text { MANOVA } \\
\text { Means and Standard } \\
\text { Deviation }\end{array}$ \\
\hline Q3 & $\begin{array}{l}\text { Are coping strategies related } \\
\text { to the number of children of } \\
\text { nontraditional female } \\
\text { students? }\end{array}$ & $\begin{array}{l}\text { Number of } \\
\text { Children }\end{array}$ & $\begin{array}{c}\text { MANOVA } \\
\text { Means and Standard } \\
\text { Deviation }\end{array}$ \\
\hline Q4 & $\begin{array}{l}\text { Are coping strategies related } \\
\text { to age groups of } \\
\text { nontraditional female } \\
\text { students? }\end{array}$ & Age Range & $\begin{array}{c}\text { MANOVA } \\
\text { Means and Standard } \\
\text { Deviation }\end{array}$ \\
\hline Q5 & $\begin{array}{l}\text { Are coping strategies related } \\
\text { to income levels of } \\
\text { nontraditional female } \\
\text { students? }\end{array}$ & Income Range & $\begin{array}{c}\text { MANOVA } \\
\text { Means and Standard } \\
\text { Deviation }\end{array}$ \\
\hline Q6 & $\begin{array}{l}\text { Are coping strategies related } \\
\text { to marital status of } \\
\text { nontraditional female } \\
\text { students? }\end{array}$ & Marital Status & $\begin{array}{c}\text { MANOVA } \\
\text { Means and Standard } \\
\text { Deviation }\end{array}$ \\
\hline
\end{tabular}


Descriptive statistics were used to determine what coping strategies nontraditional female students used the most and the least in managing everyday life situations.

\section{Summary}

This study examined the coping strategies of undergraduate nontraditional female students from two universities in Southwest Michigan and Northwest Indiana.

Information was obtained by having subjects complete a demographic questionnaire, consent form, and the CSA survey which were all completed on Survey Monkey.

The six research questions were presented and the strategies used to answer the research questions were explained. The instrument used in the study was presented, as well as the procedure used to conduct the study. 


\section{CHAPTER 4}

\section{RESULTS}

The purpose of this study was to examine the coping strategies of nontraditional female students in Southwest Michigan and Northern Indiana. The sample included nontraditional female students from both a public university and a private university. In this chapter, participants' demographic characteristics will be described. Preliminary analysis of the CSA is presented. Scale similarities between the original study and the present study are highlighted. Scale statistics, reliability, and inter-correlation information are presented along with scale, item, and standard deviation information. Results of the exploratory factor analysis of the coping strategies used by nontraditional female students are presented followed by analyses of the research questions and summary of the major findings.

\section{Participant Demographic Characteristics}

In terms of school status, two-thirds of the repondents were full-time students (64\%) who were mostly juniors and seniors (75\%) and mainly Caucasian (76\%). It should be noted that most of the respondents were returning students (84\%)) who were mainly between the ages of 25 and $44(82 \%)$. Almost half of the respondents were married (46\%); over one-third (35\%) of the respondents had no children. It is noteworthy that $42 \%$ of respondents in this study had household incomes of below $\$ 20,000$. Table 2 
Table 2

Demographic Information

\begin{tabular}{|c|c|c|c|c|c|c|}
\hline & \multicolumn{2}{|c|}{ Public (N=381) } & \multicolumn{2}{|c|}{ Private $(\mathrm{N}=63)$} & \multicolumn{2}{|c|}{ Total \% $(n=444)$} \\
\hline & $\mathrm{N}$ & $\%$ & $\mathrm{~N}$ & $\%$ & $\mathrm{~N}$ & $\%$ \\
\hline \multicolumn{7}{|l|}{ Enrollment Status } \\
\hline Full-Time Student & 233 & $61.2 \%$ & 51 & $81.0 \%$ & 284 & $64.0 \%$ \\
\hline Part-Time Student & 145 & $38.1 \%$ & 10 & $15.9 \%$ & 155 & $34.9 \%$ \\
\hline \multicolumn{7}{|l|}{ Year in College } \\
\hline Freshman & 34 & $8.9 \%$ & 3 & $4.8 \%$ & 37 & $8.3 \%$ \\
\hline Sophomore & 60 & $15.7 \%$ & 10 & $15.9 \%$ & 70 & $15.7 \%$ \\
\hline Junior & 94 & $24.7 \%$ & 18 & $28.6 \%$ & 112 & $25.2 \%$ \\
\hline Senior & 193 & $50.7 \%$ & 32 & $50.8 \%$ & 225 & $50.6 \%$ \\
\hline \multicolumn{7}{|l|}{ Student Category } \\
\hline New Student & 56 & $14.7 \%$ & 12 & $19.0 \%$ & 68 & $15.3 \%$ \\
\hline Returning Student & 325 & $85.3 \%$ & 51 & $81.0 \%$ & 376 & $84.7 \%$ \\
\hline \multicolumn{7}{|l|}{ Age Range } \\
\hline $25-29$ & 113 & $29.7 \%$ & 23 & $36.5 \%$ & 136 & $30.6 \%$ \\
\hline $30-44$ & 197 & $51.7 \%$ & 31 & $49.2 \%$ & 228 & $51.4 \%$ \\
\hline $45 \&$ above & 70 & $18.4 \%$ & 9 & $14.3 \%$ & 79 & $17.8 \%$ \\
\hline Missing & 1 & $.2 \%$ & - & - & 1 & $.2 \%$ \\
\hline \multicolumn{7}{|l|}{ Ethnicity } \\
\hline African-American & 28 & $7.3 \%$ & 13 & $20.6 \%$ & 41 & $9.3 \%$ \\
\hline Caucasian & 313 & $82.2 \%$ & 24 & $38.1 \%$ & 337 & $76.2 \%$ \\
\hline Other & 38 & $10 \%$ & 26 & $41.3 \%$ & 64 & $14.4 \%$ \\
\hline Missing & 2 & $.5 \%$ & - & - & - & - \\
\hline \multicolumn{7}{|l|}{ Marital Status } \\
\hline Married & 181 & $47.5 \%$ & 26 & $41.3 \%$ & 207 & $46.6 \%$ \\
\hline Single & 117 & $30.7 \%$ & 25 & $39.7 \%$ & 142 & $31.9 \%$ \\
\hline Widowed & & & & & & \\
\hline Separated \& & 83 & $21.8 \%$ & 12 & $19.0 \%$ & 95 & $21.4 \%$ \\
\hline Divorced & & & & & & \\
\hline \multicolumn{7}{|l|}{ Number of Children } \\
\hline None & 132 & $34.6 \%$ & 27 & $42.9 \%$ & 159 & $35.8 \%$ \\
\hline One & 83 & $21.8 \%$ & 9 & $14.3 \%$ & 92 & $20.7 \%$ \\
\hline Two & 97 & $25.5 \%$ & 16 & $25.4 \%$ & 113 & $25.5 \%$ \\
\hline Three or more & 69 & $18.1 \%$ & 10 & $15.9 \%$ & 79 & $17.7 \%$ \\
\hline Missing & - & - & 1 & $1.6 \%$ & 1 & $.2 \%$ \\
\hline \multicolumn{7}{|l|}{ Income Level } \\
\hline Below 20,000 & 146 & $38.3 \%$ & 43 & $68.3 \%$ & 189 & $42.5 \%$ \\
\hline $21,000-35,000$ & 94 & $24.7 \%$ & 9 & $14.3 \%$ & 103 & $23.1 \%$ \\
\hline $36,000 \&$ above & 138 & $36.2 \%$ & 10 & $15.9 \%$ & 148 & $33.2 \%$ \\
\hline Missing & 3 & $.8 \%$ & 1 & $1.6 \%$ & 4 & $.9 \%$ \\
\hline
\end{tabular}


presents the demographic breakdown highlighting the characteristics of repondents who participated in the study.

Table 3 highlights the original 19 scales formulated by Frydenberg and Lewis (1997) and the items that are represented on those scales. The Not Cope scale was not used in this study since the clinical scale was not approved by the IRB.

Table 3

Items Comprising the 19 Scales of the Coping Scale for Adults

\begin{tabular}{ll}
\hline \multicolumn{1}{c}{ Scale } & \multicolumn{1}{c}{ Items } \\
\hline 1. Seek Social Support & $1,17,59,71$ \\
2. Focus on Solving the Problem & $10,16,18,32,36,44,55$ \\
3. Work Hard & $3,19,25$ \\
4. Worry & $7,24,37,64$ \\
5. Improve Relationships & $40,50,53,66$ \\
6. Wishful Thinking & $29,41,54,69$ \\
7. Tension Reduction & $12,27,46,68$ \\
8. Social Action & $39,49,52,67$ \\
9. Ignore the Problem & $2,58,65$ \\
10. Self-Blame & $42,51,56,70$ \\
11. Keep to Self & $15,30,43,57$ \\
12. Seek Spiritual Support & $5,22,48$ \\
13. Focus on the Positive & $21,35,47,62$ \\
14. Seek Professional Help & $6,23,61,72$ \\
15. Seek Relaxing Diversion & $11,14,26,73$ \\
16. Physical Recreation & $4,20,34$ \\
17. Protect Self & $8,13,31,38$ \\
18. Humor & $33,45,60$ \\
19. Not Cope & $9,28,63$ \\
\hline
\end{tabular}




\section{Preliminary Analysis of the Coping Scales for Adults}

In examining the eighteen scales that were used in this study, an initial analysis of the CSA indicated that thirteen of the original 18 scales had low reliability estimates below .700, as shown in Table 4, which suggested that some of these subscales did not hold together and that, perhaps, the dimensionality of the CSA may not be supported by the data from this particular sample. There was a need to examine the dimensionality of the CSA as supported by the data, hence an exploratory factor analysis was done.

Table 4

Eighteen Scales of the Coping Scales for Adults

\begin{tabular}{lcccc}
\hline \multicolumn{1}{c}{ Scale } & Mean & $S D$ & Item \# & Cronbach's Alpha \\
\hline Seek Social Support & 12.6 & 2.8 & 4 & .521 \\
Focus on Solving the Problem & 26.8 & 3.7 & 7 & .691 \\
Work Hard & 13.3 & 1.7 & 3 & .699 \\
Worry & 12.7 & 3.0 & 4 & .580 \\
Improve Relationships & 11.2 & 3.2 & 4 & .565 \\
Wishful Thinking & 11.4 & 2.7 & 4 & .396 \\
Tension Reduction & 9.8 & 2.3 & 4 & .222 \\
Social Action & 7.1 & 2.4 & 4 & .422 \\
Ignore the Problem & 6.7 & 2 & 3 & .401 \\
Self-Blame & 12.5 & 3.5 & 4 & .724 \\
Keep to Self & 11.4 & 2.9 & 4 & .468 \\
Seek Spiritual Support & 6.0 & 2.2 & 2 & .099 \\
Focus on the Positive & 12.4 & 2.6 & 4 & .518 \\
Seek Professional Help & 9.1 & 2.8 & 4 & .318 \\
Seek Relaxing Diversions & 13.6 & 2.5 & 4 & .460 \\
Physical Recreation & 6.9 & 2.7 & 3 & .758 \\
Protect Self & 12.6 & 3.0 & 4 & .707 \\
Humour & 9.3 & 2.5 & 3 & .517 \\
\hline
\end{tabular}




\section{Data Screening/Testing Assumptions}

The factorability of the 73 item CSA was examined. The Kaiser-Meyer-Olkin (KMO) Measure of Sampling Adequacy along with Bartlett's test of sphericity create an estimated gauge of how suitable the correlations are for factor analysis (Meyers, Gamst, $\&$ Guarino, 2006). The Kaiser-Meyer-Oklin Measure of Sampling Adequacy (KMO) showed that this intercorrelation matrix was appropriate for factor analysis $(\mathrm{KMO}=$ .816). The Bartlett's Sphericity Test of sphericity was significant $(p<.001)$, demonstrating adequate correlation between the variables to continue with the study. The Bartlett's Test of Spehericity also showed that the correlation matrix was not an identity matrix (Bartlett, 1954). To decide the factorability of the R-correlation matrix, the following measures were used:

(a) verify that the item correlates with at least one other item at $\geq$.3. Items were omitted that did not correlate with one another.

(b) The Kaiser-Meyer-Olkin measure of sample adequacy criterion was used to decide if the suggested value of .6 was met. The $(\mathrm{KMO}=.816)$ exceeded the suggested value indicating that there was adequate correlation to run the factor analysis to determine what factors correlate together to form the scales for coping strategies of nontraditional female students.

(c) Bartlett's Test of Sphericity criterion was used to test the hypothesis that the correlation matrix was an identity matrix. The correlation matrix was factor analyzed as if it was not an identity matrix, and the significance level less than .05. Bartlett's Test of Sphericity shows the researcher that the variables are not significantly correlated (Meyers et al., 2006). 
(d) Communalities were examined to verify they were all $\geq .3$. This would indicate that each item shares common variance with other items.

\section{Factor Extraction}

Factor analysis (Principle Axis Factor [PAF]) was used instead of Principle Component Analysis (PCA) because PAF uses the shared intersecting variance that is common among the variables in the analysis. Principle Axis Factor analyzes the covariance whereas PCA analyzes total variance. Principle Component Analysis focuses on the overall variance in the data set.

\section{Number of Factors Retained}

Two primary extraction criterion methods were used in this study, the use of fixed number of factors and the scree plot (Cattell, 1966). Costello and Osborne (2005) ascertained that the scree test is the finest option for researchers to use. It involves assessing the point of the bend and retaining the factors above this point.

\section{Rotation of Factors}

Factor rotation is used to condense and explain the data configuration. Rotation does not perfect the fundamental characteristics of the analysis, such as the amount of variance removed from the items. An oblique procedure was utilized since it does not require that the factors remain uncorrelated in the rotation process (Meyers et al., 2006). The rotation used for the analysis was direct oblimin in order to allow for greater correlation among the factors.

Costello and Osborne (2005) stated that "behavior is rarely partitioned into neatly packaged units that function independently of one another" (p. 3). This is not the case 
with orthogonal rotation where the factors are uncorrelated. Oblique rotations permit the factors to correlate with one another. The pattern matrix was analyzed for distinctive factor loadings.

\section{Identification of Items in Each Factor}

The oblique rotation produces two matrices, the Pattern Matrix and the Structure Matrix. Tabachnick and Fidell (2001) assert:

The loading in the pattern matrix is not correlational but a measure of the unique relationship between the factor and the variable; because factors correlate the correlations between the variables and factors (available in the structure matrix) are inflated by overlap between the factors. A variable may correlate with one factor through its correlation with another factor rather than directly. Actually, the reason for interpretation of the pattern matrix rather than the structure matrix is pragmaticit's easier. The difference between high and low loadings is more apparent in the pattern matrix than the structure matrix. (p. 625)

So, in this study, a pattern matrix was used and items $\geq .3$ was the criterion for inclusion for an item.

\section{Results of the Factor Analysis}

There were 19 components with eigenvalues greater than one suggesting a nineteen factor solution, however, the rotation failed to converge in 25 iterations so a pattern matrix was not produced. The analyses was run at 150 iterations and based on the results of the scree plot fixed factors solutions were used which produced a pattern matrix. Based on this criterion, fixed factor solutions were run for eight-factor solution, seven-factor solution, six factor solution, and five factor solution.

An eight-factor solution was run, along with a seven-factor solution, a six-factor solution, and a five-factor solution all with oblique rotation. Based on this analysis, I decided that the seven-factor solution was the best and most meaningful. 
First reviewed was a fixed eight-factor model with oblique rotation as indicated by the scree plot method. The fixed eight-factor model explained $38.36 \%$ of variance however, it was not chosen because there was overlap with two of the factors which basically covered the same concept of getting help and connecting with other people who have the same problem.

A fixed seven-factor model with oblique rotation was run. In the seven-factor model, $35.96 \%$ of the total variance is explained. Table 5 shows the number of items with communalities $\geq .3$. The fixed seven-factor model was chosen for this analysis because it explained $35.96 \%$ of the variance and the model had solid loadings that depicted a more comprehensive coverage of the concepts which included the importance of working to succeed while being faced with self-defeating behaviors.

The fixed seven-factor model with oblique rotation indicates students using healthy coping strategies while also using negative coping skills to address their problems, but finding positive ways to cope by getting help from people when needed. Furthermore, nontraditional females indicated that they often do not use proactive, selfcare measures to stay fit or to improve their self-image. These factors all provided a more comprehensive picture of the coping strategies used by the nontraditional female student population in this study indicating that positive and negative coping strategies were used in this study. The oblique rotation appeared to be the best solution based on the solid reliability estimates and on the fact that the factors were strongly correlated.

Next examined was a fixed six-factor solution model with oblique rotation. The fixed six-factor model explained $33.58 \%$ of the variance however, the reliability estimate was low (.590) on the sixth factor. The items were different concepts which presented a 
mixed view of the concept that this scale would represent.

A fixed five-factor model with oblique rotation was examined. The five-factor model explained $30.86 \%$ of the variance in this model. However, the factor covered some of the coping strategy concepts but lacked some of the general themes included in the fixed seven-factor model. Table 6 presents the factor loadings, communalities, and percent variances.

Table 5

Commonalities and Percentage of Explained Variance, CSA

\begin{tabular}{ccc}
\hline Model & Commonalities $>.3$ & $\%$ of Explained Variance \\
\hline 5-Factor Model & 39 of 72 & 30.86 \\
6-Factor Model & 45 of 72 & 33.58 \\
7-Factor Model & 47 of 72 & 35.96 \\
8-Factor Model & 51 of 72 & 38.36 \\
\hline
\end{tabular}

Naming the Factors

Seven factors emerged from the exploratory factor analysis for the CSA which addresses coping strategies used by nontraditional female students in higher education. The process of naming factors emerged through reviewing the content of the items that loaded onto the same factor, and classifying mutual ideas from the factor loadings. The top items were reviewed to examine similarities or differences of the concept.

Correlations that cross loaded were included if they were $\geq .3$ or greater: although, most of the time it was much greater that $\geq .3$. The pattern coefficients for each factor were studied thoroughly to ensure that the name for each factor characterized the concept of the scale. The pattern matrix was selected over the structure matrix because it 
Table 6

Factor Loading, Commonalities $\left(h^{2}\right)$, and Percentage of Variance

\begin{tabular}{|c|c|c|c|c|c|c|c|c|}
\hline Item & $F_{1}{ }^{a}$ & $F_{2}$ & $F_{3}$ & $F_{4}$ & $F_{5}$ & $F_{6}$ & $\boldsymbol{F}_{7}$ & $\mathbf{h}^{2}$ \\
\hline Solving the problem & .683 & & & & & & & .490 \\
\hline Focus on what's important & .634 & & & & & & & .490 \\
\hline Put effort into my work & .602 & & & & & & & .345 \\
\hline Develop a plan of action & .595 & & & & & & & .499 \\
\hline Work hard & .582 & & & & & & & .344 \\
\hline I get stressed out and despair & .570 & & & & & & & .410 \\
\hline Assess the situation & .565 & & & & & & & .396 \\
\hline What am I doing/why & .549 & & & & & & & .309 \\
\hline Try to have a cheerful outlook & .475 & & & & & & & .505 \\
\hline Try to keep up with work & .469 & & & & & & & .247 \\
\hline Look on the bright side & .415 & & & & & & -.352 & .458 \\
\hline Improve relationship with others & & .580 & & & & & & .514 \\
\hline Imagine things working out well & & .535 & & & & & & .291 \\
\hline Daydream things turning out well & & .481 & & .358 & & & & .337 \\
\hline Tell jokes & & .468 & & & & & & .230 \\
\hline I suffer head/stomach aches & & .463 & & & & & & .293 \\
\hline Make time for leisure & & .462 & & & & & & .379 \\
\hline Try to make close friends & & .461 & & & & & & .291 \\
\hline More time with significant other & & .461 & & & & & & .245 \\
\hline Ways of dealing with problem & & .401 & & & & & & .192 \\
\hline Keep long term goals clear $(\mathrm{R})$ & & & .633 & & & & & .566 \\
\hline Worry about what is happening & & & .624 & & & & & .449 \\
\hline Cry or scream & & & .592 & & & & & .425 \\
\hline Worry about my future & & & .583 & & & & & .403 \\
\hline Criticize myself & & & .583 & & & & & .459 \\
\hline Worry about my happiness & & & .564 & & & & & .351 \\
\hline Don't share my problems & & & .557 & & & & & .350 \\
\hline I get sick (head/stomach ache) & & & .519 & & & & & .292 \\
\hline Hope problem will self-solve & & & .490 & & & & & .263 \\
\hline Separate from problem to avoid it & & & .435 & & & & & .368 \\
\hline Blame myself & & & & .863 & & & & .754 \\
\hline See myself as being at fault & & & & .820 & & & & .680 \\
\hline Get annoyed at myself & & & & .739 & & & & .548 \\
\hline What will happen to me & & & & .607 & & & & .370 \\
\hline Consciously block out the problem & & & & .544 & & & & .398 \\
\hline Ask a professional for help & & & & .527 & & & & .296 \\
\hline Don't let others know my feelings & & & & .482 & & -.340 & & .414 \\
\hline Take frustrations out on others & & & & .449 & & & & .217 \\
\hline Put the problem out of mind & & & & .360 & & & & .220 \\
\hline Keep feelings to myself $(\mathrm{R})$ & & & & & .654 & & & .473 \\
\hline Talk /give each other support & & & & & .644 & & & .517 \\
\hline Wish a miracle would happen & & & & & .621 & & & .400 \\
\hline Keep worries to self & & & -.409 & & .620 & & & .546 \\
\hline What will others do in my place $(\mathrm{R})$ & & & & & .551 & & & .324 \\
\hline Spend time with close friends $(\mathrm{R})$ & & & & & .463 & & & .330 \\
\hline Find way to let off steam (R) & & & & & .445 & & & .477 \\
\hline Make time for friends/family (R) & & & & & .364 & & & .326 \\
\hline Find a way to relax (music/book) (R) & & & & & .323 & & & .334 \\
\hline Discuss problem with professional (R) & & & & & & .763 & & .568 \\
\hline
\end{tabular}


Table 6-Continued.

\begin{tabular}{|c|c|c|c|c|c|c|c|c|}
\hline Item & $F_{1}{ }^{a}$ & $F_{2}$ & $F_{3}$ & $F_{4}$ & $F_{5}$ & $F_{6}$ & $F_{7}$ & $\mathbf{h}^{2}$ \\
\hline Ask professional for help (R) & & & & & & .659 & & .419 \\
\hline Talk to others about concern (R) & & & & & & .565 & & .464 \\
\hline Get support from others $(\mathrm{R})$ & & .307 & & & & .508 & & .459 \\
\hline Join with people w/ same concern (R) & & .372 & & & & .487 & & .449 \\
\hline Meetings that look at the problem (R) & & & & & & .466 & & .248 \\
\hline Form group to deal with concern $(\mathrm{R})$ & & & & & & .338 & & .202 \\
\hline Keep fit and healthy & & & & & & & -.658 & .527 \\
\hline Improve my appearance & & & & & & & -.613 & .404 \\
\hline Work on my self-image & & & & & & & -.548 & .440 \\
\hline Go for a workout at the gym & & & & & & & -.498 & .270 \\
\hline Play sport & & & & & & & -.407 & .186 \\
\hline Organize an action or petition & & & & & & & -.371 & .183 \\
\hline Positive self-talk & .330 & & & & & & -.367 & .386 \\
\hline Protect my self-esteem & & & & & & & -.349 & .306 \\
\hline Pray for help and guidance & & & & & & & -.312 & .101 \\
\hline Percent of Variance & 11.73 & 6.75 & 4.81 & 4.31 & 3.57 & 2.62 & 2.18 & \\
\hline
\end{tabular}

Note. Factor Labels: $\mathrm{F}_{1}{ }^{\mathrm{a}}$ - Work at Succeeding; $\mathrm{F}_{2}$ - Healthy Coping Strategies; $\mathrm{F}_{3}$ - Self-Defeating Behaviors; $\mathrm{F}_{4}$ - Negative Coping Skills; $\mathrm{F}_{5}$ - Positive Ways to Cope; $\mathrm{F}_{6}$ - Means of Getting Help; $\mathrm{F}_{7}$ - Proactive Self-Care; ${ }^{*} \mathrm{R}$ - Reverse Coded Items.

is an example of distinctive correlations which is not affected by the similarity between the components (Tabachnick \& Fidell, 2001). Three colleagues who are experts in this area but not associated with this study were requested to examine the subscales to give input with the naming of the factors.

Factor 1: The first subscale, "work at succeeding," encompasses the construct of "working hard," "working at solving the problem," and "developing a plan of action." This scale focuses on students' looking on the "bright side" of things and focusing on what is most important. "Work at succeeding" (eigenvalue $=9.03$ ) accounted for 11.73 percent of the variance and had eleven items. The factor loadings ranged from .415 to .683 and Table 6 shows the loadings (those $\geq$ than .3 ) for this factor. There was one cross-loading on factor one, "look on the "bright side"" (.415), with factor seven (-.352), "proactive self-care." Factor seven was characterized by behaviors which foster an 
individual to take care actively of one's self emotionally and physically. "Look on the "bright side" is included on factor one because it aligns better with the other items on the factor "work at succeeding." "Proactive self-care was a factor where nontraditional female students did not do well in utilizing these coping strategies.

Factor 2: The second subscale, "healthy coping strategies," focuses on students' developing healthy coping strategies for solving their problems. This includes improving their relationships with others and making time for leisure activities. "Healthy coping strategies" (eigenvalue $=5.42$ ) represented 6.75 of the variance percent and had nine items. The loadings ranged from .401 to .580 and Table 6 shows the significant loadings for this factor. There was a cross-loading with "daydream things turning out well" (.481) with factor four, "negative copings skills" (.358). The "negative coping skills" factor will be discussed later. The item "daydream things turning out well" was included on the "healthy coping strategy" factor because it showed the process of resolving conflicts using positive methods.

Factor 3: A third subscale emerged, "self-defeating behaviors," which addresses how students worry about the future, shut themselves off from the problem, and get sick with headaches or stomach aches. "Self-defeating behaviors" (eigenvalue $=4.08$ ) accounted for 4.81 percent of the variance and had ten items. The loadings ranged from .435 to .633 and Table 6 shows the significant loadings (those $\geq$ than .3) for this factor.

Factor 4: The fourth subscale included items depicting where the person sees herself as being at fault, taking her frustrations out on other people, and asking for professional help. This fourth subscale was named "negative coping skills." "Negative coping skills" (eigenvalue $=3.68$ ) explained 4.31 percent of the variance and had nine 
items. The loadings ranged from .360 to .863 and Table 6 shows the significant loadings (those $\geq$ than .3) for this factor. There were two cross-loading on the "negative coping skills" factor (.482): the "don't let others know my feeling" item which cross-loaded with subscale six, "means of getting help" factor (-.340). The second cross-loading on the negative coping factor was "daydream things turning out well" (.358) with factor two, "healthy coping strategies" (.481).

Factor 5: The fifth subscale focused on talking to others to see what they would do if they had the problem, spending time with close friends, and finding ways to let off steam. The subscale was named "positive ways to cope." "Positive ways to cope" (eigenvalue $=3.18)$ represented 3.57 percent of the variance and had nine items. The loadings ranged from .323 to .654 and Table 6 shows the significant loadings (those $\geq$ than .3) for this factor. The positive loadings depict coping strategies used to cope positively with problems which nontraditional female students may encounter. For example, "what would others do in my place" (.551), "spend time with friends" (.463), and "find a way to let off steam" (.445). There was one cross-loading on factor five, "positive ways to cope," with "keep my worries to myself" (.620), which cross-loaded with factor three, "self-defeating behaviors" factor (-.409). This item was included on factor five, "positive ways to cope," because it focuses on ways used to cope with problems in a positive manner which could depict ways that nontraditional female students use problem solving coping mechanisms to solve problems.

Factor 6: The sixth subscale looks at ways to cope by asking a professional for help, going to meetings which look at the problem, and getting support from others such as parents or friends. This subscale was named "means of getting help" because of these 
attributes. "Means of getting help" (eigenvalue $=2.52$ ) accounted for 2.62 percent of the variance and had seven items. The loadings ranged from .338 to .763 and Table 6 shows the significant loadings (those $\geq$ than .3) for this factor. The loadings depict coping strategies used to reach out to others because of a person's inability to solve problems independently. For example, "discuss problem with professional” (.763), "ask professional for help" (.659), and "talk to others about concern" (.565). There were three cross-loading items on the sixth factor, "means of getting help." Item "don't let others know my feelings" (-.340), cross-loaded with factor four, "negative coping skills," on the same item (.482). This item was included on factor four, "negative coping skills" factor. Another item that cross-loaded on the "means of getting help" scale was "get support from others" (.508), and this item also loaded on factor two, "healthy coping strategies" factor (.307). This item was included on factor six, "means of getting help," because it represented looking for ways to reach out to others in order to solve their problems. The last item that cross-loaded on the "means of getting help" was the item "join with people with the same concern" (.487), which cross-loaded on factor two, "healthy coping strategies" factor (.372). This item was included on factor six, "means of getting help," because it describes a way to reach out actively to others to deal with personal problems.

Factor 7: The seventh subscale was characterized by behaviors which actively lead to taking care of oneself emotionally and physically. These qualities focus on coping strategies that focus on helping one stay positive. This subscale was named "proactive self-care" because of these traits. "Proactive self-care" (eigenvalue $=2.22$ ) accounted for 2.18 percent of the variance and had nine items. The loadings ranged from -.312 to -.658 and Table 6 shows the loadings for this factor. There were two cross-loadings on factor 
seven, "proactive self-care" (-.367), with factor one, "work at succeeding" factor (.330), on the item "positive self-talk," and the second cross loading with factor one, "work at succeeding," and factor seven (.352), the "proactive self-care" on the item "look on the bright side" (.415).

The eighteen scales in Table 4 presented similar themes as the final seven coping strategies. For instance, "seek social support" and "seek professional help" was equivalent to "means of getting help" on the seven fixed factor scale. Another scale that was similar was "focus on solving the problem" and "focus on the positive" which was similar to "healthy coping" and "positive ways to cope." The scale "work hard" matched up with "work at succeeding” scale. "Worry," "ignore the problem," "self-blame," and "keep to self" were also equivalent to "self-defeating behaviors" on the seven fixed factor scale. Another match-up was "tension reduction," "seek relaxing diversions," and "physical recreation," which were similar to "proactive self-care" on the seven fixed factor scale. A correlation analysis was run to see if there was a linear relationship among the variables. Table 7 shows little if any (.003) relationship to low positive (.438) relationships among the variables.

Table 8 shows the seven factors derived from the exploratory factor analysis along with the mean and standard deviation. The skewness statistics indicate that this is a normal distribution. This scale is based on a 5-point scale. 
Table 7

Scale Statistics, Reliability, and Inter-correlation

\begin{tabular}{|c|c|c|c|c|c|c|c|c|c|c|}
\hline \multirow{2}{*}{ Scale } & \multirow{2}{*}{ Mean } & \multirow{2}{*}{$\mathrm{SD}$} & \multirow{2}{*}{$\begin{array}{l}\text { Number } \\
\text { of Items }\end{array}$} & \multirow{2}{*}{$\begin{array}{c}\text { Cronbach's } \\
\text { Alpha }\end{array}$} & \multicolumn{6}{|c|}{ Correlation } \\
\hline & & & & & 2 & 3 & 4 & 5 & 6 & 7 \\
\hline 1. Work at succeeding & 4.08 & .54 & 11 & .853 & .337 & .037 & -.356 & .438 & .010 & .001 \\
\hline 2. Positive ways to cope & 3.31 & .67 & 9 & .808 & & .003 & -.320 & .377 & -.036 & .015 \\
\hline 3. Healthy coping strategies & 3.01 & .65 & 9 & .743 & & & -.047 & .107 & -.123 & .376 \\
\hline 4. Self-defeating behaviors & 2.83 & .73 & 10 & .846 & & & & -.279 & .060 & -.001 \\
\hline 5. Proactive self-care & 2.74 & .64 & 9 & .742 & & & & & -.041 & .028 \\
\hline 6. Negative coping skills & 2.63 & .75 & 9 & .841 & & & & & & -.176 \\
\hline 7. Means of getting help & 2.14 & .70 & 7 & .797 & & & & & & \\
\hline Total Scale & 2.95 & .67 & & & & & & & & \\
\hline
\end{tabular}

Table 8

Coping Strategies Used by Nontraditional Female Students

\begin{tabular}{|l|c|c|c|c|}
\hline \multicolumn{1}{|c|}{ Factors } & $\mathrm{N}$ & Mean & $S D$ & Skewness: Statistic \\
\hline Work at succeeding & 444 & 4.08 & .54 & -.538 \\
\hline Positive ways to cope & 444 & 3.31 & .67 & -.256 \\
\hline Healthy coping strategies & 444 & 3.01 & .65 & -.037 \\
\hline Self-defeating behaviors & 444 & 2.83 & .73 & .329 \\
\hline Proactive self-care & 444 & 2.74 & .64 & .149 \\
\hline Negative coping skills & 444 & 2.63 & .75 & .326 \\
\hline Means of getting help & 444 & 2.14 & .70 & .512 \\
\hline
\end{tabular}

\section{Research Questions}

1. What are the coping strategies used by nontraditional female students in higher education?

2. Are coping strategies related to ethnicity of nontraditional female students? 
3. Are coping strategies related to the number of children of nontraditional female students?

4. Are coping strategies related to age groups of nontraditional female students?

5. Are coping strategies related to income levels of nontraditional femalestudents?

6. Are coping strategies related to marital status of nontraditional female students?

\section{Research Question 1}

What are the coping strategies used by nontraditional female students in higher education?

As reported earlier (see Table 8) in the seven coping strategies, "work at succeeding," which encompasses the construct of "working hard," "working at solving the problem," and "developing a plan of action $(M=4.08)$, was the most used by non traditional female students in this study. Table 9 shows the means and standard deviations of the items that define this coping strategy. Used often are specific strategies such as "work hard" $(M=4.48)$, "put effort into my work" $(M=4.43)$, "keep up with work as required" $(M=4.35)$ and "work at solving the problems to the best of my ability" $(M=$ 4.25). However, to a lesser extent, "having a cheerful outlook on life" $(M=3.73)$ and "looking on the bright side of things/think of all that is good" $(M=3.54)$ were also used often. 
Table 9

Scale and Item Mean and Standard Deviation: Work at Succeeding

\begin{tabular}{|l|c|c|c|}
\hline Item & $\mathrm{N}$ & Mean & $S D$ \\
\hline Work Hard & 444 & 4.48 & .66 \\
\hline Put effort into my work & 444 & 4.43 & .71 \\
\hline Keep up with work as required & 444 & 4.35 & .78 \\
\hline Work at solving the problems to the best of my ability & 444 & 4.25 & .75 \\
\hline Focus on what's most important & 444 & 4.16 & .80 \\
\hline I get stressed out and despair & 444 & 4.12 & .94 \\
\hline Assess the situation & 444 & 3.94 & .84 \\
\hline Think about what I am doing and why & 444 & 3.92 & .87 \\
\hline Develop a plan of action & 444 & 3.88 & .90 \\
\hline Try to have a cheerful outlook on life & 444 & 3.73 & .93 \\
\hline Look on the bright side of things and think of all that is good & 444 & 3.54 & 1.04 \\
\hline Total Scale & 444 & 4.07 & .83 \\
\hline
\end{tabular}

Previously mentioned (see Table 8) in the seven coping strategies, "positive ways to cope" $(M=3.31)$ focused on "talking to others to see what they would do if they had the problem," "spending time with close friends," and "finding ways to let off steam" and was used sometimes as a coping strategy by nontraditional female students. Table 10 shows the means and standard deviations of the items that define this coping strategy. Used often are specific strategies as "find ways to relax," for example, "listen to music, read a book" $(M=3.69)$, "make time for friends or family" $(M=3.60)$, and "talk to others and give each other support" $(M=3.51)$. By comparison, "find a way to let off steam" $(M=3.43)$, "keep others from knowing what is worrying me" $(M=3.06)$, and "talk to others to see what they would do it they had a problem" $(M=3.02)$, were used sometimes by nontraditional female students. A coping strategy used to a lesser degreesometimes — was "keep my feelings to myself" $(M=2.97)$. 
Table 10

Scale and Item Mean and Standard Deviation: Positive Ways to Cope

\begin{tabular}{|l|c|c|c|}
\hline Item & $\mathrm{N}$ & Mean & $S D$ \\
\hline Find a way to relax; for ex. Listen to music, read a book (R) & 444 & 3.69 & 1.06 \\
\hline Make time for friends and family (R) & 444 & 3.60 & .93 \\
\hline Talk to others and give each other support (R) & 444 & 3.51 & 1.03 \\
\hline Find a way to let off steam (R) & 444 & 3.43 & 1.03 \\
\hline Wish a miracle would happen & 444 & 3.40 & 1.12 \\
\hline Spend time with close friends (R) & 444 & 3.08 & 1.04 \\
\hline Keep others from knowing what is worrying me & 444 & 3.06 & 1.16 \\
\hline $\begin{array}{l}\text { Talks to others to see what they would do if they had the } \\
\text { problem (R) }\end{array}$ & 444 & 3.02 & 1.13 \\
\hline Keep my feelings to myself & 444 & 2.97 & 1.12 \\
\hline Total Scale & 444 & 3.31 & 1.06 \\
\hline
\end{tabular}

Note. R stands for Reverse Coded Items.

As stated before (see Table 8) in the seven coping strategies, "Healthy coping strategies" $(M=3.01)$, which focuses on students' developing healthy coping strategies for solving their problems, was used sometimes as a coping strategy for nontraditional female students. Table 11 shows the means and standard deviations of the items that define this coping strategy. Used often was the specific strategy "think of different ways to solve the problem" $(M=3.65)$. Specific coping strategies as "imagine that things will work out well" $(M=3.32)$, "make time for leisure activities" $(M=3.17)$, "spend time with husband/wife/boy/girlfriend" $(M=2.83)$, and "tell jokes" $(M=2.77)$, were sometimes used. However, to a lesser degree, "try to make close friends with a guy or girl, husband or wife" $(M=2.44)$ was used very little. 
Table 11

Scale and Item Mean and Standard Deviation: Healthy Coping Strategies

\begin{tabular}{|l|c|c|c|}
\hline Item & $\mathrm{N}$ & Mean & $S D$ \\
\hline Think of different ways of dealing with the problem & 444 & 3.65 & .93 \\
\hline Imagine that things will work out well & 444 & 3.32 & 1.09 \\
\hline Make time for leisure activities & 444 & 3.17 & 1.05 \\
\hline Improve my relationship with others & 444 & 3.01 & 1.07 \\
\hline I suffer headaches or stomach aches & 444 & 2.99 & .95 \\
\hline Daydream about how things will turn out well & 444 & 2.89 & 1.30 \\
\hline Spend time with husband/wife/boy/girlfriend & 444 & 2.83 & 1.28 \\
\hline Tell jokes & 444 & 2.77 & 1.24 \\
\hline Try to make close friends with a guy or girl. Husband or wife & 444 & 2.44 & 1.22 \\
\hline Total Scale & 444 & 3.00 & 1.12 \\
\hline
\end{tabular}

As reported earlier (see Table 8) in the seven coping strategies, "self-defeating behaviors" $(M=2.83)$, which addresses how students worry about the future, shut themselves off from the problem, and get sick with headaches or stomach aches, was used sometimes as a coping strategy for nontraditional female students. Table 12 shows the means and standard deviations of the items that depict this coping strategy. Used often was the specific strategy of "worry about my future" $(M=3.66)$, while "worry about what is happening" $(M=3.41)$, "keep my long term goals clear" $(M=3.01)$, and "hope that the problem will sort itself out" $(M=2.58)$ were used sometimes. To a much lesser extext, "cry or scream" $(M=2.46)$, and "shut myself off from the problem so that I can avoid it" $(M=2.10)$ were used very little. 
Table 12

Scale and Item Mean and Standard Deviation: Self-Defeating Behaviors

\begin{tabular}{|l|c|c|c|}
\hline Item & $\mathrm{N}$ & Mean & $S D$ \\
\hline Worry about my future & 444 & 3.66 & 1.19 \\
\hline Worry about what is happening & 444 & 3.41 & 1.08 \\
\hline Keep my long term goals clear (R) & 444 & 3.01 & 1.05 \\
\hline Criticize myself & 444 & 3.00 & 1.14 \\
\hline I get sick, for ex. Headache, stomach & 444 & 2.72 & 1.38 \\
\hline Don't share my problems with other people & 444 & 2.67 & 1.17 \\
\hline Worry about my happiness & 444 & 2.64 & 1.12 \\
\hline Hope that the problem will sort itself out & 444 & 2.58 & 1.05 \\
\hline Cry or scream & 444 & 2.46 & 1.03 \\
\hline Shut myself off from the problem so that I can avoid it & 444 & 2.10 & 1.04 \\
\hline Total Scale & 444 & 2.82 & 1.12 \\
\hline
\end{tabular}

Note. $R$ stands for Reverse Coded Items.

Previously mentioned (see Table 8) in the seven coping strategies, "proactive selfcare" $(M=2.74)$ was characterized by behaviors which actively lead to taking care of oneself emotionally and physically; it was used sometimes as a coping strategy for nontraditional female students. Table 13 show the means and standard deviations of the items that depict this coping strategy. Used sometimes are specific strategies as "positive self-talk" $(M=3.33)$, "protect my self-esteem" $(M=3.25)$ and "pray for help and guidance so that everything will be all right $(M=3.04$, although, to a lesser degree, "go for a workout at the gym" $(M=2.15)$, "organize an action or petition regarding my concern" $(M=2.11)$, and "play sport" $(M=1.76)$ were used very little. 
Table 13

Scale and Item Mean and Standard Deviation: Proactive Self-Care

\begin{tabular}{|l|c|c|c|}
\hline Item & $\mathrm{N}$ & Mean & $S D$ \\
\hline Positive self-talk & 444 & 3.33 & 1.03 \\
\hline Protect my self-esteem & 444 & 3.25 & 1.07 \\
\hline Pray for help and guidance so that everything will be all right & 444 & 3.04 & 1.50 \\
\hline Work on my self-image & 444 & 2.99 & .99 \\
\hline Improve my appearance & 444 & 2.99 & .96 \\
\hline Keep fit and healthy & 444 & 2.96 & 1.11 \\
\hline Go for a workout at the gym & 444 & 2.15 & 1.14 \\
\hline Organize an action or petition regarding my concern & 444 & 2.11 & 1.18 \\
\hline Play sport & 444 & 1.76 & 1.05 \\
\hline Total Scale & 444 & 2.73 & 1.11 \\
\hline
\end{tabular}

Mentioned earlier (see Table 8) in the seven coping strategies, the "negative coping skills" $(M=2.63)$ subscale included items depicting where the person sees herself as being at fault, taking her frustrations out on other people, and asking for professional help. This was mentioned sometimes as a coping strategy for nontraditional female students. Table 14 shows the means and standard deviations of the items that depict this coping strategy. Specific coping strategies such as "get annoyed at myself" $(M=3.10)$, "worry about what will happen to me" $(M=3.01)$ and "blame yourself" $(M=2.85)$ were used sometimes, although, to a lesser extent, "put the problem out of my mind" $(M=$ 2.42), "consciously block out the problem" $(M=2.20)$, and "take frustrations out on others" $(M=2.03)$ were used very little. 
Table 14

Scale and Item Mean and Standard Deviation: Negative Coping Skills

\begin{tabular}{|l|c|c|c|}
\hline Item & $\mathrm{N}$ & Mean & $S D$ \\
\hline Get annoyed at myself & 444 & 3.10 & 1.15 \\
\hline Worry about what will happen to me & 444 & 3.01 & 1.12 \\
\hline Blame yourself & 444 & 2.85 & 1.25 \\
\hline Don't let others know how I am feeling & 444 & 2.79 & 1.17 \\
\hline See myself as being at fault & 444 & 2.67 & 1.22 \\
\hline Ask a professional person for help & 444 & 2.60 & 1.28 \\
\hline Put the problem out of my mind & 444 & 2.42 & .92 \\
\hline Consciously block out the problem & 444 & 2.20 & 1.09 \\
\hline Take frustrations out on others & 444 & 2.03 & .94 \\
\hline Total Scale & 444 & 2.63 & 1.12 \\
\hline
\end{tabular}

As reported earlier (see Table 8) in the seven coping strategies, the "means of getting help" $(M=2.14)$ subscale looks at ways to cope by asking a professional for help, going to meetings which look at the problem, and getting support from others such as parents or friends. This was the least used of the coping strategies by nontraditional female students. Table 15 shows the means and standard deviations of the items that depict this coping strategy. Specific strategies as "get support from others as parents of friends" $(M=3.11)$ and "talk to other people about my concern to help sort it out" $(M=$ 2.93) were used sometimes, while, to a lesser extent, "discuss the problem with qualified people" $(M=2.08)$, "join with people who have the same concern" $(M=2.06)$, and "go to meetings which look at the problem" (1.53) were used very little. 
Table 15

Scale and Item Mean and Standard Deviation: Means of Getting Help

\begin{tabular}{|l|c|c|c|}
\hline Item & $\mathrm{N}$ & Mean & SD \\
\hline Get support from others such as parents or friends (R) & 444 & 3.11 & 1.18 \\
\hline Talk to other people about my concern to help sort it out (R) & 444 & 2.93 & 1.12 \\
\hline Discuss the problem with qualified people (R) & 444 & 2.08 & 1.18 \\
\hline Join with people who have the same concern (R) & 444 & 2.06 & 1.05 \\
\hline Ask a professional person for help (R) & 444 & 1.88 & 1.07 \\
\hline Go to meetings which look at the problem (R) & 444 & 1.53 & .88 \\
\hline Organize a group to deal with my concern (R) & 444 & 1.37 & .78 \\
\hline Total Scale & 444 & 2.09 & 1.03 \\
\hline
\end{tabular}

Note. $R$ stands for Reverse Coded Items.

A one-way Multivariate Analysis of Variance (MANOVA) was conducted to examine the relationship between the two universities and the set of seven coping strategies of "work at succeeding," "positive ways to cope," "healthy coping strategies," "self-defeating behaviors," "proactive self-care," "negative coping skills," and "means of getting help."

Statistical Package for the Social Sciences (SPSS) MANOVA was used for the analysis. A statistically nonsignificant Box's $M$ test $(p>.05)$ indicated equality of variance-covariance matrices of the dependent variables across the levels of the independent variables.

The means and standard deviation table by university is presented in Table 16. Using Wilks' criterion, there were significant university group differences on the linear combination of the seven coping strategies $F(7,436)=7.33, p<.05, \eta^{2}=.11$.

Approximately $11 \%$ of the variance of the set of coping strategies can be explained by the university group differences. Univariate Analysis of Variances (ANOVAs) were conducted on each dependent measure separately to determine the locus of the statistical 
significant multivariate effect. Table 16 indicates that at $\alpha=0.05$, there are statistically significant university difference on the proactive self-care strategy, $F(1,442)=31.96, p$ $<.05$, partial $\eta^{2}=.07$. The reason I chose to combine the analysis is because both universities responded with similar coping strategies. Both universities used proactive self-care sometimes. However, the private university is slightly higher on the proactive self-care scale.

Table 16

Univariate Table for the Two Universities

\begin{tabular}{llcccccc}
\hline Variable & Group & $\mathrm{N}$ & Mean & $S D$ & $\mathrm{~F}$ & $\mathrm{P}$ & $\eta^{2}$ \\
\hline Work at Succeeding & Public- & 381 & 4.09 & .54 & 1.323 & .251 & .003 \\
& Private & 63 & 4.00 & .55 & & & \\
& Total & 444 & 4.07 & .54 & & & \\
Positive Ways to Cope & Public- & 381 & 3.29 & .69 & 1.012 & .215 & .002 \\
& Private & 63 & 3.39 & .59 & & & \\
& Total & 444 & 3.31 & .67 & & & \\
Healthy Coping & & & & & & & \\
& Public- & 381 & 3.00 & .64 & 1.110 & .293 & .003 \\
Self-Defeating & Private & 63 & 3.09 & .68 & & & \\
& Total & 444 & 3.01 & .65 & & & \\
Proactive Self-Care & Public- & 381 & 2.83 & .75 & .004 & .951 & .000 \\
& Private & 63 & 2.82 & .63 & & & \\
Negative Coping & Total & 444 & 2.83 & .73 & & & \\
& Public- & 381 & 2.67 & .63 & 31.96 & .000 & .067 \\
& Private & 63 & 3.14 & .62 & & & \\
& Total & 444 & 2.74 & .65 & & & \\
Means of Getting Help & Public- & 381 & 2.65 & .77 & .750 & .387 & .002 \\
& Private & 63 & 3.15 & .68 & & & \\
& Total & 444 & 2.63 & .76 & & & \\
& Public- & 381 & 2.13 & .70 & 1.73 & .279 & .003 \\
& Private & 63 & 2.23 & .71 & & & \\
& Total & 444 & 2.14 & .70 & & & \\
\hline
\end{tabular}




\section{Research Question 2}

Are coping strategies related to ethnicity of nontraditional female students?

A one-way MANOVA was conducted to examine the relationship between ethnicity and the set of seven derived coping strategies of nontraditional students from the two universities in this study.

Statistical Package for the Social Sciences MANOVA was used for the analysis. A statistically nonsignificant Box's $M$ test $(p>.05)$ indicated equality of variancecovariance matrices of the dependent variables across levels of the independent variables.

The means and standard deviation table by race group is presented in Table 17. Using Wilks' criterion, there were significant race group differences on the linear combination of the seven coping strategies $\left.F(14,866)=4.01, p<.05, \eta^{2}=.06\right)$. Approximately $6 \%$ of the variance of the set of coping strategies can be explained by the race group differences. Univariate ANOVAs were conducted on each dependent measure separately to determine the locus of the statistical significant multivariate effect. Table 18 indicates that at $a=0.05$, there are statistically significant ethnic differences on proactive coping strategy, $F(2,439)=10.2, p<.05$, partial $\eta^{2}=.04$. Bonferroni post hoc tests indicated that "Multicultural group" $(M=2.98, S D=.703)$ female group had the same amount of proactive self-care as the African-American $(M=2.98, S D=.650)$ while the Caucasian female students $(M=2.66, S D=.617)$ had lower proactive self-care than the two other groups of female students. 
Table 17

Means and Standard Deviations by Race Group

\begin{tabular}{lcccccc}
\hline Variable & \multicolumn{2}{c}{$\begin{array}{c}\text { African American } \\
\text { N=41 }\end{array}$} & \multicolumn{2}{c}{$\begin{array}{c}\text { Caucasian } \\
\text { N=337 }\end{array}$} & \multicolumn{2}{c}{$\begin{array}{c}\text { Other } \\
\text { N=64 }\end{array}$} \\
\hline & $\boldsymbol{M}$ & $\boldsymbol{S D}$ & $\boldsymbol{M}$ & $\boldsymbol{S D}$ & $\boldsymbol{M}$ & $\boldsymbol{S D}$ \\
Work at succeeding & 4.01 & .53 & 4.09 & .53 & 4.02 & .58 \\
Healthy coping skills & 3.00 & .75 & 2.98 & .64 & 3.16 & .584 \\
Self-defeating behaviors & 2.83 & .74 & 2.81 & .73 & 2.91 & .75 \\
Negative coping skills & 2.73 & .69 & 2.65 & .77 & 2.45 & .68 \\
Positive ways to cope & 3.16 & .70 & 3.34 & .67 & 3.22 & .64 \\
Means of getting help & 2.25 & .71 & 2.10 & .69 & 2.28 & .72 \\
Proactive self-care & 2.98 & .65 & 2.66 & .62 & 2.98 & .70 \\
\hline
\end{tabular}

Table 18

Univariate Analysis Table for Race Group

\begin{tabular}{|c|c|c|c|c|c|c|c|}
\hline Variable & Source & Df & $\mathrm{SS}$ & MS & $\mathrm{F}$ & $\mathrm{P}$ & $\eta^{2}$ \\
\hline Work at Succeeding & $\begin{array}{l}\text { Between } \\
\text { Within } \\
\text { Total }\end{array}$ & $\begin{array}{c}2 \\
439 \\
442\end{array}$ & $\begin{array}{r}.399 \\
128.85 \\
7469.63\end{array}$ & $\begin{array}{l}0.200 \\
0.293\end{array}$ & 0.680 & .507 & .003 \\
\hline Healthy Coping & $\begin{array}{l}\text { Between } \\
\text { Within } \\
\text { Total }\end{array}$ & $\begin{array}{c}2 \\
439 \\
442\end{array}$ & $\begin{array}{r}1.66 \\
185.89 \\
4198.33\end{array}$ & $\begin{array}{l}0.832 \\
0.423\end{array}$ & 1.964 & .141 & .009 \\
\hline Self-Defeating & $\begin{array}{l}\text { Between } \\
\text { Within } \\
\text { Total }\end{array}$ & $\begin{array}{c}2 \\
439 \\
442\end{array}$ & $\begin{array}{r}.579 \\
237.20 \\
3780.30\end{array}$ & $\begin{array}{l}0.290 \\
0.540\end{array}$ & 0.536 & .586 & .002 \\
\hline Negative Coping & $\begin{array}{l}\text { Between } \\
\text { Within } \\
\text { Total }\end{array}$ & $\begin{array}{c}2 \\
439 \\
442\end{array}$ & $\begin{array}{r}2.789 \\
248.50 \\
3323.40\end{array}$ & 1.394 & 2.463 & .086 & .011 \\
\hline Positive Ways to Cope & $\begin{array}{l}\text { Between } \\
\text { Within } \\
\text { Total }\end{array}$ & $\begin{array}{c}2 \\
439 \\
442\end{array}$ & $\begin{array}{r}1.762 \\
199.64 \\
5053.89\end{array}$ & $\begin{array}{c}0.881 \\
.455\end{array}$ & 1.937 & .145 & .009 \\
\hline Means of Getting Help & $\begin{array}{l}\text { Between } \\
\text { Within } \\
\text { Total }\end{array}$ & $\begin{array}{c}2 \\
439 \\
442\end{array}$ & $\begin{array}{r}2.372 \\
217.68 \\
2248.50\end{array}$ & $\begin{array}{l}1.186 \\
0.496\end{array}$ & 2.392 & .093 & .011 \\
\hline Proactive Self-Care & $\begin{array}{l}\text { Between } \\
\text { Within } \\
\text { Total }\end{array}$ & $\begin{array}{c}2 \\
439 \\
442\end{array}$ & $\begin{array}{c}8.197 \\
175.98 \\
3489.46\end{array}$ & $\begin{array}{l}4.099 \\
0.401\end{array}$ & 10.224 & .000 & .045 \\
\hline
\end{tabular}




\section{Research Question 3}

Are coping strategies related to the number of children of nontraditional female students?

A one-way MANOVA was conducted to examine the relationship between number of children and the set of seven derived coping strategies of nontraditional students from the two universities.

Statistical Package for the Social Sciences MANOVA was used for the analysis. A statistically non-significant Box's $M$ test $(p>.05)$ indicated equality of variancecovariance matrices of the dependent variables across levels of the independent variables.

The means and standard deviation table by number of children is presented in Table 19. Using Wilks' criterion, there was significance in number of children group difference on the linear combination of the seven coping strategies, $F(21,1243)=1.71, p$ $<.05$, partial $\eta^{2}=.03$. Approximately $3 \%$ of the variance of the set of coping strategies can be explained by the number of children differences. Univariate ANOVAs were conducted on each dependent measure separately to determine the locus of the statistical significant multivariate effect. Results shown in Table 20 indicate that the number of children is related to coping on the "work at succeeding" strategy $F(3,439)=4.21, p<$ .05 , partial $\eta^{2}=.03$. Bonferroni post hoc tests indicate that nontraditional female students with one child $(M=4.23, S D=.537)$ coped better on the "work at succeeding" strategy than those female students with no children $(M=4.04, S D=.532)$, students with two children $(M=3.98, S D=.566)$ or those students with three or more children $(\mathrm{M}=4.09$, $\mathrm{SD}=.489)$ 
Table 19

Means and Standard Deviation by Number of Children

\begin{tabular}{|c|c|c|c|c|c|c|c|c|}
\hline \multirow[t]{2}{*}{ Variable } & \multicolumn{2}{|c|}{$\begin{array}{c}\text { None } \\
\mathrm{N}=159\end{array}$} & \multicolumn{2}{|c|}{$\begin{array}{c}1 \\
\mathrm{~N}=92\end{array}$} & \multicolumn{2}{|c|}{$\begin{array}{c}2 \\
N=113\end{array}$} & \multicolumn{2}{|c|}{$\begin{array}{c}3 \text { or more } \\
N=79\end{array}$} \\
\hline & $M$ & $S D$ & $M$ & $S D$ & $M$ & $S D$ & $M$ & $S D$ \\
\hline Work at succeeding & 4.04 & .53 & 4.23 & .53 & 3.98 & .56 & 4.09 & .48 \\
\hline Healthy coping skills & 2.99 & .66 & 2.95 & .70 & 3.03 & .61 & 3.07 & .59 \\
\hline Self-defeating behaviors & 2.87 & .73 & 2.78 & .74 & 2.77 & .73 & 2.86 & .71 \\
\hline Negative coping skills & 2.62 & .73 & 2.72 & .84 & 2.56 & .69 & 2.65 & .77 \\
\hline Positive ways to cope & 3.38 & .71 & 3.28 & .75 & 3.29 & .58 & 3.23 & .61 \\
\hline Means of getting help & 2.19 & .68 & 2.11 & .72 & 2.19 & .702 & 1.99 & .70 \\
\hline Proactive self-care & 2.79 & .63 & 2.75 & .70 & 2.64 & .61 & 2.71 & .63 \\
\hline
\end{tabular}

Table 20

Univariate Analysis Table for Number of Children

\begin{tabular}{llrrrrrr}
\hline Variable & Source & Df & \multicolumn{1}{c}{ SS } & MS & F & P & $\eta^{2}$ \\
\hline \multirow{2}{*}{ Work at Succeeding } & Between & 3 & 3.11 & 1.204 & 4.12 & .006 & .030 \\
& Within & 439 & 125.40 & 0.286 & & & \\
& Total & 442 & 7482.77 & & & & \\
Healthy Coping & Between & \multicolumn{1}{c}{3} & 0.647 & 0.216 & 0.509 & .676 & .003 \\
& Within & 439 & 186.114 & 0.424 & & & \\
& Total & 443 & 4196.661 & & & & \\
Self-Defeating & Between & 3 & .861 & 0.287 & 0.530 & .662 & .004 \\
& Within & 443 & 237.785 & 0.542 & & & \\
Negative Coping & Total & 442 & 3781.646 & & & & \\
& Between & 3 & 1.400 & 0.467 & 0.818 & .484 & .006 \\
& Within & 438 & 250.103 & 0.571 & & & \\
Total & 443 & 3328.680 & & & & \\
Positive Ways to Cope & Between & 3 & 1.280 & 0.427 & 0.935 & .424 & .006 \\
& Within & 439 & 200.290 & 0.456 & & & \\
& Total & 443 & 5062.956 & & & & \\
Means of Getting Help & Between & 3 & 2.527 & 0.842 & 1.701 & .166 & .011 \\
& Within & 438 & 217.321 & 0.496 & & & \\
& Total & 442 & 2248.002 & & & & \\
Proactive Self-Care & Between & 3 & 1.514 & 0.505 & 1.211 & .305 & .008 \\
& Within & 438 & 182.788 & 0.417 & & & \\
& Total & 442 & 3489.490 & & & & \\
\hline & & & & & & &
\end{tabular}




\section{Research Question 4}

Are coping strategies related to age groups of nontraditional female students? Aone-way MANOVA was conducted to examine the relationship between age range and the set of seven derived coping strategies of nontraditional students from the two universities.

Statistical Package for the Social Sciences MANOVA was used for the analysis. A statistically non-significant Box's $M$ test $(p>.05)$ indicated equality of variancecovariance matrices of the dependent variables across levels of the independent variables.

The means and standard deviation table for age range is presented in Table 21. Using Wilks' criterion, there was a significant age range group difference on the linear combination of the seven coping strategies $F(14,868)=3.19, p<.05$, partial $\left.\eta^{2}=.05\right)$. Approximately $5 \%$ of the variance of the set of coping strategies can be explained by the age range group differences. Univariate ANOVAs were conducted on each dependent measure separately to determine the locus of the statistical significant multivariate effect. Table 22 shows that age range is related to coping on the "self-defeating behaviors" strategy which is significant, $F(2,440)=9.84, p<.05$, partial $\left.\eta^{2}=.043\right)$. Age range is related to coping on the "positive ways to cope" strategy $F(2,440)=4.05, p<.05$, partial $\eta^{2}=.019$; age range is also related to coping on the "proactive self-care" strategy $F(2,440)=3.52, p<.05$, partial $\eta^{2}=.02$. Bonferroni post hoc tests suggested that female students in the age range of $25-29(M=2.97, S D=.712)$ practiced the most "selfdefeating behaviors" of all the age ranges, female respondents in the $30-44(M=2.85, S D$ $=.737)$ age group had higher "self-defeating behaviors" than the $45 \&$ above group $(M=$ $2.52, S D=.683)$. The 45 and above group practiced the least "self-defeating behaviors." 
Table 21

Means and Standard Deviations by Age Range

\begin{tabular}{|c|c|c|c|c|c|c|}
\hline \multirow[t]{2}{*}{ Variable } & \multicolumn{2}{|c|}{$\begin{array}{c}25-29 \\
N=136\end{array}$} & \multicolumn{2}{|c|}{$\begin{array}{c}30-44 \\
N=228\end{array}$} & \multicolumn{2}{|c|}{$\begin{array}{c}45 \& \text { above } \\
N=79\end{array}$} \\
\hline & $M$ & $S D$ & $M$ & $S D$ & $M$ & $S D$ \\
\hline Work at succeeding & 4.02 & .53 & 4.06 & .54 & 4.18 & .53 \\
\hline Healthy coping skills & 3.00 & .64 & 3.03 & .67 & 2.95 & .60 \\
\hline Self-defeating behaviors & 2.97 & .71 & 2.85 & .73 & 2.52 & .68 \\
\hline Negative coping skills & 2.65 & .79 & 2.61 & .72 & 2.63 & .77 \\
\hline Positive ways to cope & 3.44 & .68 & 3.24 & .67 & 3.31 & .64 \\
\hline Means of getting help & 2.19 & .70 & 2.15 & .70 & 2.02 & .68 \\
\hline Proactive self-care & 2.71 & .66 & 2.69 & .61 & 2.91 & .68 \\
\hline
\end{tabular}

Table 22

Univariate Analysis Table for Age Range

\begin{tabular}{|c|c|c|c|c|c|c|c|}
\hline Variable & Source & Df & SS & MS & $\mathrm{F}$ & $\mathrm{P}$ & $\eta^{2}$ \\
\hline Work at Succeeding & $\begin{array}{l}\text { Between } \\
\text { Within } \\
\text { Total }\end{array}$ & $\begin{array}{c}2 \\
440 \\
443\end{array}$ & $\begin{array}{r}1.310 \\
128.078 \\
7489.475\end{array}$ & $\begin{array}{l}0.655 \\
0.291\end{array}$ & 2.250 & .107 & .010 \\
\hline Healthy Coping & $\begin{array}{l}\text { Between } \\
\text { Within } \\
\text { Total }\end{array}$ & $\begin{array}{c}2 \\
440 \\
443\end{array}$ & $\begin{array}{r}0.322 \\
187.312 \\
4208.081\end{array}$ & $\begin{array}{l}0.161 \\
0.426\end{array}$ & 0.378 & .685 & .002 \\
\hline Self-Defeating & $\begin{array}{l}\text { Between } \\
\text { Within } \\
\text { Total }\end{array}$ & $\begin{array}{c}2 \\
440 \\
443\end{array}$ & $\begin{array}{r}10.222 \\
228.463 \\
3786.768\end{array}$ & $\begin{array}{l}5.111 \\
0.519\end{array}$ & 9.843 & .000 & .043 \\
\hline Negative Coping & $\begin{array}{l}\text { Between } \\
\text { Within } \\
\text { Total }\end{array}$ & $\begin{array}{c}2 \\
440 \\
443\end{array}$ & $\begin{array}{r}0.113 \\
252.611 \\
3323.742\end{array}$ & $\begin{array}{l}0.057 \\
0.574\end{array}$ & 0.098 & .906 & .000 \\
\hline Positive Ways to Cope & $\begin{array}{l}\text { Between } \\
\text { Within } \\
\text { Total }\end{array}$ & $\begin{array}{c}2 \\
440 \\
443\end{array}$ & $\begin{array}{r}3.641 \\
197.929 \\
5062.956\end{array}$ & $\begin{array}{l}1.821 \\
0.450\end{array}$ & 4.047 & .018 & .018 \\
\hline Means of Getting Help & $\begin{array}{l}\text { Between } \\
\text { Within } \\
\text { Total }\end{array}$ & $\begin{array}{c}2 \\
440 \\
443\end{array}$ & $\begin{array}{r}1.459 \\
218.637 \\
2253.137\end{array}$ & $\begin{array}{l}0.730 \\
0.497\end{array}$ & 1.468 & .231 & .007 \\
\hline Proactive Self-Care & $\begin{array}{l}\text { Between } \\
\text { Within } \\
\text { Total }\end{array}$ & $\begin{array}{c}2 \\
440 \\
443 \\
\end{array}$ & $\begin{array}{r}2.908 \\
181.541 \\
3498.660\end{array}$ & $\begin{array}{l}1.454 \\
0.413\end{array}$ & 3.524 & .030 & .016 \\
\hline
\end{tabular}


The 30-44 nontraditional female students practiced fewer "self-defeating behaviors" than the 25-29 nontraditional female students who had greater "self-defeating behaviors."

Bonferroni post hoc test also showed that "positive ways to cope" was also significant $F(2,440)=4.05, p<.05$, partial $\eta^{2}=.02$. Female students in the 25-29 age range ( $M=3.44, S D=.682)$ had higher "positive ways to cope" than those female students in the 30-44 age range $(M=3.24, S D=.672)$. "Proactive self-care" was also significant $F(2,440)=3.52, p .<.05$, partial $\left.\eta^{2}=.02\right)$. Female students in the $45 \&$ above age range $(M=2.90, S D=.680)$ have slightly higher "proactive self-care" than the female students in the 30-44 age range $(M=2.69, S D=.614)$.

\section{Research Question 5}

Are coping strategies related to income levels of nontraditional female students? A one-way MANOVA was conducted to examine the relationship between income range and the set of seven derived coping strategies of nontraditional students from the two universities.

Statistical Package for the Social Sciences MANOVA was used for the analysis. A statistically nonsignificant Box's $M$ test $(p>.05)$ indicated equality of variancecovariance matrices of the dependent variables across levels of the independent variables.

The means and standard deviation table by Income Range are presented in Table 23. Using Wilks' criterion, there was a significant income range difference on the linear combination of the seven coping strategies, $F(14,862)=2.46, p<.05, \eta^{2}=.04$. Approximately $4 \%$ of variance of the variance of the set of coping strategies can be explained by income differences. Univariate ANOVAs were conducted on each dependent measure separately to determine the locus of the statistical significant 
Table 23

Means and Standard Deviations by Income Range

\begin{tabular}{lcccccc}
\hline & \multicolumn{2}{c}{$\begin{array}{c}\text { Below 20,000 } \\
\text { N=189 }\end{array}$} & \multicolumn{2}{c}{$\begin{array}{c}\mathbf{2 1 , 0 0 0 - 3 5 , 0 0 0} \\
\text { N=103 }\end{array}$} & \multicolumn{2}{c}{$\begin{array}{c}\mathbf{3 6 0 0 0} \text { or more } \\
\text { N=148 }\end{array}$} \\
\hline & $\boldsymbol{M}$ & $\boldsymbol{S D}$ & $\boldsymbol{M}$ & $\boldsymbol{S D}$ & $\boldsymbol{M}$ & $\boldsymbol{S D}$ \\
Work at succeeding & 4.08 & .56 & 4.09 & .50 & 4.06 & .53 \\
Healthy coping skills & 3.06 & .64 & 3.01 & .70 & 2.94 & .62 \\
Self-defeating behaviors & 2.93 & .75 & 2.86 & .65 & 2.69 & .74 \\
Negative coping skills & 2.60 & .72 & 2.69 & .74 & 2.64 & .80 \\
Positive ways to cope & 3.40 & .67 & 3.19 & .66 & 3.29 & .66 \\
Means of getting help & 2.18 & .67 & 2.10 & .77 & 2.10 & .69 \\
Proactive self-care & 2.80 & .69 & 2.77 & .55 & 2.63 & .65 \\
\hline
\end{tabular}

multivariate effect. Results show that income is significantly related to coping on the “self-defeating behaviors" strategy $F(2,437)=4.49, p<.05, \eta^{2}=.02$. Nontraditional female students with incomes of $\$ 36,000$ or more had lower "self-defeating behaviors" $(M=2.69, S D=.741)$ than those nontraditional female students with an income of $\$ 20,000$ or below $(M=2.93, S D=.751)$. The analysis revealed that income is significantly related to coping on the "positive ways to cope" strategy $F(2,437)=3.50, p$ $<.05, \eta^{2}=.02$. Furthermore, income is significantly related to coping in the "proactive self-care" strategy $F(2,437)=3.11, p<.05, \eta^{2}=.01$.

Bonferroni post hoc test indicate that those nontraditional female students in the $\$ 21,000$ to $\$ 35,000$ income $(M=3.19, S D=.666)$ had lower "positive ways to cope" than those female students in the $\$ 20,000$ and below $(M=3.40, S D=.673)$ category. Female students in the $\$ 36,000$ or more $(M=2.63, S D=.650)$ had lower "proactive selfcare" than those female students in the $\$ 20,000$ and below category $(M=2.80, S D=$ $.688)$ and the $\$ 21,000$ to $\$ 35,000$ category $(M=2.77, S D=.55)$. Univariate analyses are presented in Table 24. 
Table 24

Univariate Analysis Table for Income Range

\begin{tabular}{|c|c|c|c|c|c|c|c|}
\hline Variable & Source & Df & $\mathrm{SS}$ & MS & $\mathrm{F}$ & $\mathrm{P}$ & $\eta^{2}$ \\
\hline \multirow[t]{3}{*}{ Work at Succeeding } & Between & 2 & 0.081 & 0.040 & \multirow[t]{3}{*}{0.137} & \multirow[t]{3}{*}{.872} & \multirow[t]{3}{*}{.001} \\
\hline & Within & 437 & 128.334 & 0.294 & & & \\
\hline & Total & 440 & 7446.450 & & & & \\
\hline \multirow[t]{3}{*}{ Healthy Coping } & Between & 2 & 1.250 & 0.625 & \multirow[t]{3}{*}{1.466} & \multirow[t]{3}{*}{.232} & \multirow[t]{3}{*}{.007} \\
\hline & Within & 437 & 186.260 & 0.426 & & & \\
\hline & Total & 440 & 4180.957 & & & & \\
\hline \multirow[t]{3}{*}{ Self-Defeating } & Between & 2 & 4.710 & 2.355 & \multirow[t]{3}{*}{4.488} & \multirow[t]{3}{*}{.012} & \multirow[t]{3}{*}{.020} \\
\hline & Within & 436 & 229.296 & 0.525 & & & \\
\hline & Total & 440 & 3760.286 & & & & \\
\hline \multirow[t]{3}{*}{ Negative Coping } & Between & 2 & 0.666 & 0.333 & \multirow[t]{3}{*}{0.582} & \multirow[t]{3}{*}{.559} & \multirow[t]{3}{*}{.003} \\
\hline & Within & 437 & 250.071 & 0.572 & & & \\
\hline & Total & 440 & 3314.483 & & & & \\
\hline \multirow[t]{3}{*}{ Positive Ways to Cope } & Between & 2 & 3.095 & 1.548 & \multirow[t]{3}{*}{3.491} & \multirow[t]{3}{*}{.031} & \multirow[t]{3}{*}{.016} \\
\hline & Within & 437 & 193.78 & 0.443 & & & \\
\hline & Total & 440 & 5038.117 & & & & \\
\hline \multirow[t]{3}{*}{ Means of Getting Help } & Between & 2 & 0.596 & 0.298 & \multirow{3}{*}{$\begin{array}{l}0.599 \\
0.498\end{array}$} & \multirow[t]{3}{*}{.550} & \multirow[t]{3}{*}{.003} \\
\hline & Within & 436 & 217.633 & & & & \\
\hline & Total & 440 & 2229.55 & & & & \\
\hline \multirow[t]{3}{*}{ Proactive Self-Care } & Between & 2 & 2.583 & 1.291 & \multirow[t]{3}{*}{3.112} & \multirow[t]{3}{*}{.045} & \multirow[t]{3}{*}{.014} \\
\hline & Within & 437 & 181.3291 & 0.415 & & & \\
\hline & Total & 440 & 3472.549 & & & & \\
\hline
\end{tabular}

Research Question 6

Are coping strategies related to marital status of nontraditional female students?

A one-way MANOVA was conducted to examine the relationship between marital status and the set of seven derived coping strategies of nontraditional students from the two universities in the study.

Statistical Package for the Social Sciences MANOVA was used for the analysis. A statistically nonsignificant Box's $M$ test $(p>.05)$ indicated equality of variance- 
covariance matrices of the dependent variables across levels of the independent variables.

Using Wilks' Lamba criterion, there was not a significance in the marital status group differences on the linear combination of the seven coping strategies $F(14,870)=$ $.687, p>.05, \eta^{2}=.01$.

This present study produced some interesting results which will be discussed in following section. The findings in this study depict the outcome of what nontraditional female students indicate are ways they cope with stress. It is anticipated that these findings will add to the body of literature ways in which this population of nontraditional female students' cope.

\section{Summary of Major Findings}

- "Work at succeeding" $(M=4.08)$ is used often as a coping strategy.

- "Positive ways to cope" $(M=3.31)$, "healthy coping skills" $(M=3.01)$, "selfdefeating behaviors" $(M=2.83)$, "proactive self-care" $(M=2.74)$ and "negative coping skills" $(M=2.63)$ are used sometimes; "means of getting help" $(M=2.14)$ is the least used coping strategy.

- Non traditional female students used "proactive self-care" only sometimes with Caucasian students $(M=2.65)$ using it significantly less than AfricanAmerican students $(M=2.97)$ or students from other ethnic backgrounds $(M=$ 2.97).

- Non traditional female students used "work at succeeding" frequently: students with one child $(M=4.23)$ used it more frequently than those having no children $(M=4.04)$, two children $(M=3.98)$ or three or more children $(M$ $=4.09$ ). 
- "Self-defeating behaviors," "positive ways to cope," and "proactive self-care" as coping strategies are related to income levels. Generally, higher income non traditional students used these coping strategies at lower levels than lower income students.

- "Self-defeating behaviors," "positive ways to cope," and "proactive self-care" were also related to age groups. Younger students tended to use "selfdefeating behaviors" and "positive ways to cope" slightly more than older students. Older students tended to use proactive self-care slightly more than younger students.

- Coping strategies are not related to marital status. 


\section{CHAPTER 5}

\section{SUMMARY, DISCUSSION, IMPLICATIONS,}

\section{AND RECOMMENDATIONS}

This chapter presents a summary of the study, discussion of the six research questions, conclusions as well as recommendations for further research. The summary includes a statement of the rationale for the study, the purpose of the study, the six research questions, reviewed literature, methodology, and findings. Also, highlighted are the conclusions, implications, limitations, and recommendations.

\section{Purpose of the Study}

The purpose of this study was to examine the coping strategies of nontraditional female undergraduate students in Southwest Michigan and Northern Indiana. The sample included nontraditional female students from a public university and a private university.

\section{Overview of the Literature Review}

The literature indicates that education for adult females have come full circle once again from the days of the state normal schools where they are presenting in higher education in record numbers. The literature points to the continued growth of the nontraditional female student in higher education and the challenges that are present for this group of students. 


\section{Reasons why Nontraditional Female Students are Going to College}

There have been a few trends in society which have led many nontraditional female students to the classroom. These can be divided into:

(a) those caused by changes in society such as financial, technological changes, and

(b) those produced by personal concerns such as marriage, family and relationship issues. Often it is difficult to separate the two and the literature most often suggests a combination of societal and personal concerns. (Miller, 2000, p. 65)

Reentry nontraditional female students are divided into three categories: those who have already been in the workforce and want promotion, but need additional skills and training; those who had experienced a life-changing event such as death; children leaving home; and finally, those female students who were coming to school for the first time (Pierre, 1989; Rifenbary, 1995). Unmarried nontraditional female students who have children definitely need a college education to receive the amplified earning potential that goes along with having a degree (Haleman, 2004).

Nontraditional female students are coming to college for a number of different reasons, as outlined in the literature, and there are clear differences between Caucasian female students and African-American and multicultural female students. However, when they come to college, they are presented with problems that they may not have anticipated when they made the decision to further their education.

\section{Problems Nontraditional Female Students Face While Pursuing a College Education}

The literature points to several key studies which indicate that for adult female students work and loved ones are the primary foci of worry for this group of students which often diverts their attention from their studies (Bay, 1999; Chartrand, 1990; Dill \& 
Henley, 1998; Home, 1997, 1998; Kirk \& Dorfman, 1983; Meemeduma, 1993). Other research has validated the idea that loved ones and schools are selfish organizations (Coser, 1974; Edwards, 1993; Gouthro, 2005) that require a massive quantity of tangible periods, care, and inner strength from female students.

DeGregoria (1987) discovered that the Italian-American women she studied who were returning community college students received limited support from their loved ones, along with gender bias, and adverse impressions of Italian Americans. Likewise, LaPaglia (1994) found that along with the condescending implications connected with community college, returning adult female students faced feeling put down and irritated, mainly from managing numerous responsibilities and duties, especially with limited economic means. Freeman (1989) discovered that academic institutions victimize nontraditional female students merely by not advocating for their success. Adult female students, more often than their male counterparts, feel inadequate self-worth and little assurance as well as remorse because they are putting more importance on their education at the economic and personal sacrifice to their loved ones (Astin \& Kent, 1983).

Minority nontraditional female student often face multiple layers of challenges upon entering the academe. Bonner, Marbley, Evans, and Robinson (2014) cited Johnson-Bailey (1998) who posited, "The experiences of Black women in the world are different from those of other groups, based on the established societal hierarchies of race, gender, and class" (p. 37).

\section{Role Conflicts for Nontraditional Female Students}

Studies show that nontraditional female students experience more difficulties remaining in higher education than nontraditional men. Tinto (1993) discovered that 
marriage, while "generally associated with higher rates of persistence among men, is often related to lower rates of completion among women" (pp. 64-65), a result that he ascribes to nontraditional female students and their varied obligations with their jobs and loved ones which reduces their participation in activities of the university. Adult female students frequently state obstacles at home as the main cause for not achieving their degree (Leavitt, 1989; Schliebner, 1990).

Also, admission into the academic setting produces its own set of taxing stimuli for the nontraditional female student. They are now taking on a new job as student and intermingling with other students that are usually traditional-aged students and who have diverse standards and concerns. Furthermore, adult students are noticeably unlike traditional students and may have hobbies that are dissimilar to those of younger undergraduates, which can add to their belief of being ostracized and omitted from college activities (Padula, 1994).

Nontraditional female students face a myriad of challenges in the academy which often leads them to discontinue their education if mechanisms are not in place to promote their success and retention.

\section{Theoretical Perspectives on Nontraditional Female Students}

Gilligan (1982) established a foundation for understanding the moral and psychological make up of women and how it stems from their views on responsibility and relationship. Miller (1994) depicted the relationship that females encounter as being centered on a sense of connectedness with others, which Gilligan (1982) also talked about in her writings. Noddings (1986) based her viewpoints on women's being in a loving association that have mutual characteristics. These theorists maintain that because women 
want to sustain their present relationships they attempt to be agreeable. Transactional analysis and vigilant anticipatory coping are ways that nontraditional females cope. However, the fundamental makeup of a woman's existence is how she has been socialized by her family and society to be a person.

\section{Coping Strategies Used by Nontraditional Female Students}

Nontraditional female students utilize a variety of coping strategies which assist them in managing the stressors of college life. Nontraditional female students in one qualitative study (Bonner et al., 2014) cited their loved ones and acquaintances, fellow believers, and work companions as giving necessary foundation and encouragement. Adult students whose relatives provide them with assistance, safeguarding that college does not affect their job may be vital to relieving a nontraditional females worry. Studies have shown that backing from one's loved ones, close acquaintances, and co-workers has indicated the lessening of the adverse effects of responsibility tension (Dyk, 1987). Familial encouragement has been associated with retaining nontraditional females in college (Chartrand, 1992).

Resilience is developed as nontraditional female students take charge of their power and abilities. And, resilience is cultivated by facing trials and hardships and formulating positive reactions to them. Cultivating an attitude of acknowledgement and gratitude as they conquer problems leads to the growth of resilience; this can foster some to produce solutions that propel them to recognize the assets they possess, capitalize on their gifts, and use them to conquer difficulties (Howell, 2004). 


\section{Summary of the Methodology}

The following is a summary of the statistical analyses used in this study.

1. A correlation analysis was also conducted to ascertain whether there was a relationship among the variables.

2. An exploratory factor analysis was also done to determine the factors that may be supported by data in this study. A seven factor solution emerged from this analysis.

3. Descriptive statistics were used to determine what coping strategies nontraditional female students use to cope.

4. A one-way MANOVA indicated that all the independent variables except marital status were significant on the linear combination of the seven variables.

5. A one-way MANOVA of the the public and private universities in this study indicated significance on the linear combination of the seven variables.

This present study produced some interesting results which will be discussed in following section. The findings in this study depict the outcome of what nontraditional female students indicate are ways they cope with stress. It is anticipated that these findings will add to the body of literature of ways in which this population of nontraditional female students' cope.

\section{Summary of Major Findings}

1. Work at succeeding $(M=4.08)$ is often used as a coping strategy.

2. Positive ways to cope $(M=3.31)$, healthy coping strategies $(M=3.01)$, selfdefeating behaviors $(M=2.83)$, proactive self-care $(M=2.74)$ and negative coping skills $(M=2.63)$ were used sometimes.

3. Means of getting help $(M=2.14)$ was the least used coping strategy. 
4. Non traditional female students used proactive self-care only sometimes with Caucasian students $(M=2.65)$ using it significantly less than African-American students $(M=2.97)$ or students from other ethnic backgrounds $(M=2.97)$.

5. Non traditional female students used work at succeeding often with students having one child $(M=4.23)$ using it more often than those having no children $(M=4.04)$, two children $(M=3.98)$, or three or more children $(M=4.09)$.

6. Self-defeating behaviors, positive ways to cope, and proactive self-care as coping strategies were related to income levels. Generally, higher income, non traditional students used these coping strategies less than lower income students.

7. Self-defeating behaviors, positive ways to cope, and proactive self-care were related to age groups. Younger students tended to use self-defeating behaviors and positive ways to cope slightly more than older students.

8. Older nontraditional female students tended to use proactive self-care slightly more than do younger students.

9. Coping strategies were not related to marital status.

\section{Discussion of Major Findings}

This study produced several relevant findings that are important regarding the coping strategies of nontraditional female students in higher education. Coping is paramount in dealing with problems and handling them in a manner which is appropriate and useful to the individual. Six research questions were formulated for this study to glean information from respondents. The first research question addresses what are the coping strategies of nontraditional female students. These results generated seven coping strategies that assist nontraditional female students in coping with daily stressors while 
being a student. Furthermore, a discussion will follow on how coping relates to race, number of children, age, income, and marital status. It seemed beneficial to ascertain how all these variables were related to coping. The outcomes are presented in the following sections. The Likert scale in this study (1- don’t do it; 2-used very little; 3-used sometimes; 4-used often; 5-used a great deal) was used to address the specific responses made by respondents.

\section{Research Question 1 and Discussion/Implications}

Research Question 1: What are the coping strategies used by nontraditional female students in higher education?

The findings in this study indicated that the most used coping strategy by nontraditional female students was the "work at succeeding factor" $(\mathrm{M}=4.08)$ and the strategy of this type used the most was "work hard." The coping strategies on this factor were used often by nontraditional female students in this study. These items produced a mindset of overcoming difficulties by "putting effort into one's work," "keeping up with work as required," "working to solve the problem to the best of my ability." These items connect well with problem-focused coping where they are focused on problem-solving. One item states "focus on what's most important." The scale also produced real life emotions from the respondents as evidenced by "I get stressed out and despair," but they noted they were able to "assess the situation" and "think about what I am doing and why." These are important coping strategies for nontraditional female students to use. They were able to recognize the importance of "developing a plan of action." Studies show that nontraditional females often do not count the costs emotionally or financially of being in school. Thus, when difficult times arise they are not prepared to deal with the 
challenges presented. (Bonner et al., 2014; Goncalves \& Trunk, 2014; Vaccaro \& Lovell, 2010). Finally, the scale ends with "look on the bright side of things and think of all that is good." It would seem that this would have been higher on the scale because as they are working hard and putting effort into their work it helps to look on the bright side and think of all that is good when you are trying to achieve a goal.

The implications here showed the importance of family/friends providing tangible support whether it was in the form of verbal or physical support such as providing childcare or providing financial assistance. Nontraditional female students who received emotional support from family, friends, or their community may have a foundation on which to build that would assist them to endure difficult times as they arise. Research showed that nontraditional students acknowledged that being around their family as the biggest stress reducer (Canales-Gonzales \& Kranz, 2008).

Tangible emotional support would aid in retention for the student since these students all already working hard trying to keep everything together with family, school, and work. Families who demonstrate an interest in their love one's success reap the benefits as well in tangible ways such increased financial earning, which increases improved socioeconomic status for the family, and the satisfaction of a goal achieved which can be a motivator for other family members. This is consistent with what is found in the literature that support from family increases retention in college (Chartrand, 1992). Thomas (2001) found in her study that it was mostly a family member, friend or coworker who encouraged the female to further education.

Thus, it would be important for families and universities to assist students in their endeavors to succeed in achieving their degree. Vaccaro and Lovell (2010) discussed the 
importance of the university's harnessing the family's power. They talk about involving the family in school events and making the family an intricate part of the student's academic journey. Not all families are supportive of their loved one's going to school. This might, then, be an additional challenge for the students to deal with as they figure out how they going to be successful in school. They may need to find other means of emotional support such as the "sister circles" mentioned earlier or other support groups for nontraditional students. Finally, the literature notes that many nontraditional female students are the first in their family to attend college so they may not understand fully what to expect from being in school (Hardin, 2008). It would seem beneficial for these students to be paired with "more seasoned" students as mentors to help them navigate through the academy. "Work at succeeding" was an important coping strategy for respondents who were a part of my study as they continued their education.

In this study, nontraditional female selected "positive ways to cope" $(M=3.31)$ as a coping strategy for them with "find ways to relax" as a strategy sometimes used. It appeared that the coping strategies of "making time for friends and family" or "talk to others and giving support" appeared to be high on their list of ways to cope. There were coping strategies such as "find a way to let off steam" or "wish a miracle would happen" which seemed to suggest that the way looking for ways to escape the challenges they were facing, but this still points to their looking at ways to solve the problem. Participants acknowledged that they would spend time "with close friends" to cope, but they also wanted to "keep others from knowing what is worrying me" and "keep my feelings to myself," which seemed to imply that they wanted closeness with friends, but distance with regard to sharing the intimate challenges of their life. Low on the list was "talk to 
others to see what they would do if they had the problem." This seemed to suggest that they wanted to share they problems with others who have similar problems as a way to cope. This could be seen as emotion-focused coping or problem-focused coping depending on the way the student is utilizing the support received from the other person. Since "positive ways to cope" was high on the list, it demonstrated that nontraditional female students in this study practiced positive coping strategies.

The implications point to the necessity of having clubs and organization which specifically address the needs of nontraditional female students in higher education because their needs are clearly different than those of traditional female students. Furthermore, nontraditional female students may have a hard time finding ways to relax when they have multiple responsibilities to attend to on a daily basis. However, self-care is important in coping with the stressors that school and home present to this group of students. Clubs and organizations can provide a place where nontraditional female students can not only network but vent their frustrations regarding challenges they may be experiencing in school and in the home. Studies indicate colleges have already begun this process of creating centers and clubs whereby, nontraditional students can interact with others for purposes of networking and mentoring (Scott and Lewis, 2012). These coping strategies were sometimes used by the nontraditional female students in this study.

An additional finding in this study was that "healthy coping strategies" $(M=3.01)$ was an important coping strategy that the respondents sometimes used to cope. They seemed to combine various coping strategies to cope such as "think of different ways of dealing with the problem," "imagine that things will work out well," "make time for leisure activities." They appeared to be able to look beyond themselves to "improve 
relationships with others," but there were coping strategies where they voiced somatic complaints such as "I suffer headaches or stomach aches." The findings showed they coped by "spending time with husband/wife/boy/girlfriend or they coped by "trying to make close friends with a guy or girl, husband or wife." A different coping strategy that was sometimes used was "tell jokes." This appeared to be done to lighten the mood or make themselves feel better. There are studies that indicate several methods in place to sustain nontraditional female students, including developing a cohort encouragement structure and shared learning opportunities, to ensure that women have the support they need but for which they are afraid to ask (Massin, 1992; Taylor, 1995; Vaughn, Battle, Taylor, \& Dearman, 2009).

The implications for this strategy could be to teach nontraditional female students effective ways of coping during times of difficulty and stress, such as have them participate in a support group with other adult women who are in college and tap into support from family and resources at the university. This could be a professor or counselor from the university. Another finding of this study was that nontraditional female student sometimes used "self-defeating behaviors" $(M=2.83)$ with "worry about my future" as the coping strategy. This factor seemed problematic for younger nontraditional female students (ages 25-29) and (30-44). The concept that seemed to characterize this factor was worry. Respondents reported they "worry about what is happening," "worry about my happiness," "shut themselves off from the problem so that I can avoid it," "criticize myself," "don't share my problems with other people," and "cry or scream." They mentioned "I get sick, for example have head ache or stomach ache" as a coping strategy. The only positive coping strategy that is a part of this factor is "keep 
my long term goals clear." It appeared that amidst these emotion-focused coping strategies one problem-focused coping strategy emerged.

Nontraditional female students seem to cope ineffectively at times due to adversity. Teaching them positive ways to cope would be useful for this group of students. One possibility could be to assist nontraditional female students to recognize the importance of acknowledging their assets and skills in the development of resiliency (Howell, 2004). Furthermore, it seems beneficial for adult students to engage actively in campus life in some way so as to prevent them from isolating themselves. Another obstacle for nontraditional female students to beware of is fear of failure which often becomes apparent even in the early stages of considering entering academia. They may be worried they are "failing their friends, their family, and occasionally, their teachers" (Golden, 1987, p. 45).

The implications here point to the importance of having a positive support system in place whether that be family, peers, or campus clubs or organizations. It would seem beneficial to nontraditional female students to associate with other adult female students who have similar circumstances as themselves (Goncalves \& Trunk, 2014). Thomas (2001) found that African-American students were willing to encourage other adult students resume their education without waiting.

"Proactive self-care" $(M=2.74)$ was a coping strategy used sometimes by participants in this study. This factor indicated that these coping strategies could be implemented more frequently than respondents were doing. They implemented coping strategies such as using "positive self-talk," "protecting their self-esteem," "pray for help and guidance so that everything will be all right," which appeared to be that they used 
meaning-focused coping. Another finding in this study was that they worked on improving themselves, for instance, "work on my self-image," "improve my appearance," "keep fit and healthy," "go for a workout at the gym," or "play sport," which indicated that they care about how they look and how they feel about themselves. The odd item on this factor was "organize an action or petition regarding my concern." These findings seemed to indicate that these respondents were interested in being proactive with whatever concerns they may have in their life, but needed to use them more in order to be effective. The African-American and the multicultural group had higher proactive selfcare than Caucasian respondents in this study. These women identified focusing on improving their self-image and exercising as ways to take care of themselves.

The implications here suggest the necessity of taking care of one's body and mind in order to remain emotionally and physically healthy. Positive self-talk is important as a coping strategy to combat negative thinking and produce behavior that is healthy and uplifting during times of stress and challenge. There may be obstacles to overcome but, with determination and persistence, their goals can become their reality. The literature showed the importance of universities' having programs that are tailored made to fit the needs of this population such as fitness programs and wellness groups (Kulavic, Hultquist, \& McLester, 2013). There is a gap in the literature regarding nontraditional female students' using proactive self-care as a coping strategy. The literature seems to be focused on ways students can be active physically with walking groups and exercise groups to improve physical well-being. However, in the area of "positive self-talk," "protect my self-esteem" and "pray for help and guidance so that everything will be all right" are items that are still untapped. 
A finding of this study was that nontraditional female students sometimes used "negative coping skills" $(M=2.63)$ with "get annoyed at myself" as the coping strategy was applied sometimes. They appeared to use fundamentally negative coping strategies to manage their stressors such as "worry about what will happen to me," "blame yourself," “don't let others know how I am feeling, or "see myself as being at fault" as what they used sometimes.

The literature showed where nontraditional female students have inadequate views regarding their abilities (Howell, 2004) and nontraditional female students who did not speak English may have feelings of inadequacies due to their language deficiencies (Hardin, 2008). Negative coping is a coping strategy because people cope positively and negatively. Emotion-focused coping is centered around coping that involves venting frustrations to someone else. The problem is not necessarily being solved and while venting can be beneficial, it can also be damaging if there is no resolution to the problem.

Another finding of the study was that they would "ask a professional for help," but they would also "put the problem out of my mind," "consciously block out the problem," or "take frustrations out on others." It appears they worried, blamed, or avoided the problem. One study indicated that the only adverse consequence to attending college expressed by the participants was limited periods with their families (Wilsey, 2013). Studies have shown that participants felt their academic aspirations were selfcentered and that they experienced remorse for spending periods away from their loved ones. It is difficult for nontraditional female students to accept the importance of doing something for themselves instead of providing for the needs of their families (Marandet \& Wainwright, 2010; Reay, Ball, \& David, 2002; Stone \& O'Shea, 2013). 
The implications here suggested the importance of nontraditional female students' having a plan where they are not blaming themselves when things do not go their way. Problem-focused coping and meaning focused coping might be useful to combat negative thinking.

An additional finding of this study was that the coping strategy least used by nontraditional female students was the "means of getting help" $(M=2.14)$ coping strategy: specifically, "get support from others as parents or friends." This coping strategy was used very little by respondents. A charactistic of this factor was that the respondents seemed to want help from other people, as indicated by "talk to other people about my concern to help sort it out," "discuss the problem with qualified people," "join with people who have the same concern," "ask a professional for help," "go to meetings which look at the problem," or "organize a group to deal with my concern." While these coping strategies are beneficial, they were done very little by repsondents who participated in this study. Respondents were demonstrating problem-focused and emotion-focused coping strategies as evidenced by their responses. Chao and Good, (2004) suggested that therapy for nontraditional female students is a useful resource as well as ongoing support to assist them as they cope in place of family and other support systems in pursuit of their degree.

These implications are relevant for institutions to have resources readily available to adult female students before they are needed and make these students aware of these services, whether they be counseling or mentoring (Kohler \& Munz, 2006; McClary, 1990). It seems beneficial for family members to be aware of the intense challenges faced by this population of students and to be supportive in tangible, practical ways. 
Nontraditional female students often do not remain in higher education because they do not have a support system in their lives that can assist them through difficult times. These resources are critical for retaining nontraditional female students in the university. Professors may not be aware able of the undergraduate's task of mothering and rearing, and may be generally oblivious of undergraduate mothers' main incentive in coming and thriving in college (Wilsey, 2013). It would seem beneficial for professors to be aware of some potential challenges that nontraditional female students may encounter. Finally, there is a gap in the literature regarding nontraditional female students' using "means of getting help" as a coping strategy.

\section{Research Question 2 and Discussion/Implications}

Research Question 2: Are coping strategies related to ethnicity of nontraditional female students?

The results of this study indicated that nontraditional female students used proactive self-care sometimes, with Caucasians using it significantly less than AfricanAmerican and multicultural nontraditional female students. However, African-American female students comprised a little less than $10 \%$ of the sample; therefore, it is difficult to know exactly why they had higher proactive self-care than Caucasian female students. However, while Caucasian nontraditional female students comprised over $76 \%$ of the sample, over $75 \%$ percent of the respondents were mostly juniors and seniors which does speak to this population's ability to stay in school. While this study produced limited data on African-American female students, the literature does indicate that although making the transition into the academic environment can be a challenge for any student (Upcraft, Gardner, \& Barefoot, 2004), undergraduates of color and undergraduates from poorer 
financial circumstances frequently have additional trouble adapting to university than do mainstream undergraduates (e.g., Terenzini et al., 1994; Zwerling \& London, 1992).

The literature depicts the journey for Black female students at mainly Caucasian institutions as representative of the racism they receive in society at large (Constantine \& Greer, 2003). Minority nontraditional female students need to feel safe and attached to the institution they are attending. The university community needs to support them when they want their own support groups and associations (Howard-Hamilton, 2003). AfricanAmerican nontraditional female students and the multicultural group of nontraditional female students, comprised of Hispanic, Asian, and mixtures of other ethnic groups, used various proactive coping strategies that enabled them to cope in academia, but did not use them often enough. While there is some information on Hispanic nontraditional students (Rifenbary, 1995; Rodriguez, 1997), it is scarce (Harris \& Brooks, 1998).

The implications suggest that minority nontraditional female students have had to develop other coping strategies in life that have helped them cope in an often racist and discriminatory society that assists them as they matriculate in the university. Findings from various studies indicate that persistent racist incidents have frequently been aimed at African-American students (Altbach \& Lomotey, 1991; Feagin, 1992; Wilson, 1993). Because of previous experience to hardship, Blacks might become more familiar with handling pressure, so that a different, demanding occurrence may have little effect (Williams et al., 1997). Vigilant anticipatory coping seems to cover ethnic inequality in despondency that is larger than formerly recorded. For this reason, it may be viewed as helpful. It has probably developed as a defense method in response to extended bigotry and prejudice (LaVeist et al., 2014). 


\section{Research Question 3 and Discussion/Implications}

Research Question 3: Are coping strategies related to the number of children of nontraditional female students?

The findings of this study indicated that nontraditional female students use coping strategy coded as "work at succeeding" (which encompasses the construct of "working hard," "working at solving the problem," and "developing a plan of action"). This coping strategy is used often by nontraditional female students with one child (20\%), using it more often than those with no children (35\%) or those students with two or more children $(43 \%)$.

The implications indicated the extreme pressure experienced by nontraditional female students as they try to balance their role as parent and student plus manage their own inner feelings of guilt over being in school to provide a better life for their children. Professors need to provide this particular population of students with empathy and support as these students attend college so that they are able to remain in school.

Studies show that multiple role obligations cause problems for nontraditional female students. For instance, Home (1998) found that nontraditional females who parented little ones felt greater responsibility, discord, and pressure. Quimby and O'Brian, (2006) found that nontraditional female students who were firmly committed and self-assured in handling both learner and parental responsibilities felt that they had help and encouragement and reported that this had helped them have minimal amounts of mental anguish. Nontraditional female students who have learned to manage their time reap the benefits of enriched performance and fewer thoughts of worry (Kearns \& Gardiner, 2007). 
In one study, the participants reported feeling "out of place" as adult students. The females often reported being "put down" or belittled by teachers, in particular as it related to their children, as one woman illustrated, "The majority of professors do not treat nontraditional students as adults. It disturbs me that so many professors tell nontraditional students that they need to put their kids and family life on the back burner. Professors have criticized me for having children and given me a rough time when I miss class because of my child being sick" (Markle, 2015, p. 277). However, Goncalves and Trunk (2014) found that the participants in their study overall appreciated the interaction with their professors because they are older and have a level of admiration for their professors.

\section{Research Question 4 and Discussion/Implications}

Research Question 4: Are coping strategies related to age groups of nontraditional female students?

The findings of this study indicated that students in the 25-29 age range and 30-44 age range tended to use coping strategies coded as "self-defeating behaviors" (which depict how students worry about the future and shut themselves off from the problem) and "positive ways to cope" (talking to others to see what they would do and spending time with close friends) more than those female students in the 45 and above age range. Female students in the 25-29 age range used the highest self-defeating behaviors ( $M=$ $2.97)$ in the study followed by those in the $30-44$ age range $(M=2.85)$. Nontraditional female students in the age range 30-44 used self-defeating coping strategies slightly more than female students in the 45 and above age range $(M=2.52)$. Students in the 45 and above age range $(M=2.91)$ tended to use "proactive self-care" (behaviors which lead to taking care of oneself emotionally and physically) slightly more than those in the age 
ranges of 25-29 $(M=2.72)$ and 30-44 $(M=2.69)$. This factor indicates that adult female students are not using this coping strategy as much as they could to assist them with coping.

However, an additional finding in this study showed that nontraditional female students in the $25-29$ age range $(M=3.44)$ used positive ways to cope slightly more than older nontraditional female students in the 45 and above $(M=3.31)$ and those in the 30 $44(M=3.24)$. Younger nontraditional female students sought to "find a way to relax," for example, "listening to music, reading a book" or "make time for family or friends." Respondents also said they like to "talk to others and give each other support." They also stated they like to "find a way to let off steam." This may be helpful for them to release tension. Women in this time of life are still discovering who they are as individuals and may look to others to help validate their self-esteem. Erik Erikson in his psychosocial approach to human development referred to young adulthood stage as "intimacy vs. isolation" where, in this framework, intimacy represents the capacity to communicate one's real character, both the wholesome side and the immoral side (Ashford \& LeCroy, 2013).

These implications seem to suggest the importance of providing younger, nontraditional female students with coping strategies that will help them combat the challenges of academia while balancing the other obstacles in their life. Secondly, it may be beneficial to have support groups or a peer support system whereby they can encourage one another and provide the necessary foundation which will enable them to stay in school. Mentoring groups for younger, nontraditional female students would also be helpful in assisting them cope with the challenges of school and home while forming 
relationships with other nontraditional female students (Scott \& Lewis, 2012).

Furthermore, $82 \%$ of the respondents in this study were in the age range of $25-29$

$(30.6 \%)$ and $30-44$ age range $(51.4 \%)$. This coincides what is found in the literature which cited nontraditional students "over the age of 25 as the fastest growing group of undergraduates and the majority of this group are [sic] female" (Carney-Compton \& Tan, 2002, p.140; Graham \& Donaldson, 1999; Kasworm, 2003; Sales et al., 2001). Additional studies done by Choy (2002) and Kohler et al. (2007) have depicted them as first-time college students, women, part-time students attending community colleges, and parents. In quantitative studies done by Shank et al. (2001), Haggan (2000), and Quimby and O'Brien (2006), these factors are based on what has been seen in colleges and universities across the United States.

\section{Research Question 5 and Discussion/Implications}

Research Question 5: Are coping strategies related to income levels of nontraditional female students?

The findings of this study showed that nontraditional female students with incomes of $\$ 36,000$ and above $(M=2.69)$ had lower "self-defeating behaviors" than those students with incomes of $\$ 20,000$ and below $(M=2.92)$. This is possibly the case because nontraditional female students with greater financial resources might have less stress regarding how they are going to pay their bills and support their families. The findings also showed that nontraditional female students in the $\$ 21,000$ to $\$ 35,000(M=$ 3.19) income range had lower "positive ways to cope" scores than those females in the $\$ 20,000$ and below category $(M=3.40)$. It seems possible that nontraditional female students in $\$ 21,000$ to $\$ 35,000$ income category may need to find ways to relax, spend 
time with their family and get support from others in order to cope in a more positive way. Furthermore, additional findings revealed that nontraditional female students in the $\$ 36,000$ or more $(M=2.63)$ income range had lower "proactive self-care" than those female students in the $\$ 20,000$ and below $(M=2.80)$ category. Therefore, it may be that nontraditional female students in the $\$ 20,000$ and below category have had to develop coping strategies to keep themselves encouraged in order to keep going. Thus, they may have developed a stronger sense of resilience from past experiences which were then enabling them to be more successful in school. Generally, the higher the income, the less they used the coping strategies.

Nontraditional female students in academia with limited financial resources have stated experiencing additional pressure and greater difficulties handling stressors (Home, 1998). It is often the case that nontraditional female students return to school in the hope of securing a more stable financial future. Bettering their loved ones' station is sometimes the main goal for nontraditional female students to resume their learning (Babineau \& Wai-Ling Packard, 2006; Bauman et al., 2004). In their study, Vaccaro and Lovell (2010) found that participants

were indeed making an investment, but not in their careers. Instead they were investing in themselves. The investment was not purely with the hopes of gaining physical capital related to career advancement. By making sacrifices, studying long hours, and pushing themselves to the limit, women were not investing in the degree or the paper on which it was printed. Instead, time and energy were devoted to their personal growth. (p. 171)

These implications suggest that nontraditional female students may experience more stress and tension when they have to worry about how they are going to pay the bills and finance their educational pursuits. Academic institutions need to be forthright with adult female students regarding available financial funding for their education. 
Goncalves and Trunk (2014) found in their study,

a few participants stated they received unsolicited information on scholarships that was helpful, with one admitting that they were partly responsible for not getting the information because they did not take the initiative and look in the college catalog. One participant was receiving a full scholarship, but felt that, if they were not, their financial needs would not be met. Another participant stated that the financial aid office never answers the telephone and that specific needs would not be addressed unless students specifically visited the department with questions. (p. 167)

Nontraditional female students would probably have fewer "self-defeating behaviors" as coping strategies if they did not have to worry about finances.

\section{Research Question 6 and Discussion/Implications}

Research Question 6: Are coping strategies related to marital status of nontraditional female students?

The findings of this study indicated that coping strategies are not related to marital status. Therefore, it did not matter if the respondents were married, divorced, or single in relation to their coping strategies. However, these implications suggest that while marital status was not related to coping strategies for these respondents in this study, this is not always the case. Nontraditional female students who are married often experience inter-role conflict and, at times, overload if they do not receive the necessary help from their support system or the academic institution. Nontraditional female students who are single may feel overwhelmed if they do not have the support available to them to avert the onslaught of tension that may occur if they are not prepared to handle the stress brought on by multiple stressors all at once which can be the case when they decide to go to college.

The findings of other studies showed where various partners have divided domestic responsibilities and care of their offspring they were able to adapt to 
adjustments in calendars and jobs (Sweet \& Moen, 2007). Canales-Gonzales and Kranz (2008) asserted handling the tension brought on by additional duties; nontraditional students related that devoting periods where they interact with their loved ones is a great way for them to decrease anxiety.

However, it is a tremendous sacrifice when nontraditional females decide to attend college. Hart (1995) asserted, "The sexual division of labor still gives an almost exclusive responsibility for raising children to women because the work is devalued" (p. 118). Other findings indicate that nontraditional married female students hardly ever encounter any rearrangement of chores in the home (Deutsch \& Schmertz, 2011). These adult female students often find chores in the home and household tasks to be excessively difficult, whereas this is not the case with males (Reay et al., 2002; Stone \& O'Shea, 2013; Wlodkowski, Mauldin, \& Campbell, 2002).

The concluding section gives an overview of the study and what the results mean for nontraditional female students who seek to obtain an education in the future.

\section{Conclusion}

The findings of this study indicated the coping strategy nontraditional female students used often was the "work at succeeding strategy." "Healthy coping strategies," "self-defeating behaviors," "negative coping skills," "positive ways to cope," and "proactive self-care coping strategies were sometimes used. The coping strategy "means of getting help" was the least used coping strategy and it was used very little.

Another finding of this study showed nontraditional female students used "proactive self-care" only sometimes, with Caucasian students using it significantly less than African-American or multicultural female students. This is a coping strategy where 
nontraditional female students could increase their usage. Since only $9.3 \%$ of the sample was African-American, the results cannot be generalized. However, further study should be done with a larger African-American sample where inferences regarding coping strategies for minority nontraditional female students can be made.

An additional finding of this study show the "work at succeeding" coping strategy was used often by students with one child. Therefore, universities may want to include students' loved ones a part of activities put on by the college, whether it be regular school events or orientation with daycare provided (Johnson et al., 2000).

Coping strategies that help relieve stress and anxiety may help students perform better in their studies and yield a higher retention rate of nontraditional female students remaining in college. Coping strategies such as problem-focused or meaning-focused coping may be useful in addressing the needs of nontraditional female students who are juggling multiple responsibilities.

Another finding of this study revealed that "healthy coping strategies" were used sometimes by respondents such as, "improve my relationship with others." This supports Goncalves and Trunk (2014) finding in their study that showed nontraditional female students revealed they would be happy to belong to a group whose participants comprised only adult students. They liked the concept of having their own space where they could meet and gather with other adult students.

In this study, nontraditional female students used "negative coping skills" sometimes as a coping strategy. It may not be the most effective or positive coping strategy, but respondents did identify this as coping strategies they sometimes use to handle their problems. This finding is consistent with findings from Coker (2003) who 
studied African-American women in higher education and found that they experienced anxiety regarding their ability to perform in college after taking time off from their education. They also were concerned if they could compete with traditional students who had an uninterrupted educational experience.

A finding of this study indicated that nontraditional female students used very little the "means of getting help" coping strategy. While these coping strategies are used very little, they could prove beneficial to nontraditional female students to help them when stress arises. Previous findings by Quimby and O'Brien (2006) recommended that counselors who work with nontraditional female students with children may want to (a) assess students' levels of secure attachment, parent and student self-efficacy, perceived social support; (b) educate women about the potential for increased stress in returning to school and discuss the positive impact of secure attachment, social support, and self-efficacy; (c) encourage women to join interpersonal support groups or initiate groups designed specifically to provide social support and enhance selfefficacy for nontraditional female students with children; and (d) recommend therapy for women [who] exhibit insecure attachment, have low self-efficacy, or have few sources of social support. (p. 457)

The results of this study indicated that "self-defeating behaviors," "positive ways to cope," and "proactive self-care" were related to age groups. Nontraditional female students in the 25-29 age range had the highest "self-defeating behaviors" $(M=2.97)$ in comparison with those in the $30-44$ age range $(M=2.85)$. An interesting finding of this study was "positive ways to cope" was slightly higher for those students in the 25-29 age category $(M=3.44)$ than for older nontraditional female students age 30-44 $(M=3.23)$ and for those 45 and above $(M=3.30)$. Younger nontraditional female students may have higher "positive ways to cope" because they have developed behaviors which have helped them take better care of themselves emotionally and physically. Dyk (1987) found that nontraditional female students who receive support from their loved ones and co- 
workers have less adverse outcomes of stress.

Another finding of this study indicated that older students in the 45 and above age range tended to use "proactive self-care" $(M=2.91)$ slightly more than younger students in the 25 - 29 age range $(M=2.72)$ and even more than those students in the $30-44$ age range $(M=2.69)$. This is consistent with previous findings that indicated that problemfocused coping was utilized more by adult students than by younger university undergraduates (Morris et al., 2003). Younger, nontraditional female undergraduates may be less developmentally prepared or less self-regulating in comparison to their older, nontraditional peers. Graham (1998) found that younger undergraduates depend upon a "feelings-management" approach, therefore demonstrating a probable reason as to why adult undergraduates often obtain better grades than younger undergraduates. Using one's feelings is frequently thought of as an unwanted, acquired behavior that is adversely related to learners' grades. Recognizing methods that relieve or lessen such a trait ought to be a significant aim for teachers, therapists, and undergraduate-activities authorities (Johnson \& Nussbaum, 2012).

The results of this study show that "self-defeating behaviors," "positive ways to cope," and "proactive self-care" are coping strategies related to income levels. Generally, higher income non traditional students used these coping strategies at lesser levels than lower income students. Students in the $\$ 21,000$ to $\$ 35,000(M=3.19)$ category had lower positive ways to cope than those in the $\$ 20,000$ and below $(M=3.40)$ category. In this study, respondents in the $\$ 36,000$ or more $(M=2.62)$ category had lower proactive selfcare than those in the $\$ 20,000$ and below $(M=2.80)$ category. However, nontraditional female students in the $\$ 20,000$ and below $(M=2.92)$ category had higher self-defeating 
behaviors than the $\$ 21,000$ to $\$ 35,000(M=2.86)$ students and the $\$ 36,000$ and more ( $M$ $=2.69$ ) students. These findings support Home (1998) findings that nontraditional female students with lower incomes were apt to describe feeling overwhelmed due to multiple obligations and being enrolled full-time in school.

There were trends in this study with younger nontraditional female students using higher self-defeating behaviors along with those who had incomes $\$ 20,000$ and below. Nontraditional female students in the $\$ 21,000$ to $\$ 35,000$ income category and those female students in the 30-44 age category had lower positive ways to cope.

In this study, there was no difference whether respondents were married, single, widowed, separated, or divorced as it relates to their coping strategies. However, studies indicated that the main reason adult women do not finish their college degree usually relate to their home life (Leavitt, 1989; Schliebner, 1990). Quimby and O'Brien (2006) found that nontraditional female students who sense secure and caring connections, as well as those associations where their abilities and experience were acknowledged, revealed reduced amounts of tension.

Numerous nontraditional female students are the first ones among their loved ones to pursue higher education (Hardin, 2008). Nontraditional female students who are first-generation college students may find attending college overwhelming. However, finding a support system, such as mentoring clubs or organizations will assist them as they continue their education.

The results of this study have recommendations for practitioners who are working with this population. The study has provided helpful information for assisting 
nontraditional female students who may experience challenges and who seek therapy for support.

\section{Limitations of Study}

This study has several limitations. This study would be more generalizable if the sample of nontraditional female students had been drawn from a greater cross-section of the country. Due to the small number of undergraduate nontraditional females at the private university, subjects were not randomly selected for this study. The undergraduate, nontraditional female students from the public university were selected by using the total number of nontraditional female student population who were interested in participating in the study.

Second, the CSA that was used in the study was a self-report coping instrument; it had all the limitations of such self-reports, including the tendency for the respondents to choose socially desirable responses. The CSA does not address the effectiveness of strategies that respondents say they used to cope. Third, this study focused only on coping strategies used by nontraditional female students. The study does not examine in any great detail how nontraditional males cope in higher education or in other challenges they encounter.

\section{Recommendations for Practice}

Based on the findings of this study, the following recommendations are suggested for practitioners and universities who provide services to nontraditional female students.

1. Seminars that focus on teaching skills for success in higher education can provide nontraditional female students with useful tools on how to practice "healthy 
coping strategies" and "positive ways to cope" as they juggle multiple responsibilities while attending college, providing counseling information as resource for them.

2. Universities can partner with nontraditional female students by having focus groups to address barriers and challenges they may be facing and allow them to develop solutions that will address their unique needs.

3. Orientations can provide information for nontraditional female students to acquaint them with the administration, student life personnel, and university procedures.

4. Support groups can provide a connection with other nontraditional female students which can create a sense of community for nontraditional female students on university campuses to address their special needs.

5. Universities may consider having seminars that address cultural competence for their faculty and administrators. It is not enough to assume that educators are knowledgeable regarding how to work with students from various cultural groups.

6. University events that involve family members may assist nontraditional female students feel a part of the university community. Institutions can utilize the family system by making it a partner in the success for goal completion for the student.

\section{Recommendations for Future Research}

1. This study can be replicated with various universities; however, students' perception of their own state of coping may be measured by using a specific situation with a pre- and post-test to measure coping differences

2. Future studies can be conducted using multiple coping self-inventories.

3. The use of a mix methods design would allow for more intensive study of the variables and provide more conclusive information. 
4. Finally, further research can be done on the coping strategies of undergraduate nontraditional male students. 
APPENDIX A

INFORMED CONSENT AGREEMENT AND SURVEY 
Study Information Sheet \#12065

* 1. You are invited to participate in a research study. The purpose of this study is to compare the coping strategies of undergraduate nontraditional (25 years and older) female students from Andrews University with Indiana University South Bend undergraduate nontraditional female students.

Information

If you agree to participate you will be asked to complete a survey which asks your opinion regarding how you cope. This study is expected to take 10 minutes to complete. Students from Indiana University and Andrews University will be participating in the study. You must be female and at least 25 years old to participate in the study.

Benefits

While there are no direct benefits to you, we hope to contribute to the body of knowledge surrounding coping strategies of undergraduate nontraditional female students in higher education.

Risks

We do not anticipate any risks associated with this study.

Confidentiality

No identifiable information about you will be collected. It is possible, however, with internet communications that through intent or accident someone other than the intended recipient may see your responses. In addition, other Advanced Level Practice Evaluation student researchers, who have trained in confidentiality procedures, could potentially have access to your responses. There is one open ended question on the survey-\#12. Please do not provide any information that would identify you as an individual.

Compensation

IUSB students who complete the survey would be eligible to participate in the random gift card drawing for one of six $\$ 25$ gift cards.

Andrews University students who complete the survey would be eligible to participate in the random drawing for one of six $\$ 25$ gift cards.

Contact

If you have questions at any time about the study or the procedures, you may contact the researcher, Desiree Davis at 574-250-0095, desireed@andrews.edu, Dr. Carolyn Schult, 574-520-4118,cschult@iusb, or Dr. Elvin Gabriel at 269-471-6223,gabriel@andrews.edu.

If you feel you have not been treated according to the descriptions in this form, or your rights as a participant in research have been violated during the course of this project, you may contact the Indiana University South Bend Review Board for the Protection of Human Research Subjects, 1700 Mishawaka Ave., A247 South Bend, IN 46634, 574-520-4118, by email at sbirb@iusb.edu or the Andrews University at 
269-471-6361 or irb@au.edu.

Participation

Your participation in this study is voluntary; you may refuse to participate without penalty. If you decide to participate, you may withdraw from the study at any time without penalty. If you decide to withdraw simply close your browser window. You may submit a partially completed or completely blank questionnaire and still be eligible for the $\$ 25$ dollar drawing. Since the surveys do not contain any identifiers, once they are submitted you will not be able to withdraw from the study.

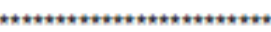

IUSB IRB Approval

Approval Date: 10/20/12

Expires: 10/19/13

**************************

If you wish to participate please place an ' $\mathrm{X}$ ' in the box below. 
Demographic Information

2. Please check the university type that you attend:

Public University Private University

3. Please check your current school status:

Ful-Time Student $\bigcirc$ Part-Time Student

4. Please indicate what year you are in college.

Freshman Sophomore Junior $\bigcirc$ Senior

5. Please choose your student category.

New Student Returning Student

6. Please select your age range.
$25-29$
$45-59$
$30-44$
60 \& above

7. Please indicate the background you mostly identify with.
African-American
Native-Americar
Asian-American
Hispanic
Caucasian
Multiethnic
Other

8. Please indicate your marital status.

Married $\bigcirc$ Single Widowed $\bigcirc$ Separated $\bigcirc$ Divorced

9. Please indicate the number of dependent children in household.

none one $\circlearrowleft$ two $\circlearrowleft$ three $\circlearrowleft$ four or more

10. Please indicate your household income.

Below $20,000 \bigcirc 21,000-35,000 \bigcirc 36,000-49,000 \bigcirc 50,000-69,000 \bigcirc 70,000$ and above 
Coping Scale for Adults

11. People have a number of concerns or worries about things such as work, studies, family, the world and the like. Please describe your main concerns that you generally worry about. For example, you might have worries about childcare, finances, or work scheduling.

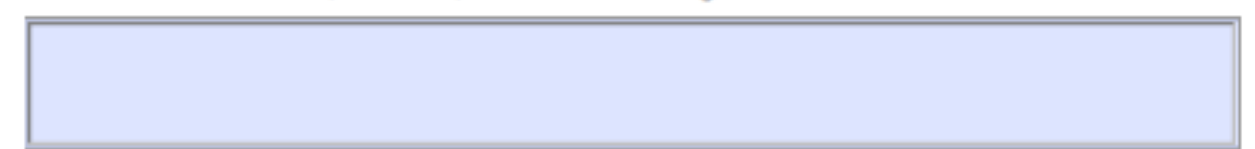


Below are a list of ways in which people cope with a wide variety of concerns or problems. While thinking about your personal concerns, please indicate the things you do to deal with your concerns or worries by selecting the appropriate number for the questions below.

\section{REMEMBER: YOU ARE THINKING ABOUT A SPECIFIC CONCERN}

\begin{tabular}{|c|c|c|c|c|}
\hline & Used very little & Used sometimes & Used often & Used a great deal \\
\hline $\begin{array}{l}\text { 1. Talk to others to see } \\
\text { what they would do if } \\
\text { they had the problem }\end{array}$ & & & & \\
\hline $\begin{array}{l}\text { 2. Shut myself off from } \\
\text { the problem so that I can } \\
\text { avoid it }\end{array}$ & & & & \\
\hline $\begin{array}{l}\text { 3. Keep up with work as } \\
\text { required }\end{array}$ & & & & \\
\hline 4. Play sport & & & & \\
\hline $\begin{array}{l}\text { 5. Let the Lord take care } \\
\text { of my worries }\end{array}$ & & & & \\
\hline $\begin{array}{l}\text { 6. Seek help from a } \\
\text { qualified person }\end{array}$ & & & & \\
\hline 7. Worry about my future & & & & \\
\hline $\begin{array}{l}\text { 8. Protect my self } \\
\text { esteem }\end{array}$ & & & & \\
\hline $\begin{array}{l}\text { 9. Keep my long term } \\
\text { goals clear }\end{array}$ & & & & \\
\hline
\end{tabular}

\section{REMEMBER: YOU ARE THINKING ABOUT A SPECIFIC CONCERN}

Don't do it Used very ittle Used sometimes Used often
"10. I get stressed out
and despair




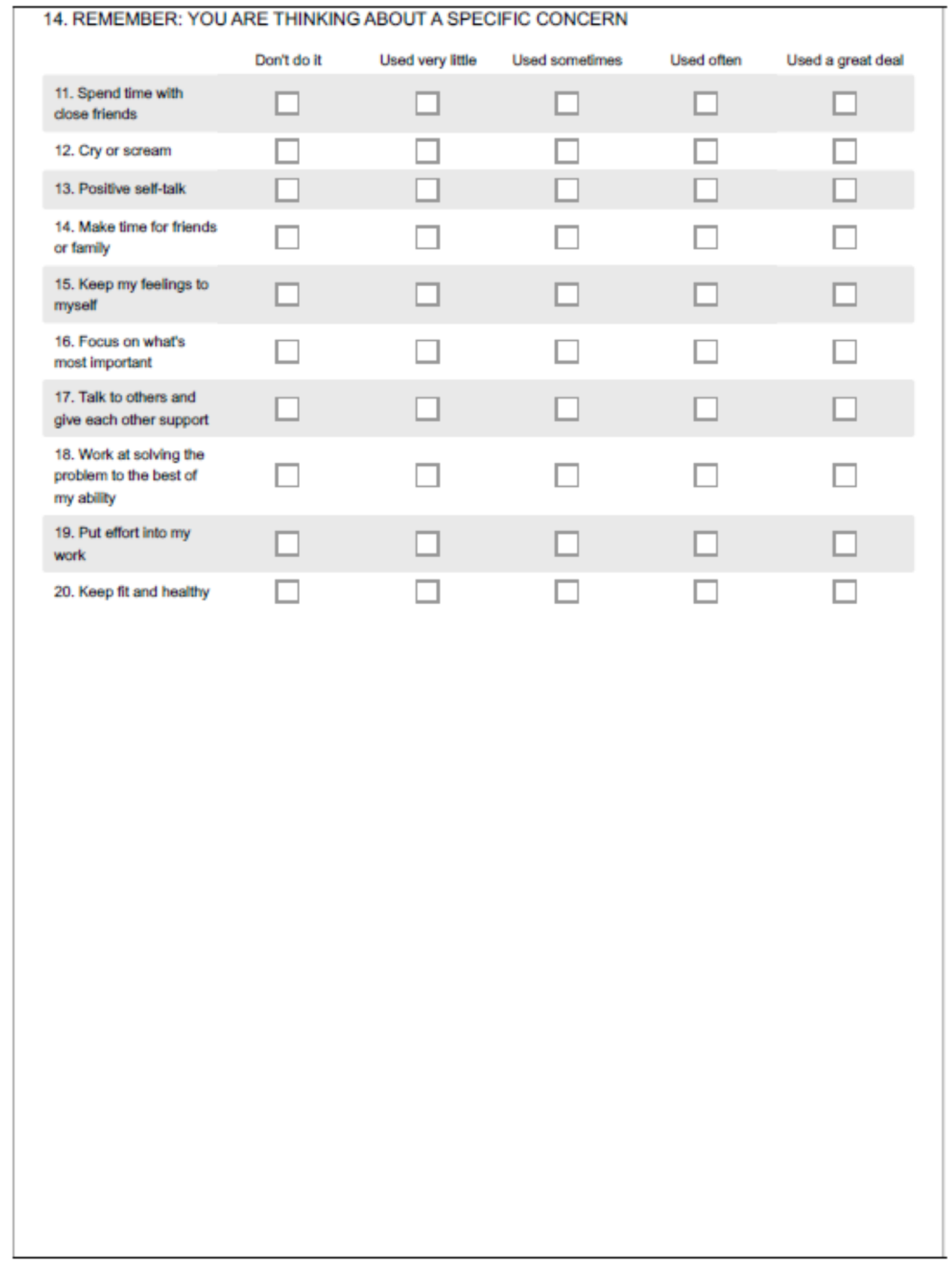




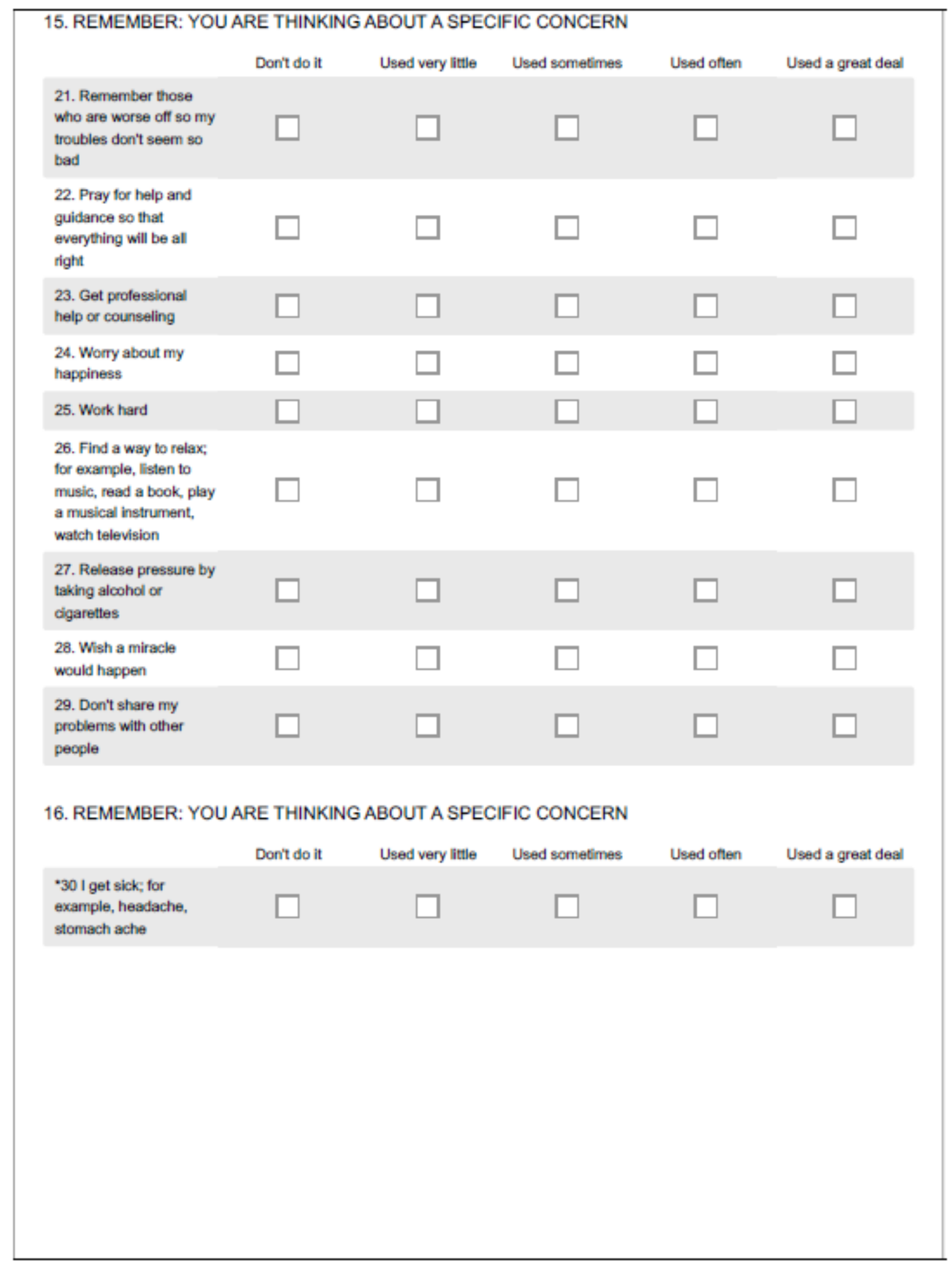




\begin{tabular}{|c|c|c|c|c|c|}
\hline \multicolumn{6}{|c|}{ 17. REMEMBER: YOU ARE THINKING ABOUT A SPECIFIC CONCERN } \\
\hline & Don't do it & Used very ittle & Used sometimes & Used often & Used a great deal \\
\hline $\begin{array}{l}\text { 31. Work on my self } \\
\text { image }\end{array}$ & $\square$ & $\square$ & $\square$ & $\square$ & $\square$ \\
\hline 32. Assess the situation & $\square$ & $\square$ & $\square$ & $\square$ & $\square$ \\
\hline $\begin{array}{l}\text { 33. Create a humorous } \\
\text { diversion }\end{array}$ & $\square$ & $\square$ & $\square$ & $\square$ & $\square$ \\
\hline $\begin{array}{l}\text { 34. Go for a workout at } \\
\text { the gym }\end{array}$ & $\square$ & $\square$ & $\square$ & $\square$ & $\square$ \\
\hline $\begin{array}{l}\text { 35. Look on the bright } \\
\text { side of things and think } \\
\text { of all that is good }\end{array}$ & $\square$ & $\square$ & $\square$ & $\square$ & $\square$ \\
\hline $\begin{array}{l}\text { 36. Develop a plan of } \\
\text { action }\end{array}$ & $\square$ & $\square$ & $\square$ & $\square$ & $\square$ \\
\hline $\begin{array}{l}\text { 37. Worry about what is } \\
\text { happening }\end{array}$ & $\square$ & $\square$ & $\square$ & $\square$ & $\square$ \\
\hline $\begin{array}{l}\text { 38. Improve my } \\
\text { appearance }\end{array}$ & $\square$ & $\square$ & $\square$ & $\square$ & $\square$ \\
\hline $\begin{array}{l}\text { 39. Organize an action } \\
\text { or petition regarding my } \\
\text { concern }\end{array}$ & $\square$ & $\square$ & $\square$ & $\square$ & $\square$ \\
\hline $\begin{array}{l}\text { 40. Get into or improve } \\
\text { an existing special } \\
\text { relationships; for } \\
\text { example,husband, wife, } \\
\text { boytriend/git friend }\end{array}$ & $\square$ & $\square$ & $\square$ & $\square$ & $\square$ \\
\hline
\end{tabular}




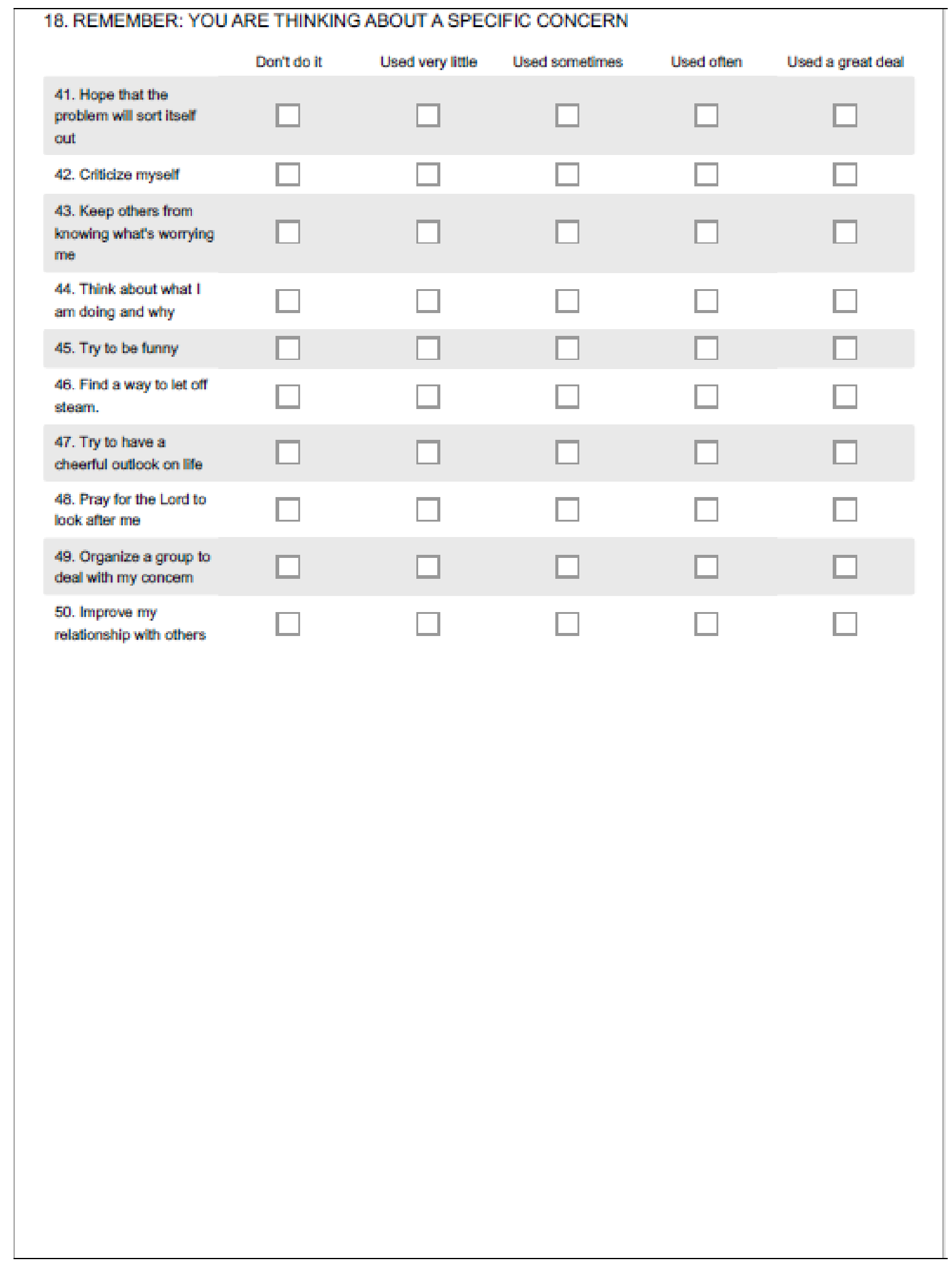




\begin{tabular}{|c|c|c|c|c|c|}
\hline \multicolumn{6}{|c|}{ 19. REMEMBER: YOU ARE THINKING ABOUT A SPECIFIC CONCERN } \\
\hline & Don't do it & Used very ittle & Used sometimes & Used often & Used a great deal \\
\hline $\begin{array}{l}\text { 51. Get annoyed at } \\
\text { myself }\end{array}$ & $\square$ & $\square$ & $\square$ & $\square$ & $\square$ \\
\hline $\begin{array}{l}\text { 52. Go to meetings } \\
\text { which look at the } \\
\text { problem }\end{array}$ & $\square$ & $\square$ & $\square$ & $\square$ & $\square$ \\
\hline $\begin{array}{l}\text { 53. Try to make close } \\
\text { friends with a guy or git, } \\
\text { husband or wile }\end{array}$ & $\square$ & $\square$ & $\square$ & $\square$ & $\square$ \\
\hline $\begin{array}{l}\text { 54. Daydream about } \\
\text { how things wlal tum out } \\
\text { well }\end{array}$ & $\square$ & $\square$ & $\square$ & $\square$ & $\square$ \\
\hline $\begin{array}{l}\text { 55. Think of different } \\
\text { ways of dealing with the } \\
\text { problem }\end{array}$ & $\square$ & $\square$ & $\square$ & $\square$ & $\square$ \\
\hline 56. Blame myset & $\square$ & $\square$ & $\square$ & $\square$ & $\square$ \\
\hline $\begin{array}{l}\text { 57. Don't let others know } \\
\text { how I am teeling }\end{array}$ & $\square$ & $\square$ & $\square$ & $\square$ & $\square$ \\
\hline $\begin{array}{l}\text { 58. Consciously block } \\
\text { out the problem }\end{array}$ & $\square$ & $\square$ & $\square$ & $\square$ & $\square$ \\
\hline $\begin{array}{l}\text { 59. Talk to other people } \\
\text { about my concem to } \\
\text { help me sort it out }\end{array}$ & $\square$ & $\square$ & $\square$ & $\square$ & $\square$ \\
\hline 60. Tell jokes & $\square$ & $\square$ & $\square$ & $\square$ & $\square$ \\
\hline \multicolumn{6}{|c|}{ 20. REMEMBER: YOU ARE THINKING ABOUT A SPECIFIC CONCERN } \\
\hline & Don't do it & Used very ittle & Used sometimes & Used often & Used a great deal \\
\hline $\begin{array}{l}\text { "61. I suffer heasdaches } \\
\text { or stomach aches }\end{array}$ & $\square$ & $\square$ & $\square$ & $\square$ & $\square$ \\
\hline
\end{tabular}




\begin{tabular}{|c|c|c|c|c|c|}
\hline \multicolumn{6}{|c|}{ 21. REMEMBER: YOU ARE THINKING ABOUT A SPECIFIC CONCERN } \\
\hline & Don't do it & Used very ittle & Used sometimes & Used often & Used a great deal \\
\hline $\begin{array}{l}\text { 62. Ask a professional } \\
\text { person for help }\end{array}$ & $\square$ & $\square$ & $\square$ & $\square$ & $\square$ \\
\hline $\begin{array}{l}\text { 63. Be happy with the } \\
\text { way things are }\end{array}$ & $\square$ & $\square$ & $\square$ & $\square$ & $\square$ \\
\hline $\begin{array}{l}\text { 64. Worry about what } \\
\text { wal happen to me }\end{array}$ & $\square$ & $\square$ & $\square$ & $\square$ & $\square$ \\
\hline $\begin{array}{l}\text { 65. Put the problem out } \\
\text { of my mind }\end{array}$ & $\square$ & $\square$ & $\square$ & $\square$ & $\square$ \\
\hline $\begin{array}{l}\text { 66. Spend more time } \\
\text { with my } \\
\text { husband/wiserboylgit } \\
\text { friend }\end{array}$ & $\square$ & $\square$ & $\square$ & $\square$ & $\square$ \\
\hline $\begin{array}{l}\text { 67. Join with people who } \\
\text { have the same concern }\end{array}$ & $\square$ & $\square$ & $\square$ & $\square$ & $\square$ \\
\hline $\begin{array}{l}\text { 68. Take my frustrations } \\
\text { out on others }\end{array}$ & $\square$ & $\square$ & $\square$ & $\square$ & $\square$ \\
\hline $\begin{array}{l}\text { 69. Imagine that things } \\
\text { wal work out well }\end{array}$ & $\square$ & $\square$ & $\square$ & $\square$ & $\square$ \\
\hline $\begin{array}{l}\text { 70. See myself as being } \\
\text { at fault }\end{array}$ & $\square$ & $\square$ & $\square$ & $\square$ & $\square$ \\
\hline \multicolumn{6}{|c|}{ 22. REMEMBER:YOU ARE THINKING OF A SPECIFIC CONCERN } \\
\hline & Don't do it & Used very ittle & Used sometimes & Used often & Used a great deal \\
\hline $\begin{array}{l}\text { 71. Get support from } \\
\text { others such as parents } \\
\text { or friends }\end{array}$ & $\square$ & $\square$ & $\square$ & $\square$ & $\square$ \\
\hline $\begin{array}{l}\text { 72. Discuss the problem } \\
\text { with qualified people }\end{array}$ & $\square$ & $\square$ & $\square$ & $\square$ & $\square$ \\
\hline $\begin{array}{l}\text { 73. Make time for leisure } \\
\text { activities }\end{array}$ & $\square$ & $\square$ & $\square$ & $\square$ & $\square$ \\
\hline
\end{tabular}




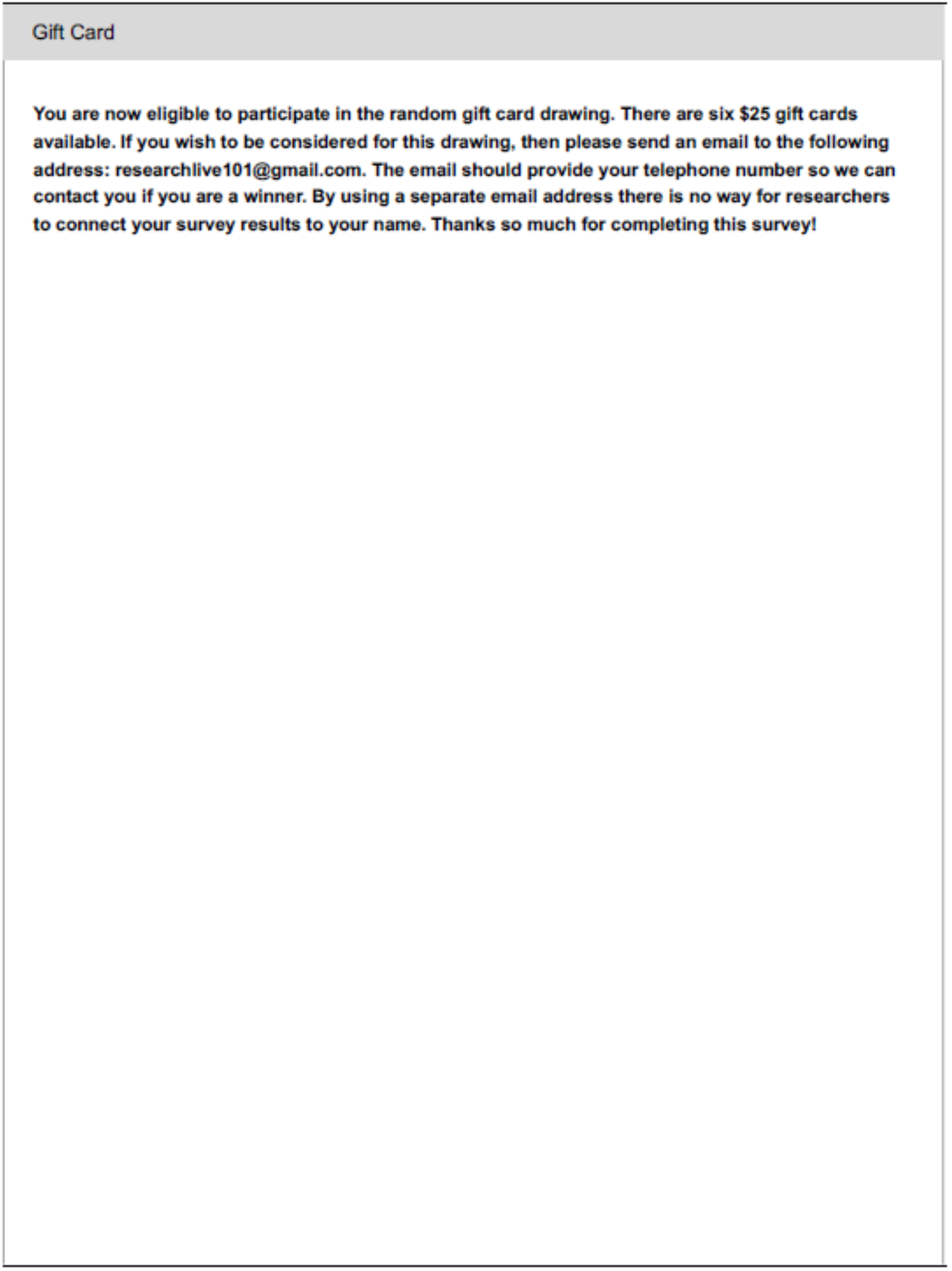


APPENDIX B

PERMISSION LETTERS 


\section{IT INDIANA UNIVERSITY
SOUTH BEND}

NOTICE OF APPROVAL EXEMPT REVIEW

DATE: December 17,2012

TO: Desiree Davis

COPY: Carolyn Schult, Psychology - PSY

From: Erika fnd Contracts \& Grants Coordinator

Re: Protocol Entitled: The Coping Strategies of the Nontraditional Female Student in Higher Fducation

Protocol $\# \mathbf{H} 2065$

Approval Date: October 20, 2012

The IUSB Institutional Review Board (IRB) has reviewed and approved the research protocol referenoed above as exempt; $\$ 46.101 \mathrm{~b}, \uparrow 2$. This study is approved from October 20,2012 to October 19,2013 . As the principal investigator of this study you assume the following reporting responsibilities:

AMENDMENTS: Investigators are required to report on these forms ANY changes to the research study (such as design, procedures, study information sheet/consent form, or subject population, including size). The new procedure may not be initiated until IRB approval has been given. An amendment form can be found at http:/www.iusb.edu/-sbirb/amendment.doc.

AUDIT OR INSPECTION REPORTS: Investigators are required to provide to the IRB a copy of any audit or inspection reports or findings issued to them by regulatory agencies, cooperative research groups, contract research organizations, the sponsor, or the funding agency.

COMPLETION: It is your responsibility to let the IRB know when this study is complete by sending an email to sbirb@iusb. edu. Approximately one month before the date you indicated your study will end, we will send a notice to you at the address on your application, requesting information on the current status of your study. If this is a student project and we don't hear from you, we will send a notice to your faculty sponsor. If we do not receive any response we will consider the study as ended and change our files to show that. It is your responsibility to let the IRB office know of address changes and project date changes.

CONSENT FORMS/STUDY INFORMATION SHEET: All subjects should be given a copy of the stamped approved study information sheet or consent form. You must retain signed consent documents for at least three years past completion of the research activity.

We suggest you keep this letter with your copy of the approved protocol. Please refer to the exact project title and protocol number in any future correspondence with our office. All correspondence must be typed.

Enclosures:Approved Amendment

Federal Wide Assurance \#FWA00003544-IRB00000222

For additional FWA information, see the Web site at http:/www.iupui.edu/-resgrad/spon/fwa.htm

IRB Administration | 574-520-4181 | sbirb@iusb.edu | www.iusb.edu/ -sbirb 


\section{Andrews University}

April 20, 2012

Desiree Davis (Principal Investigator)

Tel: (574) 250-0095

Email: desired@andrews,edu

\section{RE: APPLICATION FOR APPROVAL OF RESEARCH INVOLVING HUMAN SUBJECTS IRB Protocol \#: 12-068 Application Type: Original Dept.: Social Work Review Category: Exempt Action Taken: Approved Advisor: Elvin Gabriel Title: The Coping Strategies of the Nontraditional Female in Higher Education}

Your IRB application for approval of research involving human subjects entitled: "The Coping Strategies of the Nontraditional Female in Higher Education" IRB protocol "12068 has been evaluated and determined to be Exempt under category 46.101 (b) (2). You may now proceed with your research.

We ask that you reference the protocol number in any future correspondence regarding this study for easy retrieval of information.

Please note that any future changes made to the study design and/or consent form require prior approval from the IRB before such changes can be implemented.

While there appears to be no more than minimum risks with your study, should an incidence occur that results in a research-related adverse reaction and/or physical injury, this must be reported immediately in writing to the IRB. Any research-related physical injury must also be reported immediately to the University Physician, Dr. Hamel, by calling (269) 473-2222.

Please feel free to contact our office if you have any questions.

All the best in your research.

Sincerely,

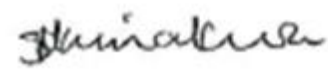

Sarah Kimakwa

IRB, Research \& Creative Scholarship 
February 21, 2013

\section{Andrews University}

Desiree Davis

Tel: (574) 250-0095

Email: desired@andrews.edu

RE: APPLICATION FOR APPROVAL OF RESEARCH INVOLVING HUMAN SUBJECTS

IRB Protocol s: 12-068 Application Type: Modified Dept.: Graduate Psychology

Review Category: Expedited Action Taken: Approved Advisor: Blvin Gabriel

Title: The Coping Strategies of the Nontraditional Female in Higher Education

This letter is to advise you that the Institutional Review Board (IRB) has reviewed and approved your IRB application of research involving human subjects entitled: "The Coping Strategies of the Nontraditional Female in Higher Education" IRB protocol number 12068 under Expedited category. This approval is valid until April 20, 2013. If your research is not completed by the end of this period you must apply for an extension at least four weeks prior to the expiration date. We ask that you inform IRB whenever you complete your research. Please reference the protocol number in future correspondence regarding this study.

Any future changes made to the study design and/or consent form require prior approval from the IRB before such changes can be implemented. Please use the attached report form to request for modifications, extension and completion of your study.

While there appears to be no more than minimum risk with your study, should an incidence occur that results in a research-related adverse reaction and/or physical injury, this must be reported immediately in writing to the IRB. Any project-related physical injury must also be reported immediately to the University physician, Dr. Hamel, by calling (269) 473-2222. Please feel free to contact our office if you have questions.

Best wishes in your research.

Sincerely

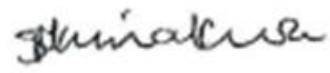

Sarah Kimakwa

Research Integrity \& Compliance Officer

IRB Office 
APPENDIX C

PARTICIPANT LETTERS 


\section{Dear Participant,}

I am a PhD Candidate in Educational Psychology at Andrews University, Berrien Springs, Michigan. In order to fulfill the final phase of my doctoral degree, I am conducting a study that will examine the coping strategies of undergraduate nontraditional (25 and older) female students in public and private institutions of higher education.

Results from this study may provide insights regarding coping strategies of female students who attend public universities in comparison to those who attend private universities. I am inviting you to learn more about the study. The survey which can be accessed at: www.surveymonkey.com/s/copingscale should take approximately 10 minutes to complete.

Completing this survey is voluntary. Your responses will be anonymous and your participation is greatly valued. Participants who complete the survey have the choice of being entered into a random drawing for a $\$ 25$ dollar gift card. Further information will be provided for the drawing at the end of the survey.

If you have any questions about the procedures or other aspects of this research or if you would like information about the findings, you may contact Desiree Davis at desireed@andrews.edu or (269) 471-6875. You can also contact my faculty sponsor-Dr. Elvin Gabriel at gabriel@andrews.edu, Andrews University, Berrien Springs, MI: (269) 471-6223.

To access the online survey, click the following link:

www.surveymonkey.com/s/copingscale

Thank you,

Desiree Davis, MSW, LMSW, LCSW

PhD Candidate, Educational Psychology

Andrews University

Berrien Springs, MI 


\section{Dear Participant,}

I am a PhD Candidate in Educational Psychology at Andrews University, Berrien Springs, Michigan. In order to fulfill the final phase of my doctoral degree, I am conducting a study that will examine the coping strategies of undergraduate nontraditional (25 and older) female students in public and private institutions of higher education.

Results from this study may provide insights regarding coping strategies of female students who attend public universities in comparison to those who attend private universities. I am inviting you to learn more about the study. The survey which can be accessed at: www.surveymonkey.com/s/copingscale should take approximately 10 minutes to complete.

Completing this survey is voluntary. Your responses will be anonymous and your participation is greatly valued. Participants who complete the survey have the choice of being entered into a random drawing for a \$25 dollar gift card. Further information will be provided for the drawing at the end of the survey.

If you have any questions about the procedures or other aspects of this research or if you would like information about the findings, you may contact Desiree Davis at desireed@andrews.edu or (269)-471-6875. You can also contact my faculty sponsor-Dr. Carolyn Schult at cschult@iusb.edu, Indiana University, South Bend, IN; (574) 5204118.

This study has been approved by the Indiana University Institutional Review Board (Protocol \#12065). Questions or concerns about research participants' rights may be directed to the Office of Research, Indiana University, South Bend, In. The phone number is (574)520-4181.

To access the online survey, click the following link:

Www.surveymonkey.com/s/copingscale

Thank you,

Desiree Davis, MSW, LMSW, LCSW

PhD Candidate, Educational Psychology

Andrews University

Berrien Springs, MI 
APPENDIX D

FOLLOW UP LETTER 


\section{Dear Students:}

A few weeks ago, I sent you a request to complete a survey about the Coping Strategies of the Nontraditional Female Student in Higher Education and how they cope with life stressors while in school. Results from this study may provide insights regarding coping strategies of female students who attend public universities in comparison to those who attend private universities.

If you have not already done so, could you please complete this survey? I will only take a few minutes of your time (about ten minute) to complete and your feedback is needed to gather data on how nontraditional female students cope in higher education. This survey can be accessed at:

WWW.surveymonkey.com/s/copingscale

Thank you very much!

Sincerely,

Desiree Davis, MSW, LMSW, LCSW

PhD Candidate, Educational Psychology

Andrews University

Berrien Springs, MI 
APPENDIX E

SCRIPT LETTER 
Hi my name is Desi Davis and I am a Ph.D candidate at Andrews University in Berrien Springs, Michigan. A few weeks ago I sent you a request to complete a survey about the Coping Strategies of the Nontraditional Female Student in Higher Education.

Have you completed the survey that I sent you? If you have, I appreciate the time that you took, and the effort you expended, to complete it.

If you have not completed the survey, will you be willing to answer the survey questions now via the phone, and, will you grant me permission to record your answers? I can assure you that confidentiality will be maintained throughout this process. If you respond in the affirmative, I will proceed with asking the questions. If you are not willing to participate in this exercise, I would like to thank you for taking the time to talk with me. If you would like to complete the survey at a later time, I will give you the URL, which is: www.surveymonkey.com/s/copingscale. 


\section{REFERENCE LIST}




\section{REFERENCE LIST}

Abramovitz, M. (1996). Regulating the lives of women: Social welfare policy from colonial times to the present (Rev. ed.). Boston, MA: South End Press.

Adelman, C. (1999). Answers in the toolbox: Academic intensity, attendance patterns, and bachelors degree attainment. Washington, DC: U.S. Department of Education, Office of Educational Research and Improvement.

Allen, B. (1993). The student in higher education: Nontraditional student retention. Catalyst, 23(3), 19-22.

Altbach, P., \& Knight, J. (2007). The internationalization of higher education: Motivation and realities. Journal of Studies in International Education, 11(3/4), 290-305.

Altbach, P. G., \& Lomotey, K. (1991). The racial crisis in American higher education. Albany, NY: State University of New Press.

Amaro, H., Russo, N. F., \& Johnson, J. (1987). Family and work predictors of psychological well-being among Hispanic women professionals. Psychology of Women Quarterly, 11, 505-521.

Arnold, M. S. (1995). Exploding the myths: African-American families 'At promise.' In B. Swadener \& Sally Lubeck (Eds.), Children and families 'At promise': Deconstructing the discourse of risk, 143-162. Albany, NY: State University of New York Press.

Ashford, J. B., \& LeCroy, C.W. (2013). Human behavior and in the social environment: A multidimensional perspective. Belmont, CA: Brooks/Cole.

Astin, H. S., \& Kent, L. (1983). Gender roles in transition: Research and policy implications for higher education. Journal of Higher Education, 54, 309-324.

Averill, J. R. (1972). Vigilant and nonvigilant coping strategies and psychophysiological stress reactions during the anticipation of electric shock. Journal of Personality and Social Psychology, 23, 128-141.

Babineau, M. E., \& Packard, B. W. (2006). The pursuit of college in adulthood: Reclaiming past selves or constructing new? Journal of Adult Development, 13(3/4), 109-117. 
Backels, S., \& Meashey, L. (1997). Anxiety, depression and the 4.0: Brief therapy with high-achieving nontraditional female students. Journal of College Student Psychotherapy, 12, 45-56.

Baines, C., Evans, P., \& Neysmith, S. (1992). Confronting women's caring: Challenges for practices and policy. Affilia, 7(1), 21-24.

Bartlett, M. S. (1954). A note on the multiplying factors for various chi square approximations. Journal of the Royal Statistical Society, 16(Series B), 296-298.

Bauman, S. S., Wang, N., DeLeon, C. W., Kafentzis, J., Zavala-Lopez, M., \& Lindsely, M. S. (2004). Nontraditional students' service needs and social support resources: A pilot study. Journal of College Counseling, 7, 13-17.

Bay, L. (1999). Twists, turns, and returns: Returning adult students. Teaching English in the Two Year College, 26(3), 305-312.

Bean, J. P., \& Metzer, B. S. (1985). A conceptual model of nontraditional undergraduate student attrition. Review of Educational Research, 55, 485-540.

Belenky, M. F., Clinchy, B. M., Goldberger, N. R., \& Tarule, J. M. (1986). Women's ways of knowing: The development of self, voice and mind. New York, NY: Basic Books.

Benshoff, J. M., \& Lewis, H. A. (1992). Nontraditional college students. Ann Arbor: ERIC Clearinghouse on Counseling and Personel Services. (ERIC No. ED347483)

Benshoff, J. S. (1991). Nontraditional college students: A developmental look at the needs of women and men returning to school. Journal of Young Adulthood and Middle Age, 3, 47-61.

Bewick, B., Koutsopoulou, G., Miles, J., Slaa, E., \& Barkham, M. (2010). Changes in undergraduate students' psychological well-being as they progress through university. Studies in Higher Education, 35, 633-645.

Bianchi, A. (1991). Re-entry 101: A syllabus for the returning student. Modern Maturity, 34(4), 25-27.

Boekaerts, M. (1993). Being concerned with well-being and with learning. Educational Psychologist, 28, 149-167.

Bonner, F. A., Marbley, A. F., Evans, M. P., \& Robinson, P. (2014). Triple jeopardy: A qualitative investigation of the experiences of nontraditional African-American female students in one Hispanic-serving institution. Journal of African American Studies, 19, $36-51$. 
Bourdieu, P. (1977). Cultural reproduction and social reproduction. In J. Karabel \& A. H. Halsey (Eds.), Power and ideology in education (pp. 487-510). New York, NY: Oxford University Press.

Brandenburg, J. (1974). Needs of women returning to school. Personnel and Guidance Journal, 53, 11-18.

Brazier, A. A. (1998). Nontraditional students in nontraditional graduate programs in education: Coping with conflicts between family and career responsibilities and institutional demands of higher education. Dissertation Abstracts International, 54(2-A), 0383. (UMI No. AAM9824729).

Breese, J. R., \& O'Toole, R. (1994). Adult women students: Development of a transitional status. Journal of College Student Development, 35, 183-189.

Burden, D. S. (1986). Single parents and the work setting: The impact of multiple job and home life responsibilities. Family Relations, 35(1), 37-43

Calaguas, G. M. (2011). Sex differences and the relation of age in adjustment difficulties among college freshmen. Journal of Advances in Developmental Research, 2, 221-226.

Canales-Gonzales, P. L., \& Kranz, P. L. (2008). Perceived stress by students in a pharmacy curriculum. Education, 129, 139-146.

Cantwell, R., Archer, J., \& Bourke, S. (2001). A comparison of the academic experiences and achievement of university students entering by traditional and non-traditional means. Assessment and Evaluation in Higher Education, 1, 209-222.

Carney-Crompton, S., \& Tan, J. (2002). Support systems, psychological functioning and academic performance of non-traditional female students. Adult Education Quarterly, 52, 140-154.

Carothers, S. (1990). Catching sense: Learning to be Black and female from our mothers. In F. Ginsberg \& A. Lowenhaupt-Tsing (Eds.), Uncertain terms: Negotiating gender in American culture (pp. 232-247). Boston, MA: Beacon Press.

Cattell, R. B. (1966). The screen test for the number of factors. Multivariate Behavioral Research, 1, 245-276.

Chao, R., \& Good, G. E. (2004). Nontraditional students' perspectives on college education: A qualitative study. Journal of College Counseling, 7, 5-12.

Chapdelaine, R. F., \& Alexitch, L. R. (2004). Social Skills difficulty: Model of culture shock for international graduate students. Journal of College Student Development, 45(2), 167-184. 
Chartrand, J. M. (1990). A causal analysis to predict the personal and academic adjustment of nontraditional students. Journal of Counseling Psychology, 37, 6577.

Chartrand, J. M. (1992). An empirical test of a model of nontraditional student adjustment. Journal of Counseling and Psychology, 39, 193-202.

Choy, S. (2002). Nontraditional undergraduates: Findings from "The Condition of Education, 2002." Washington, DC: National Center for Education Statistics. Retrieved from http://www.eric.ed.gov/ERICWebPortal/detail?accno=ED471077.

Coker, A. (2003). African-American female learners: Motivations, challenges, and coping strategies. Journal of Black Studies, 33(5), 654-674.

Collins, P. H. (1991). The meaning of motherhood in Black culture and Black motherdaughter relationships. In P. Bell-Scott (Ed.), Doublestitch: Black women write about mothers and daughters (pp. 42-60). New York, NY: Harper Perennial.

Compton, J. I., Cox, E., \& Laanan, F. S. (2006). Adult Learners in Transition. In F. S. Laanan (Ed.), Understanding Students in Transition: Trends and Issues, New Directions for Student Services, no. 114. San Francisco, CA: Jossey-Bass.

Constantine, M. G., \& Greer, T. M. (2003). Personal, academic, and career counseling of African-American women in college settings. New Directions for Student Success, 140, 41-50. doi:10.2307/ss.106

Coping Scale for Adults. (2003). In B. S. Plake, J. C. Impara., \& R. A. Spies (Eds.), The fifthteenth mental measurement yearbook (pp.263-266). Lincoln, NE: Buros Institute of Mental Measurements.

Corrigan M. E. (2003). Beyond access: Persistence challenges and the diversity of lowincome students. New Directions for Higher Education, 121, 25-33.

Cose, E. (1993). The rage of a privileged class. New York, NY: Harper Collins.

Coser, L. (1974). Greedy institutions. New York, NY: Free Press.

Costello, A., \& Osborne, J. (2005). Best practices in exploratory factor analysis: Four recommendations for getting the most from your analysis. Practical Assessment, Research \& Evaluation, 10(7), 1-9.

Council on Adult and Experiential Learning. (2000). Serving Adult Learners in Higher Education. Retrieved from http://www.cael.org/pdf/publication_pdf/ Summary\%20of \%20Alfi\%20Principles\%20of \%20Effectiveness.pdf. 
Coverman, S. (1989). Role overload, role conflict, and stress: Addressing consequences of multiple role demands. Social Forces, 6(4), 965-982.

Cross, K. P. (1980). Our changing students and their impact on colleges: Prospects for a true learning society. Phi Delta Kappan, 61(9), 627-630.

Davies, P. (eds.). (1995). Adults in higher educational: International perspectives on access and participation. London, England: Jessica Kingsley.

DeGregoria, B. (1987). Counseling the nontraditional Italian-American student. Community Review, 8(1), 38-41.

Deutsch, N., \& Schmertz, B. (2011). "Starting from zero": Constraints and experiences of adult women returning to college. Review of Higher Education, 34, 477-504. In G. Markle, Factors influencing persistence among nontraditional university students. Adult Education Quarterly, 65(3), 267-285.

Dill, P. L., \& Henley, T. P. (1998). Stressors of college: A comparison of traditional and nontraditional students. Journal of Psychology, 132(1), 25-32.

Donaldson, J. F., \& Graham, S. (1999). A model of college outcomes for adults. In M. L. Johnson \& J. L. Kestler, Achievement goals of traditional and nontraditional aged college Students: Using 3 X 2 achievement goal framework. International Journal Educational Research, 61, 48-59.

Donohue, T. L., \& Wong, E. H. (1997). Achievement motivation and college satisfaction in traditional and nontraditional students. Education, 119, 237-244.

DuBois, W. E. B. (1903/1953). The souls of Black folk. Greenwich: Fawcett.

Dweck, C. S., \& Leggett, E. L. (1988). A social-cognitive approach to motivation and personality. Psychological Review, 95, 256-273. In E. A. Morris, P. R. Brooks, \& J. L. May (2003). The relationship between achievement goal orientation and coping style. College Student Journal, 37(1), 3-8.

Dyk, P. (1987). Graduate student management of family and academic roles. In J. Giancola, M. Grawitch, \& D. Borchert, Dealing with the Stress of College. Adult Education Quarterly. 59(3), 246-263.

Edwards, R. (1993). Mature women students: Separating or connecting family and education. Washington, DC: Taylor \& Francis. In G. Markle, Factors influencing persistence among nontraditional university students. Adult Education Quarterly, 65(3), 267-285.

Eifler, K., \& Potthoff, D. E. (1998). Nontraditional teacher education students: A synthesis of the literature. Journal of Teacher Education, 49, 187-195. 
Ely, E. E. (1997). The non-traditional student. Paper presented at the American Association Community Colleges Annual Conference, Anaheim, CA.

Endler, N. S. \& Parker, J. D. A. (1990). Multidimensional assessment of coping: A critical evaluation. Journal of Personality and Social Psychology, 42, 207-220.

Eppler, M. A., Carsen-Plentl, C., \& Harju, B. L. (2000). Achievement goals, failure attributions, and academic performance in nontraditional and traditional college students. Journal of Social Behavior \& Personality, 15, 353 -372.

Essed, P. (1991). Understanding everyday racism. Newbury Park, CA: Sage.

Evanoski, P. (1988). Community colleges and the education of women. Education, 109(2), 155-159.

Evelyn, J. (2002). Nontraditional students dominate undergraduate enrollments, study finds. Chronicle of Higher Education, 48(40), 34.

Evert, H. (1996). Gender, culture, psychological and social resources and their influences on coping behavior in physiotherapy students. In E. Frydenberg \& R. Lewis, The Coping Scale for Adults: Construct Validity and What the Instrument Tells Us. Paper presented at the Annual Meeting of the American Educational Research Association Conference, New Orleans, April 2000.

Feagin, J. R. (1991). The continuing significance of race: Antiblack discrimination in public places. American Sociological Review, 56(1), 101-116.

Feagin, J. R. (1992). The continuing significance of racism: Discrimination against Black students at White colleges. Journal of Black Studies, 22, 546-578.

Ferguson, M. (1992). Is the classroom still chilly climate for women? College Student Journal, 26(4), 507-511.

Folkman, S. (1997). Positive psychological states and coping with severe stress. Social Science Medicine, 45(8), 1207-1221.

Folkman, S. (2008). The case for positive emotions in the stress process. Anxiety, Stress, \& Coping, 21(1), 3-14.

Folkman, S. (2010). Stress, coping, and hope. Psycho-Oncology, 19, 901-908. doi:10.1002/pon

Folkman, S., \& Lazarus, R. S. (1980). An analysis of coping in a middle-aged community sample. Journal of Health and Social Behavior, 21, 219-239. 
Folkman, S., \& Lazarus, R. S. (1985). If it changes it must be a process: A study of emotion and coping during three stages of a college examination. Journal of Personality and Social Psychology, 48(1), 150-170.

Folkman, S., \& Lazarus, R. S. (1988). Manual: Ways of Coping Questionnaire. In B. S. Plake \& J. C. Impara (Eds.), The fifthteenth mental measurement yearbook (pp. 263-266). Lincoln, NE: Buros Institute of Mental Measurements.

Folkman, S., \& Moskowitz, J. (2000). Positive affect and the other side of coping. The American Psychologist, 55, 647 -654.

Folkman, S., Moskowitz, J. T., Ozer, E. M., \& Park, C. L. (1997). Positive meaningful events and coping in the context of HIV/AIDS. In B. H. Gottlieb (Eds.), Coping with chronic stress (pp. 293-314). New York, NY: Plenum Press.

Forbus, P., Newbold, J., \& Mehta, S. (2011). A study of non-traditional students in terms of their time management behaviors, stress factors, and coping strategies. Academy of Educational Leadership Journal. 15, 109-125.

Frame, M. W., Williams, C. B., \& Green, E. L. (1999). Balm in Gilead: Spiritual dimensions in counseling African American women. Journal of Multicultural Counseling and Development 27, 182-192.

Fraser, N. (1989). Unruly practices: Power, discourse, and gender in contemporary social theory (unpublished doctoral dissertation). Minneapolis, MN: University of Minnesota Press.

Freeman, C. E. (2004). Trends in Educational Equity of Girls \& Women, 2004 (NCES 2005-016). U. S. Department of Education, National Center for Education Statistics. Washington, DC: U. S. Government Printing Office.

Freeman, J. (1989). How to discriminate against women without really trying. In Detour from Nowhere: The remarkable journey of a re-entry community college woman. Initiatives, 58(1), 1-9.

Frydenberg, E., \& Lewis, R. (1993). The Adolescent Coping Scale: Administrator's manual. Melbourne, Australia: Australian Council on for Educational Research.

Frydenberg, E., \& Lewis, R. (1997). Coping Scale for Adults: Administrator's manual. Melbourne, Australia: The Australian Council for Educational Research.

Gardner, C. B. (1995). Passing by: Gender and public harassment. Berkeley, CA: University of California Press. 
Geronimus, A. T., Bound, J., Keen, D., \& Hicken, M. (2007). Black and White differences in age trajectories of hypertension prevalence among adult women and men, 1999-2002. In M. Hicken, H. Lee, J. Morenoff, J. House, \& D. Williams, Racial/Ethnic Disparities in Hypertension Prevalence: Reconsidering the Role of Chronic Stress. American Journal of Public Health, 104(1), 117 -123.

Gerson, J. M. (1985). Women returning to school: The consequences of multiple roles. Sex Roles, 13, 77-92.

Giancola, J. K., Grawitch, M. J., \& Borchert, D. (2009). Dealing with the stress of college. Adult Education Quarterly, 59(3), 246-263.

Giddings, P. (1984). When and where I enter: The impact of Black women on race and sex in America. New York, NY: Bantam Books.

Gilligan, C. (1977). In a different voice: Women's conceptions of self and of morality, Harvard Educational Review, 47(4), 481-515.

Gilligan, C. (1982). In a different voice: Psychological theory and women's development. Cambridge, MA: Harvard University Press.

Gilligan, C. (1990). Joining the resistance: Psychology, politics, girls, and women. Michigan Quarterly Review, 29(4), 501-36.

Gilligan, C. (1995). Hearing the difference: Theorizing connection, symposium on care and justice. Hypatia, 10(2), 120-127.

Glass, J. C., \& Rose, A. R. (1994). Reentry women: A growing and unique college population. NASPA Journal, 32, 110-119.

Goble, G. (1995). Assessment of Coping Strategies. In E. Frydenberg \& R. Lewis, The Coping Scale for Adults: Construct Validity and What the Instrument Tells Us. Paper presented at the Annual Meeting of the American Educational Research Association Conference, New Orleans, April 2000.

Goldberg, D. T. (1993). Racist culture: Philosophy and the politics of meaning. Cambridge, England: Blackwell.

Golden, C. (1987). "I know this is stupid, but..." Or, some thoughts on why students fear failure and not success. In Esther D. Rothblum \& Ellen Cole (Eds.), Treating women's fear of failure: From worry to enlightenment (pp. 41-50). New York, NY: Harrington Park Press.

Goncalves, S. A., \& Trunk, D. (2014). Obstacles to success for the nontraditional student in higher education, Journal of Psychological Research, 19(4), 164-171. 
Goodlad, J. I. (1990). Teachers for our nation's schools. San Francisco, CA: Jossey-Bass.

Gould, S. J. (1981). American polygeny and cranimetry before Darwin: Blacks and Indians as separate, inferior species. In The mismeasure of man (pp. 30-72). New York, NY: Norton

Gouthro, P. A. (2005). A critical feminist analysis of the homeplace as learning site: Explanding the discourse of lifelong learning to consider adult women learners. International Journal of Lifelong Learning, 24(1), 5-19.

Graham, S., \& Donaldson, J. F. (1999). Adult students' academic and intellectual development in college. Adult Education Quarterly, 49, 147-162.

Graham, S. W. (1998). Adult growth in college: The effects of age and education ethos. Journal of College Student Development, 39, 239-250.

Griffith, M., \& Connor, A. (1994). Democracy's open door: The community college in America's future. Portsmouth, NH: Boynton/Cook.

Haggan, P. S. (2000). Transition counseling in the community college. Community College Journal of Research and Practice, 24, 427-442.

Haleman, D. L. (2004). Great expectations: Single mothers in higher education. International Journal of Qualitative Studies in Education, 17(6), 769-784.

Hammer, L. B., Grisby, T. D., \& Woods, S. (1998). The conflicting demands of work, family, and school among students at an urban university. Journal of Psychology, $132,220-227$.

Hardin, C. (1998). Who belongs in college: A second look. In J. L. Higbee and P. L. Dwinell (Eds.), Developmental education: Preparing successful college students (pp. 15-24). Columbia, SC: National Resource Center for the First-Year Experience and Students in Transition, University of South Carolina.

Hardin, C. J. (2008). Adult students in higher education: A portrait of transitions. New Directions for Higher Education, 144, 49-57.

Harris, M. B., \& Brooks, J. L. (1998). Challenges for older students in higher education. Journal of Research and Development in Education, 31(4), 226-235.

Hart, M. U. (1995). Motherwork: A radical proposal to rethink work and education. In M. R. Welton (Eds.), In defense of the lifeworld: Critical perspectives on adult learning (pp. 99-126). Albany, NY: State University of New York Press. 
Hechanova-Alampay, R., Beehr, T. A., Christiansen, N. D., \& Van Horn, R. K. (2002). Adjustment and strain among domestic and international student sojourners. School Psychology International, 23(4), 458-474.

Herideen, P. E. (1998). Policy, pedagogy, and social inequality: Community college student realities in post-industrial America. Westport, CT: Bergin \& Garvey.

Hicken, M., Lee, H., Morenoff, J., House, J., \& Williams, D. (2014). Racial/ethnic disparities in hypertension prevalence: Reconsidering the role of chronic stress. American Journal of Public Health, 104(1), 117-123.

Hirsch, B., \& Rapkin, B. (1986). Multiple roles, social networks and women's wellbeing. Journal of Personality and Social Psychology, 51(6), 1237-1247.

Home, A. (1993). The juggling act: The multiple role woman in social work education. Canadian Social Work Review. 10(2), 141-156.

Home, A. (1995). Do universities support multiple role women students? Proceedings of the $36^{\text {th }}$ Annual Education Research Conference. Edmonton, Canada: University of Alberta Press.

Home, A. (1997). Learning the hard way: Role strain, stress, role demands, and support in multiple-role women students. Journal of Social Work Education, 33, 345-347.

Home, A. (1998). Predicting role conflict, overload, and contagion in adult women university students with Families. Adult Education Quarterly, 48(2), 85-98.

Hooks, B. (1990). Yearning: Race, gender, and cultural politics. Toronto, Canada: Between the Lines Press.

Howard-Hamilton, M. (2003). Theoretical frames for African American women. In Bonner, F. A., Marbley, A. F., Evans, M. P., Robinson, P. (2014). Triple jeopardy: A qualitative investigation of the experiences of nontraditional AfricanAmerican female students in one Hispanic-serving institution. Journal of African American Studies, 19, 36 -51.

Howell, C. L. (2004). Resilience in adult women students: Facilitating academic achievement and persistence. The Researcher, 18, 34-43.

Hughes, R. L. (2003). Insights: Emphasizing issues that affect African American women. New Directions for Student Services, 104, 19-27.

Huston-Hoburg, L., \& Strange, C. (1986). Spousal support among male and female returning adult students. Journal of College Student Personnel, 27, 388 -394. 
Hybertson, D., Hulme, E., Smith, W. A., \& Holton, M. A. (1992). Wellness in nontraditional-age students. Journal of College Student Development, 33, 50-55.

Jack, D. C. (1991). Silencing the self: Depression and women. New York, NY: Harper Collins.

Jackson, J. S., Brown, T. N., Williams, D. R., Torres, M., Sellers, S. L., \& Brown, K. (1996). Racism and the physical and mental health status of African Americans: A thirteen year national panel study. Ethnicity and Disease, 6(1, 2), 132-147.

Jacobi, M. (1987). Stress among re-entry women students: A contextual approach. San Diego, CA: Association for the Study of Higher Education. (ERIC Document Reproduction, Service No. ED 281460)

James, S. A., LaCroix, A. Z., Kleinbaum, D. G., \& Strogatz, D. S. (1984). John Henryism and blood pressure difference among black men. II. The role of occupational stressors. Journal of Behavioral Medicine, 7, 259-275.

Jinkins, R. C. (2009). Nontraditional students: Who are they? College Student Journal, 43(4), 970.

Johnson-Bailey, J. (1998). Black reentry women in the academy: Making a way out of no way. Initiatives, 58(4), 37-48.

Johnson-Bailey, J. (1999). Participation and retention concerns of Black women adult learners. In D. W. Ntiri (Ed.), Pedagory for adult learners: Methods and strategies (pp. 7-34). Detroit, MI: Wayne State University, Office of Adult and Lifelong Learning Research.

Johnson-Bailey, J., \& Cervero, R. (1996). An analysis of the educational narratives of Black women. Adult Education Quarterly, 46(3), 142 -157.

Johnson, L. G., Schwartz, R. A., \& Bower, B. L. (2000). Managing stress among adult women student in community colleges. Community College Journal of Research and Practice, 24, 289-300.

Johnson, M., \& Nussbaum, E. M. (2012). Achievement goals and coping strategies: Identifying the traditional/nontraditional students who use them. Journal of College Student Development, 53(1), 41- 54.

Johnson, S., \& Robson, C. (1999). Threatened identities: The experiences of women in transition to programs of professional higher education. In J. L. Quimby \& K. M. O'Brien, Predictors of well-being among nontraditional female students with children, Journal of Counseling \& Development, 84(4), 451-460. 
Joo-Young, S. (1997). The perceptions of women adult learners in continuing education programs in Korea. DissertationAbstracts International, 58, Z5055.

Josselson, R. (1987). Finding herself: Pathways to identity development in women. In A. D. Coker, African American female adult learners: Motivations, challenges, and coping strategies. Journal of Black Studies, 33(5), 654-674.

Kaiser, H. F. (1970). A second-generation Little Jiffy. Psychometrika, 35, 401-415.

Kaiser, H. F. (1974). An index of factorial simplicity. Psychometrika, 39, 31-36.

Kasworm, C. (1990). Adult undergraduates in higher education: A review of past research perspectives. Review and Educational Research, 60, 345-372.

Kasworm, C. (1993). Adult higher education from an international perspective. Higher Education, 25, 411-423.

Kasworm, C. (2003). Adult meaning making in the undergraduate classroom. Adult Education Quarterly, 53(2), 81-98.

Kearns, H., \& Gardiner, M. (2007). Is it time well spent? The relationship between time management behaviors, perceived effectiveness and work-related morale and distress in a university context. Higher Education Research \& Development, 26(2), 235-247.

Keith, P. M. (2007). Barriers and nontraditional students' use of academic and social services. College Student Journal, 41(4), 1123-1127.

Kell, C., \& Van-Deursen, R. (2000). The fight against professional obsolescence should begin in the undergraduate curriculum. Medical Teacher, 22, 160-163.

Kelly, R., \& Voydanoff, P. (1985). Work/family role strain among employed parents. Family Relations, 34, 367-374.

Kenner, C., \& Weinerman, J. (2011). Adult learning theory: Applications to nontraditional college students. In L. M. Scott \& C. W. Lewis, Nontraditional college students: Assumptions, perceptions, and directions for a meaningful academic experience. The International Journal of Interdisciplinary Social Sciences, 6(4), $1-10$.

Kerka, S. (1989). Retaining adult students in higher education. Columbus, Ohio: ERIC Clearinghouse on Adult, Career, and Vocational Education, 1989. (ED 308 401) Retrieved from http://www.ed.gov/databases/ERIC_digests/ed308401.html. 
Kevern, J., Ricketts, C., \& Webb, C. (1999). Pre-registration diploma students: A quantitative study of entry characteristics and course outcomes. Journal of Advanced Nursing, 30, 785-795.

Kim, P. S., \& Lewis, G. B. (1994). Americans in the public service: Success, diversity, discrimination. Public Administration Review, 54, 285-290.

Kirk, C. F., \& Dorfman, L. T. (1983). Satisfaction and role strain among middle-aged and older re-entry students. Educational Gerontology, 9(1), 14-29.

Koeske, R., \& Koeske, G. (1989). Working and non-working students: Roles, support and well-being. Journal of Social Work Education, 3, 244-256.

Kohler, J. M., \& Munz, D. C. (2006). Combining individual and organizational stress interventions. Journal of Counseling Psychology, 58(1), 1-12.

Kohler, J. M., Munz, D. C., \& Trares, S. (2008). First-vs. continuing- generation nontraditional students on college perceptions: Are differences actually due to demographic variance? Adult Education Quarterly 58(3), 214-228.

Kopp, R. G., \& Ruzicka, M. F. (1993). Women's multiple roles and psychological wellbeing. In J. L. Quimby \& K. M. O’Brien, Predictors of well-being among nontraditional female students with children. Journal of Counseling \& Development, 84(4), 451- 460.

Krieger, N. (1990). Racial and gender discrimination: Risk factors for high blood pressure? Social Science and Medicine, 30(12), 1273-1281.

Kulavic, K., Hultquist, C. N, \& McLester, J. R. (2013). A comparison of motivational factors and barriers to physical activity among traditional versus nontraditional college students. Journal of America College Health, 61(2), 60-66.

LaPaglia, N. (1995). Storytellers: The image of the two-year college in American fiction and in women's journals. Position paper. DeKalb, IL.

Launier, R. A. (1997). Stress balance and emotional life complexes in students in a historically African American college. The Journal of Psychology, 13(2), 175186.

LaVeist, T., Thrope, R., Pierre, G., Mance, G., \& Williams, D. (2014). The relationship among vigilant coping style, race, and depression. Journal of Social Issues, 70(2), $241-255$.

Lazarus, R. S. (1991). Emotion and Adaptation. New York, NY: Oxford University Press. 
Lazarus, R. S., \& DeLongis, A. (1983). Psychological stress and coping in aging. American Psychologist. 3, 245-253.

Lazarus, R. S., \& Folkman, S. (1984). Stress, appraisal and coping. New York, NY: Springer.

Lazarus, R. S., \& Folkman, S. (1985). If it changes it must be a process: Study of emotion and coping during three stages of a college examination. Journal of Personality and Social Psychology, 48(1), 150-170.

Lazarus, R. S., \& Folkman, S. (1987). Transactional theory and research on emotions and coping. European Journal of Personality, 1, 141-169.

Leavitt, R. S. (1989). Married women returning to college: A study of their personal and family adjustments [Special issue: Women and clinical practice]. Smith College Studies in Social Work, 59, 301-315.

Lee, J. J., \& Rice, C. (2007). Welcome to America? International student perceptions of discrimination. Higher Education, 53, 381-409.

Leonard, M. Q. (2002). An outreach framework for retaining nontraditional students at open-admissions institutions. Journal of College Counseling, 5, 60-74.

Lewis, L. (1988). Extending an invitation to returning women. In L. Lewis (Ed). Addressing the needs of returning women (pp 95-109). San Francisco, CA: Jossey-Bass.

Lloyd, M. G., \& Griffiths, C. (2008). A review of the methods of delivering HE programmes in a FE college and an evaluation of the impact this will have on learning outcomes and student progression. Journal of Further and Higher Education, 32, 15 -25.

Mac-Kinnon-Slaney, F. (1994). The adult persistence in learning model: A road map to counseling services for adult learners. Journal of Counseling and Development, $72,268-275$.

MacNair, R. R., \& Elliot, T. R. (1992). Self-perceived problem-solving ability, stress appraisal, and coping over time. Journal of Research in Personality, 26, 150-164.

Madfes, T. J. (1989). Second careers-second challenges: Meetings the needs of the older teacher education students. Paper presented at the Annual Meeting of the California Educational Association, ERIC. (ED 318 713).

Mallinckrodt, B., \& Leong, F. T. (1992). Social support in academic programs and family Environments: Sex differences and role conflicts for graduate students. Journal of Counseling and Development, 70, 716-723. 
Marandet, E., \& Wainwright, E. (2010). Invisible experiences: Understanding the choices and needs of university students with dependent children. British Educational Research Journal, 36, 787-805. In G. Markle, Factors influencing persistence among nontraditional university students. Adult Education Quarterly, 65(3), 267285.

Markle, G. (2015). Factors influencing persistence among nontraditional university students. Adult Education Quarterly, 65(3), 267-285.

Massin, T. (1992). Unlearning to not speak: Adult educations and the female learner. Adult Learning, 4(1), 30-31.

McClary, S. A. (1990). Stress, coping, and adult education. New Directions for Adult and Continuing Education, 45, 65-75.

McCue-Herliby, B. (1997). Relations among self-efficacy, academic achievement, resource utilization and persistence in a sample of nontraditional college students. Dissertation Abstracts International, $58 \mathrm{Z} 5055$.

McMillan J., \& Schumacher, S. (2001). Research in education: A conceptual introduction (5th ed.). New York, NY: Longman.

Meemeduma, P. (1993). Rearranging the balance of happiness. Australian Journal of Social Work, 46(2), 23-32.

Mercer, D. L. (1993). Older coeds: Predicting who will stay this time. Journal of Research and Development in Education, 26, 153-163.

Merdinger, J. (1991). Reaching women students: Their ways of knowing. In R. Middleman \& G. Wood (Eds.), Teaching secrets: The technology in social work education (pp. 41-58). New York, NY: Haworth.

Meyers, L., Gamst, G., \& Guarino, A. (2006). Applied multivariate research: Design and interpretation. Thousand Oaks, CA: Sage.

Michael, S. (2011). Perspectives on women's development: Instructional implications in higher education. Kentucky Journal of Excellence in College Teaching and Learning, 9(6), 1-11.

Mikolaj, E., \& Boggs, D. (1991). Interpersonal role conflict of adult women undergraduate students. Journal of Continuing Education, 39(2), 13-19.

Mikulincer, M., Florian, V., \& Weller, A. (1993). Attachment styles, coping strategies, and Post-traumatic psychological distress: The impact of the Gulf War in Israel. Journal of Personality and Social Psychology, 64, 817-826. 
Miles, A. (1989). Women's challenges to adult education. The Canadian Journal for the Study of Adult Education, 1, 1-18.

Miller, D. A. (1988). Women in public relations graduate study. Public Relations Review, 14(3), 29-35.

Miller, E. (2000). Meeting the challenge of female reentry students at a community college. The Michigan Community College Journal: Research \& Practice, 6(2), $61-71$.

Miller, J. B. (1991). The development of women's sense of self. In J. V. Jordan, A. G. Kaplan, I. P. Stiver, J. L. Surrey, \& J. B. Miller, Women's growth and connection: Writings from the stone center (pp. 11-24). New York, NY: Guilford Press.

Mohoney, C., \& Anderson, W. (1988). The effects of life events and relationships on adult women's decisions to enroll in college. Journal of Counseling and Development, 66, 271-274. (EJ 370 020).

Moore, C. I. (1990). Struggle and commitment: The experience of older minority women in returning to higher education. (Unpublished doctoral dissertation), University of Michigan. In E. L. Miller, Meeting the challenge of female reentry students at a community college. The Michigan Community College Journal: Research \& Practice, 6(2), 61-71.

Morris, E. A., Brooks, P. R., \& May, J. L. (2003). The Relationship Between Achievement Goal Orientation and Coping Style. College Student Journal, 37(1), 3-8.

Munro, B., \& Pooley, J. A. (2009). Differences in resilience and university adjustment between school leaver and mature entry university students. The Australian Community Psychologist, 21(1), 50-61.

National Audit Office (2007). Staying the course: The retention of students in higher education. London, England: TSO (The Stationary Office). Retrieved from http://www.tso.co.uk/bookshop

National Center for Education Statistics. (2015). Digest of Education Statistics, 2013 (NCES 2015-011), Chapter 3, Retrieved from http://nces.ed.gov/fast facts/display.asp? id $=98$.

National on-campus reports. (2002). An expert shares her secrets on programs for nontraditional students. National on-campus reports. Report 30, 14(3). Madison, WI: Magna. In C. J. Hardin, Adult students in higher education: A portrait of transitions. New Directions for Higher Education, 144, 49 -57. 
Newbold, J. J., Mehta, S. S., \& Forbus, P. R. (2009). Using marketing to understand the needs of non-traditional students. Paper presented at the International Academy of Business and Public Administration Disciplines (IABPAD) Winter Conference Orlando, FL.

Newbold, J. J., Mehta, S. S., \& Forbus, P. R. (2010). A comparative study between nontraditional students in terms of their demographics, attitudes, behavior and educational performance. International Journal of Education Research, 5(1), 124.

Noddings, N. (1986). Caring: A feminine approach to ethics and moral education. In S. Michael (Ed.), Perspectives on women's development: Instructional implications in higher education. Kentucky Journal of Excellence in Teaching and Learning. $9(6), 1-11$.

Nordstrom, A. D. (1997). Adult students: A valuable market to target. Marketing News, 31(19), 20.

Novak, M., \& Thacker, C. (1991). Satisfaction and strain among middle-aged women who return to school: Replication and extension of findings in a Canadian context. Educational Gerontology, 17, 332-342.

Ofori, R. (2000). Age and "type" of domain specific entry qualifications as predictors of student nurses' performance in biological, social, and behavioral sciences in nursing assessments. Nurse Education Today, 20, 298-310.

Ogbu, J. U. (1992). Understanding cultural diversity and learning. Educational Researcher, 22(8), 5-14.

Ogren, C. A. (2003). Rethinking the "nontraditional" student from a historical perspective. Journal of Higher Education, 74(6), 643-664.

O'Keefe, V. (1993). How to help adult and nontraditional students find success through the communication course. Paper presented at the Speech Communication Association, Miami Beach, FL.

Organization for Economic Cooperation and Development. (1987). Adults in higher education. Paris, France: OECD.

Organization for Economic Cooperation and Development. (1996) Lifelong learning for all. Paris, France: OECD.

Padula, M. A. (1994). Reentry women: A literature review with recommendations for counseling research. In J. Quimby \& K. O'Brien, Predictors of well-being among nontraditional female students with children. Journal of Counseling \& Development, 84, 451-460. 
Park, C. L., \& Folkman, S. (1997). Meaning in the context of stress and coping. Review of General Psychology, 2, 115-144.

Parker, J. D., \& Endler, N. S. (1992). Coping with copinig assessment: A critical review. European Journal of Personality, 6, 321-344.

Patchner, M. (1982). The practitioner becomes a student: The stresses of transition. The Journal of Continuing Social Work Education, 2(2), 21-24.

Perrucci, R., \& Hu, H. (1995). Satisfaction with social and educational experiences among international graduate students. Research in Higher Education, 36(4), 491508.

Pierre, S. S. (1989). Understanding the nontraditional female student. National Association of Student Personal Administration, 26(3), 228-234.

Pitts, S. (1992). Reentry women in higher education: The quiet revolution. College Student Affairs Journal, 12(1), 69-75.

Polakow, V. (1993). Lives on the edge: single mothers and their children in the other America. Chicago, IL: University of Chicago Press.

Poyrazli, S., \& Lopez, M. D. (2007). An exploratory study of perceived discrimination and homesickness: A comparison of international students and American students. The Journal of Psychology, 14(3), 263-280.

Puryear, A. D. (1988). Understanding the needs of adult students. Community Services Catalyst, 18, 13-16.

Quimby, J. L., \& O’Brian, K. M. (2006). Predictors of well-being among nontraditional female students with children. Journal of Counseling \& Development, 84, 451460 .

Read, N. O., Elliot, M. R., Escobar, M. D., \& Slaney, R. B. (1988). The effects of marital status and motherhood on the career concerns of reentry women. The Career Development Quarterly, 37, 46-55. (EJ 383 521).

Reay, D., Ball, S., \& David, M. (2002). "It's taking me a long time but I'll get there in the end": Mature students on access courses and higher education. British Educational Research Journal, 28(1), 5-19. In G. Markle, Factors influencing persistence among nontraditional university students. Adult Education Quarterly, $65(3), 267-285$.

Rendon, L. I. (1996). Life on the border. About Campus, 1(5), 14-20. 
Rice, J. K. (1982). Spouse support: Couples in educational transition. Lifelong Learning: The Adult Years, 6, 4-6.

Rice, J. \& Meyer, S. (1989). Continuing education for women. In Merriam, S. \& P. Cunningham (Eds.). Handbook of adult and continuing education (pp 550-568). San Francisco, CA: Jossey-Bass.

Richards, T. A. and Folkman, S. (in press) Spiritual aspects of bereavement among partners of men who died from AIDS. Death Studies.

Richter-Antion, D. (1986). Qualitative differences between adult and younger students. NASPA Journal, 23, 58-62.

Richter, D. L., \& Witten, C. H. (1984). Barriers to adult learning: Does anticipation match reality? Journal of College Student Personnel, 23, 531-537.

Rifenbary, D. (1995). Re-entering the academy: The voices of returning women students. Initiatives, 56(4), 1-10.

Robotham, (2009). Combining study and employment. Emerald Education Plus Training, 51(4): 322-332.

Rodriguez, S. (1997). Detour from nowhere: The remarkable journey of a re-entry community college woman. Initiatives, 58(1), 1-9.

Roehl, J. E., \& Okun, M. A. (1984). Depression symptoms among women reentering college: The role of negative life events and family social support. Journal of College Student Personnel, 25, 251-254.

Ross, S. E., Niebling, B. C., Heckert, T. M. (1999). Sources of stress among college students. College Student Journal, 33(2), 312-318.

Sales, A., Drolet, R., \& Bonneau, I. (2001). Academic paths, ageing and the living conditions of students in the late 20th century. Canadian Review of Sociology Anthropology, 38, 167-188.

Salgado de Snyder, V. N. (1987). Factors associated with acculturative stress and depressive symptomatology among married Mexican immigrant women. Psychology of Women Quarterly, 11, 475-488.

Sands, R., \& Richardson, V. (1984). Educational and mental health factors associated with the return of mid-life women in school. Educational Gerontology, 10(1-2), $155-170$. 
Santiago-Rivera, A. L., Bernstein, B. L., \& Gard, T. L. (1995). The importance of achievement and the appraisal of stressful events as predictors of coping. Journal of College Student Development, 36(4), 374-383.

Schliebner, C. T. (1990). Returning adult women students: The effects of role strain and perceived spouse support on the intent to remain in college. In S. CarneyCromptom \& J. Tan, Supports systems, psychological functioning, and academic performance of nontraditional female students. Adult Education Quarterly, 52(2), $140-154$.

Schmidt, V., \& Scott, N. (1986). Home-career conflict: An exploration of the delicate balance. Paper Presented at the Annual Convention of the American Psychological Association, Washington, DC.

Schneiderman, N., \& McCabe, P. M. (1989). Psychophysiological strategies in laboratory research. In N. Schneiderman, S. M. Weiss, \& P. G. Kaufmann (Eds.), Handbook of research methods in cardiovascular behavioral medicine (pp. 349-364). New York, NY: Plenum.

Scott, C., Burns, A., \& Cooney, G. (1996). Reasons for discontinuing study: The case of mature age female students with children. In J. L. Quimby \& K. O’Brien (Eds.), Predictors of well-being among nontraditional female students with children. Journal of Counseling \& Development, 84, 451-460.

Scott, L. M. \& Lewis, C. W. (2012). Nontraditional college students: Assumptions, perceptions, and directions for a meaning academic experience. The International Journal of Interdisciplinary Social Sciences, 6(4), 1-10.

Selingo, J. (2000, November 17). Facing new missions and rivals, state colleges seek a makeover. Chronicle of Higher Education, A40-A42.

Shank, M. D., Winchell, M. H., \& Myers, M. (2001). Appreciating the needs of nontraditional students: Women as a growing market for colleges and universities. Journal of Marketing for Higher Education, 11(1), 63-72.

Shields, N. (1993). Attribution processes and stages of adult life development among adult university students. Journal of Applied Social Psychology, 23(16), 13211337.

Smallwood, K. B. (1980). What to do adult women college students really need? Journal of College Student Personnel, 21, 65-73.

Spanard, J. M. (1990). Beyond intent: Reentering college to complete the degree. Review of Educational Research, 60, 309-344. 
Spanjer, K. (1999). The relationship between locus of control and coping constructs as predictors of academic performance in an adult sample. In E. Frydenberg \& R. Lewis, The Coping Scale for Adults: Construct Validity and What the Instrument Tells Us. Paper presented at the Annual Meeting of the American Educational Research Association Conference, New Orleans, April 2000.

Stern, L. (1991). Disavowing the self in female adolescence. In C. Gilligan, A. Rogers, \& D. Tolman (Eds.), Women, girls and psychotherapy: Reframing resistance, pp. 532. Birmingham, NY: Haworth Press.

Sternthal, M. J., Slopen, N., \& Williams, D. R. (2011). Racial disparities in health: How much does stress really matter? Du Bois Review, 8(1) 95-113.

Stone, C., \& O'Shea, S. (2013). Time, money, leisure and guilt: The gendered challenges of higher education for mature-age students. Australian Journal of Adult Learning, 53(1), 95-116. In G. Markle, Factors influencing persistence among nontraditional university students. Adult Education Quarterly, 65(3), 267-285.

Sweet, S., \& Moen, P. (2007). Integrating Educational Careers in Work and Family. Community, Work and Family, 10(2), 231-250.

Tabachnick, B. G., \& Fidell, L. S. (2001). Using multivariate statistics. (2001). Boston, MA: Allyn \& Bacon.

Taniguchi, H., \& Kauffman, G. (2005). Degree completion among nontraditional college students. Social Science Quarterly, 84(4), 912-927.

Taylor, K. (1995). Speaking her mind: Adult learning and women's adult development. In S. Michael, Perspectives on Women's development: Instructional Implications in Higher Education, Kentucky Journal of Excellence in College Teaching \& Learning, 9(6), 54-64.

Telles, E. E., \& Murgia, E. (1990). Phenotypic discrimination and income differences among Mexican Americans. Social Science Quarterly, 71, 682-697.

Terenzini, P., Rendon, L. I., Miller, S. B., Upcraft, M. L., Gregg, P. L., Jolomo, R., \& Allison, K. W. (1996). "Making the transition to college." In Robert Menges, Maryellen Weimer, and Associates, (Eds.), Teaching on solid ground: Using scholarship to improve practice, pp. 43-73. San Francisco, CA: Jossey Bass.

Terenzini, P. T., Rendon, L. I., Upcraft, M. L., Miller, S. B., Allison, K. W., \& Gregg, P. L. (1994). The transition to college: Diverse students, diverse stories. Research in Higher Education, 35, 57-73.

Terrell, P. S. (1990). Adapting institutions of higher ed to serve adult students' needs. NASPA Journal, 27, 241-247. 
Thomas, V. (2001). Black women in the academy: Challenges and opportunities. The Journal of Negro Education, 70(3), 139-155.

Tinto, V. (1993). Leaving college: Rethinking the causes and cures of student retention (2nd ed.). Chicago, IL: University of Chicago Press.

Towbes, L. C., \& Cohen, L. H. (1996). Chronic stress in their students: Scale development and prospective prediction of distress. Journal of Youth and Adolescence, 25(2), 199-217.

U. S. Department of Commerce, U. S. Census Bureau. (2011). Percent of people 25 years and over who have completed high school or college, by race, Hispanic origin, and sex: Selected years 1940 to 2011. CPS Historical Time Series Tables. Retrieved from http://www.census.gov/hhes/socdemo/education/data/cps/ historical/index.html

Upcraft, M. L., Gardner, J. N., \& Barefoot, B. O. (Eds.). (2004). Challenging and supporting the first-year student. San Francisco, CA: Jossey-Bass.

Urquhart, B., \& Pooley, J. A. (2007). The transition experience of Australian students to university: The importance of social support. The Australian Community Psychologist, 19(2), 78-91.

Utsey, S., Ponterollo, J., Reynolds, A., \& Cancelli, A. (2000). Racial discrimination, coping, life satisfaction, and self-esteem among Americans. Journal of Counseling and Development. 78, 72-80.

Vaccaro, A., \& Lovell, C. D. (2010). Inspiration from home: Understanding family as key to adult women's self-investment. Adult Education Quarterly, 60(2) 161-176. doi:10.1177/0741713609336111

Vaughn, L. M., Battle, J. V., Taylor, T., \& Dearman, L. (2009). Learning styles and the relationship to attachment styles and psychological symptoms in college women. College Student Journal, 43(3), 723-735.

Voydanoff, P. (1993). Work and family relationships. In T. Brubaker (Ed.), Family relations: Challenges for the future (pp. 99-111). Newbury Park, CA: Sage.

Weisz, J. R., Rothbaum, F. M., \& Blackburn, T. C. (1984). Standing out and standing in: The psychology of control in America and Japan. American Psychologist, 39, 955-969.

Wentworth, P. A., \& Peterson, B. E. (2001). Crossing the line: Case studies of identity development in first-generation college women. In S. Michael, Perspectives on women's development: Instructional implications in higher education, .Kentucky Journal of Excellence in College Teaching and Learning, 9(6), 54-64. 
Williams, D., Yu, Y., Jackson, J., \& Anderson, N. (1997). Racial differences in physical and mental health: Socio-economic status, stress and discrimination. Journal of Health Psychology, 2(3), 335-351.

Williams, D. R. (1994). The measurement of religion in epidemiologic studies: Problems and prospects. In J. S. Levin (Ed.), Religion in aging and health: Theoretical foundations and methodological frontiers (pp. 125-148). Thousand Oaks, CA: Sage.

Williams, R. B. (1986). Patterns of reactivity and stress. In K. A. Matthews, S. M. Weiss, T. Detre. T. M. Dembroski, B. Falkner, S. B. Manuck, \& R. B. Williams (Eds.), Handbook of stress, reactivity, and cardiovascular disease (pp. 109 -126). New York, NY: Wiley.

Wilsey, S. (2013). Comparisons of adult and traditional college-age student mothers: Reasons for college enrollment and views of how enrollment affects children. Journal of College Student Development, 54(2), 209-214.

Wilson, J. S. (1993). The campus racial climate and the demographic imperative. In G. M. Sill, M. T. Chaplin, J. R. Ritzke, \& D. Wilson (Eds.), Opening the American mind: Race, ethnicity, and gender in higher education (pp. 85-109). Newark, NJ: Newark University Press.

Winkelman, M. (1994). Cultural shock and adaption. Journal of Counseling and Development, 73(2), 121-126.

Wlodkowski, R. J., Mauldin, J. E., \& Campbell, S. (2002). Early exit: Understanding adult attrition in accelerated and traditional postsecondary programs. Indianapolis, IN: Lumina Foundation for Education. In G. Markle, Factors influencing persistence among nontraditional university students. Adult Education Quarterly, 65(3), 267-285.

Zwerling, L. S., \& London, H. B. (Eds.). (1992). First-generation students. New Directions for Community College Series: No. 80. San Francisco, CA: JosseyBass. 
VITA 
VITA

Name: Desiree E. Davis

Date of Birth: April 27, 1967

\section{Education:}

1990 Master of Social Work (M.S.W.) with a concentration in Mental Health, The Ohio State University, Columbus, Ohio

1989 Bachelor of Social Work (B.S.W.), Oakwood College, Huntsville, Alabama

\section{Professional Experience:}

2011-2016 BSW Program Director, Social Work Department, Andrews University 2010-2011 Nephrology Social Worker, Lakeland Liberty Dialysis, Niles, Michigan

2006-2010 Oncology Social Worker, Oncology Care Associates, St. Joseph, Michigan

1996-2004 Clinician, Visions Counseling Center, South Bend, Indiana

1994-1999 Medical Social Worker, Lakeland Medical Center, Niles, Michigan

\section{Professional Organizations:}

National Association of Social Workers

\section{Certifications:}

Academy of Certified Social WorkerS (ACSW)

Licensed Clinical Social Worker (LCSW) - Indiana

Licensed Clinical Social Worker (LMSW) - Michigan 